\title{
Efeito do ácido gama-linolênico sobre a hipertensão arterial e gordura corporal em mulheres após a menopausa
}

\author{
Lúcia de Fátima Cahino da Costa Hime
}

Tese apresentada ao Programa de Pós-Graduação em Saúde Pública na Faculdade de Saúde Pública da Universidade de São Paulo para obtenção do título de Doutor em Saúde Pública

Área de Concentração: Serviços de Saúde Pública

Orientador: Prof. Dr. Januário de Andrade

\section{São Paulo}




$$
45480 / 2005 \text { doe }
$$

Autorizo, exclusivamente para fins acadêmicos e científicos, a reprodução total ou parcial desta tese, por processos fotocopiadores.

Assinatura:

Data: 
"O importante é continuar aprendendo, desfrutar os desafios e tolerar a ambigüidade pois, em definitivo, não existem certezas".

Marina Horner 


\section{DEDICATÓRIA}

Ao meu marido Gilbert e aos meus filhos Rafael, Priscila e Rodrigo, pela tolerância e paciência, durante o período em que realizei este trabalho. Gostaria de poder ser motivo de orgulho para eles, como eles são para mim.

Aos meus pais Angela e Valter, e aos meus irmãos Valter Junior, Felix Antônio, Carlos Alberto e Marcos Antônio, que, mesmo distantes, acreditam em mim.

Aos meus avós, Maria Raquel e Felix Cahino (in memoriam), que sempre foram meus maiores incentivadores. 


\section{AGRADECIMENTOS}

Ao Prof. Dr. Januário de Andrade, que além de amigo e orientador, me abriu as portas do Setor de Cardiologia da Mulher no Instituto Dante Pazzanese de Cardiologia, dando-me a oportunidade de realizar este trabalho.

À Profa. Dra. Ceci Mendes Carvalho Lopes que está ao meu lado desde o início da minha vida profissional, fazendo parte não só deste exercício mas de toda minha trajetória de vida. Ocupa lugar especial em meu coração, não existindo palavras para expressar este sentimento de gratidão e admiração.

Ao Dr José de Anchieta Oliveira, pela realização de todos os exames ultrasonográficos.

Ao Dr. Fabio Bruno da Silva pelo apoio quanto ao atendimento clínico das pacientes.

À Dra. Maisa Guadalupe Ribeiro Champi, pela amizade, apoio e estímulo.

À Dra. Elvira Rito Rodrigues, que muito me incentivou, até com suas orações.

À Sra. Maria Inês Goes, pelo auxílio na organização e agendamento de consultas, bem como, serviços de secretaria.

Aos demais colegas do Setor de Cardiologia da Mulher, pelo apoio e coleguismo.

Ao Dr. Pierre Georges Neufel pela orientação quanto a densitometria. 
Ao Laboratório de Epidemiologia e Estatística do Instituto Dante Pazzanese de Cardiologia, na pessoa da Srta. Camila Sarteschi, pela inestimável colaboração, realizando o estudo estatístico deste trabalho.

À Renilda Shimano, Maria Aparecida Mendes e Márcia Garcia, do Serviço de Aprimoramento da Pós graduação pela paciência, orientação e carinho como me trataram durante todo o período que freqüentei a Faculdade de Saúde Pública.

À Srta. Beatriz Mendes Carvalho Lopes pela ajuda nos gráficos e esquemas.

Aos meus filhos Rafael, Priscila e Rodrigo pela organização e formatação de toda a tese.

À Elizabeth Mary Hime de Araújo e Arthur César de Araújo que gentilmente colaboraram na tradução do resumo.

Ao Bionatus Laboratório Botânico LTDA que forneceu os medicamentos e exames, sem os quais não poderiamos realizar este trabalho.

Às pacientes participantes entusiasmadas e colaborativas, às quais espero ter contribuído para melhora de sua qualidade de vida.

Enfim, gostaria de agradecer a todos que durante este período de realização desta tese estiveram ao meu redor, pacientes e tolerantes, mas que em nenhum momento me incentivaram a desistir. 


\section{LISTA DE ABREVIATURAS}

AA

ALA

$\mathbf{A M P c}$

AMP quinase

ASA

$\operatorname{Cox} 1$ e 2

$\mathbf{C} / \mathbf{Q}$

DCV

DEXA

DGLA

DHA

D5D

D6D

EFAs

EPA

EPO

FO

GLA

HDL

HETE

HPETE ácido araquidônico

ácido alfa-linolênico

adenosina monofosfato cíclica

mitogen-activated protein kinase

ácido acetil salicílico

ciclooxigenase 1 e 2

relação cintura/quadril

doença cardiovascular

densitometria por dupla emissão de raios $\mathrm{X}$

ácido di-homo-gama-linolênico

ácido docosa-hexaenóico

delta-5-dessaturase

delta-6-dessaturase

ácidos graxos essenciais

ácido eicosapentaenóico

óleo de prímula

óleo de peixe

ácido gama-linolênico

lipoproteinas de alta densidade

ácido hidroxieicosaenóico

ácido hidroperoxieicosaenóico 
indice de massa corporal

LA

ácido linoléico

LDL

lipoproteínas de baixa densidade

$\mathbf{L p}(\mathbf{a})$

lipoproteína (a)

LPL

lipase lipoprotéica

LOX

lipooxigenase

LTs

leucotrienos

$\mathbf{n - 3}, \omega-3$

ômega 3

$n-6, \omega-6$

ômega 6

PA

pressão arterial

PAD

pressão arterial diastólica

PAS

pressão arterial sistêmica

PGs

prostaglandinas

PGE1

prostaglandina $\mathrm{El}$

PGE2

prostaglandina E2

PPAR

PUFA

SO

receptor ativado de proliferação de peroxissomo

ácido graxo poliinsaturado

TGs

óleo de girassol

TH

triglicerideos

TXs

terapêutica hormonal

tromboxanos

VLDL

lipoproteínas de muito baixa densidade 


\section{RESUMO}

Hime LFCC. Efeito do ácido gama-linolênico sobre a hipertensão arterial e gordura corporal em mulheres após a menopausa. São Paulo; 2004. [Tese de DoutoradoFaculdade de Saúde Pública da USP].

O ácido gama-linolênico, proveniente do óleo de borragem, é um ácido graxo poliinsaturado, classificado como ômega-6. Esse óleo apresenta propriedades terapêuticas, podendo ser utilizado para amenizar os sintomas do climatério. Há indícios de que atue na hipertensão arterial e na distribuição da gordura corporal.

Com o objetivo de verificar sua atuação sobre a hipertensão arterial e a distribuição da gordura corporal, foi realizado estudo duplo-cego, prospectivo, placebocontrolado, aleatório, administrando cápsulas de $1000 \mathrm{mg}$ de óleo de borragem, ou óleo mineral, 3 vezes ao dia, durante 6 meses, a 81 mulheres hipertensas na pós-menopausa. Nem as pacientes, nem a pesquisadora conheciam o conteúdo das cápsulas, de aspecto idêntico, até o final do estudo. As pacientes não interromperam o tratamento antihipertensivo durante o estudo. Todas foram avaliadas previamente com exame ginecológico completo, ultra-sonogafia transvaginal, mamografia e citologia oncológica, com o objetivo de afastar ginecopatia. Foram realizadas consulta de inclusão e 6 consultas, uma a cada 30 dias. Em cada consulta realizava-se a medida de pressão arterial, após repouso, bem como a aferição de peso e, medida de cintura e quadril. Foi realizada densitometria lombar e femural antes da inclusão e ao final do estudo.

Os resultados mostraram redução da pressão arterial sistólica e diastólica, nas pacientes do grupo Ativo, e modificação na relação da medida de cintura e quadril. Não houve mudança no peso e no índice de massa corpórea, nem da porcentagem de gordura corporal, medida pela densitometria.

Conclui-se que o ácido gama-linolênico, obtido do óleo de borragem, foi eficaz como coadjuvante no tratamento da hipertensão arterial, e que modificou a deposição de gordura corporal.

Descritores: Pós-menopausa. Hipertensão. Gordura Corporal. Ácido Gama-linolênico. Óleo de Borragem. 


\section{SUMMARY}

Hime LFCC. Efeito do ácido gama-linolênico sobre a hipertensão arterial e gordura corporal em mulheres após a menopausa. [Effect of the gamma-linolenic acid over arterial hypertension and body fat in postmenopause women]. São Paulo (BR); 2004. [Tese de Doutorado-Faculdade de Saúde Pública da Universidade de São Paulo].

Gamma-linolenic acid from borage oil is an omega-6 polyunsaturated fatty acid. This oil presents therapeutic properties, and may be used to relieve climacteric symptoms. May be it acts on hypertension and on body fat distribution.

The aim of this study was to observe the action of borage oil on arterial blood pressure and on body fat distribution. A double-blind, placebo-controlled, prospective and randomized study was performed, with 81 hypertensive postmenopause patients. Each patient received gelatinous capsules containing $1000 \mathrm{mg}$ of borage oil, or placebo, to take 3 times a day, during 6 months. Neither the patientes nor the researcher have known the capsules content, which had identical aspect. The patients did not interrupt the antihypertensive treatment during the study. All of them, were previously assesment by means of gynecologic examination, transvaginal ultrasonography and oncologic citology. One a appointment for inclusion and six appointments, one at every 30 days were done. Blood pressure was taken from each patient, before starting the treatment, and at each month. Before the first and before the final interview, lumbar and femoral densitometry was performed. Waist and hip, as well as weight measuring were checked at each appointment.

The results showed a decrease in systolic and diastolic arterial blood pressure, as well as modification of the waist-to-hip girth ratio measure in the Active group. There were no changes in weight, body mass index, or body fat percentage, measured by densitometry.

The conclusion was that gamma-linolenic acid, from borage oil, was efficient as a coadjuvant treatment in postmenopause hypertensive patients and in body fat distribution.

Descriptors: Postmenopause. Hypertension. Body Fat. Gamma-Linolenic Acid. Borago Oil. 


\section{$\underline{\text { ÍNDICE }}$}

1 INTRODUÇÃO

1.1 Menopausa

1.2 Hipertensão

1.3 Gordura Corporal 10

1.4 Ácido gama-linolênico 20

1.5 Relação entre ácido gama-linolênico e hipertensão arterial 26

1.6 Relação entre ácido gama-linolênico e gordura corporal 32

2 OBJETIVOS

2.1 Objetivo Geral 35

2.2 Objetivos Especificos $\quad 35$

3 PROCEDIMENTO METODOLOGICO 36

3.1 Tipo de Pesquisa 36

3.2 Local de Estudo $\quad 36$

$\begin{array}{ll}3.4 \text { Metodologia } & 37\end{array}$

3.5 Agenda de Atendimento 39

3.6 Avaliação Estatística 39

3.6.1 Análise Descritiva 39

3.6.2 Análise Estatística $\quad 40$

4 RESULTADOS

4.1 Pressão Arterial $\quad 42$

4.2 Gordura Corporal 46

5 DISCUSSÃO

6 CONCLUSÕES

7 REFERÊNCIAS 


\section{ANEXOS}

Anexo 1: Aprovação do Comitê de Ética da Faculdade de Saúde Pública da USP.

Anexo 2: Aprovação do Comitê de Ética do Instituto Dante Pazzanese de Cardiologia.

Anexo 3: Informações destinadas as pacientes.

Anexo 4: Termo de consentimento pós-informado.

Anexo 5: Boletim de análise $7205 / 2000$ do Instituto Adolfo Lutz. Divisão de bromatologia e química.

Anexo 6: Boletim de análise 7205/2000 do Instituto Adolfo Lutz. Divisão de bromatologia e química.

Anexo 7: Boletim de análise 7206/2000 do Instituto Adolfo Lutz. Divisão de bromatologia e química.

Anexo 8: Boletim de análise 7206/2000 do Instituto Adolfo Lutz. Divisão de bromatologia e química.

Anexo 10: Relação de pacientes grupo Ativo e as medicações antihipertensivas.

Anexo 11: Relação de pacientes grupo Placebo e as medicações antihipertensivas. 


\section{INTRODUCÃO}

\subsection{Menopausa}

A mulher, em sua trajetória de vida, é marcada pelos ciclos biológicos de forma intensa, e a menopausa é a finalização dessa fase cíclica (FURTADO, 2001). A diminuição progressiva da população folicular ovariana e consequentemente da produção estrogênica caminha para o desaparecimento da menstruação (BOUER, 1999).

Apesar da afirmação de alguns profissionais da área de saúde que a menopausa deva ser uma etapa normal do ciclo biológico feminino, do mesmo modo que a menarca e a menacme, a menopausa ficou estigmatizada como fase de doença de deprivação (AMARAL, 2002).

Num período variável, de meses ou anos, antes da última menstruação, a mulher costuma apresentar sintomas sugestivos de que alguma modificação está ocorrendo em seu organismo: os ciclos menstruais se tornam irregulares, muda a textura da pele e da mucosa vaginal, surgem ondas de calor e sudorese, etc. Todas essas alterações podem ser atribuídas à produção dos esteróides sexuais, que começa a se modificar, cessando os ciclos ovulatórios e, decrescendo a produção estrogênica. Chamamos de climatério à fase que se inicia com os primeiros sintomas dessa alteração, e que dura até um ano após a cessação das menstruações. Após essa data, inicia-se a fase de pós-menopausa (FONSECA; HALBE, 1994).

Assim, embora a menopausa seja um fato fisiológico, liga-se a ela todo um quadro clínico, que deve ser abordado no sentido de que se possa proporcionar a mulher mais bem-estar, de maneira semelhante ao que se faria com o quadro de um processo patológico.

Os sintomas da síndrome climatérica têm quatro origens: deficiência estrogênica ou progestacional, envelhecimento, fatores sócio-culturais determinados pelo ambiente e fatores psicológicos dependentes da dinâmica psicológica (HALBE; FONSECA, 2000). Cerca de $40 \%$ das mulheres apresentam algumas manifestações 
clínicas atribuíveis ao climatério e à pós-menopausa. No entanto, somente cerca de $25 \%$ apresentam sintomas de intensidade mais significativa (SAKAMOTO; HALBE, 1995).

Pode-se fazer uma avaliação dos problemas ligados à menopausa, sob o ponto de vista epidemiológico. É um quadro crônico, ligado ao processo da menopausa, onde ocorrem problemas de saúde relacionados ao envelhecimento, bem como ao hipoestrogenismo. Os vários aspectos podem simplesmente coincidir, como relacionar-se. Podem ocorrer fatores casuais, fatores ligados à constituição da mulher, e fatores ligados ao estilo de vida. Determinando-se os problemas da fase climatérica e da pós-menopausa, bem como suas causas, estabelecem-se os meios de prevenção ou de deteç̧ão, para que se possa determinar este controle epidemiológico. O objetivo é propiciar qualidade de vida, o melhor possível, para os anos que se seguem, que tendem a ser cada vez mais numerosos, em função do progressivo aumento da expectativa de vida. (HURD, 1996).

A coronariopatia (e sua mais grave conseqüência, o infarto do miocárdio) tem sido associada, na mulher, ao climatério, de forma bem evidente. É um doença que decorre da aterosclerose, que, por sua vez, depende de vários fatores: as dislipidemias, a hipertensão arterial, o diabete melito, o tabagismo, a obesidade, os déficits nutricionais, o sedentarismo, o estresse, e a menopausa (BERGA, 1994). A ciclicidade ovariana, com suas variações nos níveis estrogênicos e progestacionais parecem exercer um efeito cardioprotetor. Com a falência ovariana, perde-se essa cardioproteção. Esse fato é evidenciado pela sua reversão com a terapêutica hormonal. As coronariopatias acometem as mulheres com um retardo de cerca de 10 anos em relação à população masculina, tornando-se a maior causa de morte entre mulheres acima de 50 anos. $O$ efeito cardioprotetor dos estrogênios pode ser atribuído à sua influência sobre o metabolismo das lipoproteínas, sobre as quais agem de várias formas: aumentando a produção de lipoproteínas de muito baixa densidade (VLDL), acelerando o transporte do colesterol através das lipoproteínas de baixa densidade (LDL), inibindo a lipase hepática envolvida na hidrólise de fosfolipídeos e triglicerídeos e, como conseqüência, atuando de modo que mais LDL sejam removidas pelo figado, interferindo no decréscimo da lipoproteína(a) [Lp(a)] (SHEWMON, 1994). 
O tratamento dos distúrbios da menopausa pode ser feito com terapêutica alimentar, psicológica, ambiental, física, ocupacional e também com a terapêutica medicamentosa.

A atuação dos alimentos pode ter papel importante na determinação da maior vitalidade e prevenção de doenças, desde que seja utilizado adequadamente o seu potencial energético (DI FRAIA $F^{Q}$; CORONA, 2001). Com o objetivo de uma vida mais saudável e longeva, é útil se ater à idéia de que a restrição calórica parece ser o melhor método, porque é estratégia para aumentar a duração da vida em mamíferos, e não parece ser a adiposidade o principal fator, mas o número de calorias ingeridas e absorvidas diariamente. No entanto, a longevidade só ocorre se houver retardo nos processos ligados ao envelhecimento. A restrição alimentar diminui a taxa de lipídios sangüíneos, diminuindo o risco de arteriosclerose, e, assim, o de problemas cardiovasculares, incluindo-se o risco de lesões do sistema nervoso central, decorrente dos problemas circulatórios (MORAES, 2004).

Deve-se considerar que todo tratamento tem de ser abrangido com seus prós e contras. Assim, quando se recomenda uma intervenção alimentar, pode-se estar agindo preventivamente, como é o caso da recomendação dos ácidos graxos poliinsaturados (PUFAs), ou pode desencadear distúrbios, como por exemplo, introduzindo-se gorduras saturadas (REDDY; KATAN, 2004).

A atividade fisica pode ser um fator de ajuda não só na perda de peso, como na melhora do estado psíquico (sem mencionar todos os outros benefícios em relação ao metabolismo ósseo, lipídico, etc.), e, portanto, deve ser estimulada (LOPES; HALBE, 1995). A associação de dieta e exercício é uma receita de saúde exaustivamente repisada, mas eficaz e útil.

$\mathrm{O}$ tratamento medicamentoso abrange especialmente o tratamento hormonal, pela idéia de corrigir o decréscimo estrogênico, característico dessa fase. Muitas pacientes preferem tratar-se sem produtos sintéticos, por questões variáveis, que abrangem preconceitos, ou busca por uma vida mais natural, procurando medicamentos fitoterápicos e orientações alimentares. 


\subsection{Hipertensão}

Os avanços na área tecnológica responsáveis por melhores técnicas de diagnóstico e tratamento têm permitido a realização de tratamento médico e, sobretudo, de medicina preventiva, proporcionando à população que está atingindo faixa etária mais avançada melhor qualidade de vida. Com isto, o conceito e a interpretação das diversas doenças vêm apresentando mudanças.

O conceito atual de hipertensão arterial, baseia-se na idéia, recentemente proposta por Weber, conforme citado em NOBRE; COSTA LIMA (2000) que hipertensão não pode ser entendida somente como uma condição clínica de cifras tensionais elevadas, mas como um quadro sindrômico, incluíndo alterações hemodinâmicas, tróficas e metabólicas como:

- Pressão arterial elevada,

- Dislipidemias,

- Resistência à insulina,

- Obesidade centrípeta,

- Microalbuminúria,

- Atividade aumentada dos fatores de coagulação,

- Redução da complacência arterial,

- Hipertrofia e alteração da função diastólica do ventrículo esquerdo.

Esta nova forma de conceituar hipertensão pode explicar a razão pela qual os esquemas terapêuticos propostos anteriormente, com intenção única de reduzir os níveis pressóricos, sem portanto ocupar-se da avaliação de outros aspectos sabidamente presentes na hipertensão, obtiveram insuficiente redução de morbidade e mortalidade coronarianas, a despeito de redução eficaz dos níveis pressóricos.

Segundo NOBRE; COSTA LIMA (2000), podemos classificar a hipertensão de duas formas: segundo a causa de base e segundo o grau dos níveis tensionais. Quanto a causa pode ser primária (sem uma única causa definida, com múltiplos fatores envolvidos e importante componente genético) ou secundária (ocorrendo como manifestação de uma doença conhecida ou do uso de medicamento com marcada ação hipertensiva). Ainda em relação ao tipo de hipertensão, define-se 
hipertensão sistólica isolada quando apenas a pressão arterial sistólica (PAS) se eleva por maior rigidez da parede da aorta (envelhecimento) ou por aumento do débito do ventrículo esquerdo (insuficiência aórtica, tireotoxicose, doença óssea de Paget, etc). Segundo o grau não existe linha divisória entre "normotensão" e "hipertensão". Não se pode estabelecer, sem risco de erro, um valor absoluto acima do qual ter-se iam cifras tensionais elevadas. Utiliza-se atualmente a classificação relatada no III Consenso Brasileiro da Hipertensão Arterial, 1998, incluíndo os valores da pressão arterial sistólica (PAS) e pressão arterial diastólica (PAD), como demonstrado na tabela abaixo.

Tabela 1 - Classificação Diagnóstica de Hipertensão Arterial

\begin{tabular}{lll}
\hline \hline PAD $(\mathrm{mmHg})$ & PAS $(\mathrm{mmHg})$ & Classificação \\
\hline$<85$ & $<130$ & Normal \\
$85-89$ & $130-139$ & Normal limítrofe \\
$90-99$ & $140-159$ & Hipertensão leve \\
$100-109$ & $160-179$ & Hipertensão moderada \\
$\geq 110$ & $\geq 180$ & Hipertensão grave \\
$<90$ & $\geq 140$ & Hipertensão sistólica isolada \\
\hline \hline
\end{tabular}

Fonte: III Consenso Brasileiro de Hipertensão, 1998.

O acompanhamento a longo prazo dos candidatos a desenvolverem pressão arterial primária demonstra que inicialmente a pressão arterial (PA) apresenta-se intermitentemente elevada. Com o passar do tempo os valores pressóricos vão aumentando progressivamente, de $10 \%$ aos 30 anos de idade para $30 \%$ ao redor dos 60 anos. O tempo de evolução de intermitente para hipertensão arterial estabelecida é variável. Alguns estudos demonstram que pacientes com PAD entre $85-89 \mathrm{mmHg}$, $19 \%$ progridem para valores pressóricos de $90 \mathrm{mmHg}$ ou mais num periodo de 5 anos (AMODEO, 2000). A hipertensão arterial oscila entre 10-20\% da população sendo que $50 \%$ desconhece que é hipertensa e somente $12 \%$ recebe tratamento adequado (LACRUZ et al., 1993).

Hipertensão é uma doença sistêmica que é particularmente comum na população negra. Segundo OAKLEY (1996), mulheres negras apresentam 
hipertensão mais jovens que as brancas, e sua mortalidade por doença cardiovascular é maior, em grupo etário menor. Na maioria das sociedades há uma tendência de aumentar a pressão com a idade. Nas mulheres o aumento da PAS é mais ou menos constante através da vida, ao contrário dos homens que apresentam um aumento mais rápido. Em ambos os sexos, a PAD aumenta gradualmente com a idade, ocorrendo níveis pressóricos mais elevados em pessoas mais idosas. Os que apresentam PA elevada na infầncia, apresentam maior risco de se tornarem hipertensos com o passar dos anos (WHELTON; RUSSEL, 1984). Muitos estudos (AMODEO, 2000) têm demonstrado uma tendência a aumento de pressão em grupos sócio-econômicos mais baixos.

WHELTON; RUSSELL (1984), referem influência genética e fatores ambientais relacionados à hipertensão através da observação de estreita relação entre peso corporal e hipertensão arterial. Também descrevem maior associação com aumento da ingesta de sal, deficiência de magnésio, potássio, cálcio e exposição a metais pesados. Vários trabalhos em comunidades que consomem baixo teor de sal e não apresentam vida sedentária demonstram que nessas populações a pressão arterial não aumenta com a idade. Todavia, quando indivíduos dessas comunidades migram para regiões onde existe aumento no consumo de sal e de gorduras saturadas, vida mais sedentária e competitiva no trabalho, a pressão arterial passa a aumentar com o envelhecimento. PORTO et al. (1999), afirmam que hipertensão é enfermidade de origem multicausal e multifatorial decorrente da interação de vários fatores que vão surgindo com as modificações na maneira de viver do homem moderno. Muitas possibilidades etiológicas têm sido sugeridas, porém nenhuma conclusiva no tocante à principal causa de hipertensão.

As opiniões dos diferentes autores são contraditórias quando se referem a pressão arterial e a influência recíproca com o climatério. Porém é consenso que a pressão arterial aumenta progressivamente, à medida que avança a idade, e isso ocorre tanto em homens quanto em mulheres. Contudo, este aumento é maior nas mulheres a partir da menopausa (LACRUZ et al., 1993; OAKLEY, 1996). Segundo AEPFELBACHER, MESSULLI (1996), cerca de metade das mulheres ocidentais desenvolverão hipertensão em algum momento de sua vida, e na maioria das vezes será classificada como essencial, pois não se conseguirá definir a etiologia. 
Segundo NACHTIGALL (1987), é possivel que a deprivação estrogênica tenha papel na hipertensão da mulher, visto que a reposição com estrogênios parece melhorar os casos de hipertensão. Apesar da vasta literatura disponivel, a influência da menopausa sobre o sistema cardiovascular, em particular na patogênese da hipertensão, permanece em debate. A principal razão para essa dificuldade é a separação entre os efeitos próprios da menopausa e aqueles relacionados à idade e aos fatores próprios do envelhecimento (FAGART et al., 1996).

No Brasil, os estudos de prevalência de hipertensão arterial são poucos e não representativos. Entretanto, alguns estudos isolados nos permitem observações em relação à prevalência de hipertensão em São Paulo (AYRES, 1991).

Na cidade de São Paulo, em 1981, DEBERT-RIBEIRO et al., estudando população de 5.500 trabalhadores de dez ramos diferentes de atividade observaram prevalência de hipertensão arterial dependente da faixa etária que variou entre $5.3 \%$ a $46.7 \%$ para homens e 2.7 a 27.3 para as mulheres.

Tabela 2 - Prevalência (\%) de hipertensão arterial de acordo com a idade e o sexo em amostra de trabalhadores da cidade de São Paulo.

\begin{tabular}{lll}
\hline Idade & Homens & Mulheres \\
\hline & & \\
$15-24$ & 5.3 & 2.7 \\
$25-34$ & 15.7 & 5.6 \\
$35-44$ & 29.5 & 17.8 \\
$45-54$ & 33.6 & 24.1 \\
$55+$ & 46.7 & 27.3 \\
\hline \hline
\end{tabular}

Critério PAD $\geq 90 \mathrm{mmHg}$.

Fonte: Manual de Cardiologia. Sociedade de Cardiologia do Estado de Sào Paulo (SOCESP), 2000.

À medida que se avança na faixa etária aumenta a porcentagem de portadores de hipertensão arterial. Na população idosa mais da metade apresenta hipertensão arterial sendo que nessa população há predomínio da hipertensão arterial sistólica isolada. Durante muito tempo esse aumento da PA com a idade foi aceito, dentro de determinados limites, como fisiológico. Entretanto, sabe-se hoje que tal aspecto está relacionado com estilo de vida da população (AMODEO, 2000).

A hipertensão arterial é considerada um dos principais fatores de risco para o desenvolvimento de doenças cardiovasculares. Afeta cerca de $20 \%$ dos adultos em 
populações industrializadas, e, se não tratada, determina alterações em todo sistema cardiovascular, principalmente cérebro, coração e rins. BARRETO (2002), afirma que a hipertensão arterial, isoladamente, pode provocar insuficiência cardiaca, mas também pode participar de muitos quadros dessa insuficiência, contribuindo para o desenvolvimento de insuficiência coronária, que representa a principal causa de insuficiência cardíaca no mundo moderno.

O papel da hipertensão arterial como causa de insuficiência cardiaca vem sendo demonstrado em vários trabalhos. O estudo Framingham demonstra grande incidência de insuficiência cardíaca relacionada à hipertensão (LEVY et al., 1996). Estudos como o de LENFANT; ROCCELLA (1997) têm demonstrado relação diretamente proporcional entre o grau de hipertensão e o desenvolvimento de insuficiência cardiaca com o passar do tempo. PALAC (1998), afirma com base em estudos epidemiológicos, que a hipertensão é responsável por dobrar ou triplicar a incidência de insuficiência cardíaca, que este risco é 2,07 vezes nos homens e 3,35 vezes nas mulheres.

A identificação da pessoa hipertensa obriga-nos a instituir um tratamento correto visando melhor qualidade de vida. Segundo REIS DA COSTA (2002), as evidências científicas disponíveis orientam a manter os niveis pressóricos abaixo de $130 \times 85 \mathrm{mmHg}$ a fim de possibilitar redução da morbi-mortalidade cardiovascular. Tratar esta doença significa atuar na prevenção de acidente vascular cerebral, doença arterial coronariana, insuficiência cardíaca, insuficiência renal e principalmente reduzir a mortalidade determinada por essa entidade silenciosa e altamente letal que é a hipertensão arterial. No caso da mulher, torna-se ainda mais atual a preocupação com o diagnóstico e tratamento, porque a doença cardiovascular atinge o sexo feminino de forma peculiar, aumentando sua incidência e sua morbi-letalidade, nos anos após a menopausa (FERNANDES et al., 2003).

A descoberta do peptídeo natriurético atrial explicaria o processo da hipertensão diastólica da mulher climatérica e a perda da natriurese que a acompanha. Segundo LACRUZ et al. (1993), este peptídeo atuaria no néfron distal e teria importante papel na prevenção da hipertensão arterial. Há indicações de que no climatério a produção deste peptídeo está diminuida por privação estrogênica. 
URBANETZ et al. (1998), afirmam que a terapia estrogênica é benéfica para a vasoconstrição que ocorre nas doenças coronarianas e, em especial, na hipertensão.

Segundo ROCHA (1998), deve-se antes de instituir tratamento para hipertensão, avaliar a possibilidade de interferência de determinadas substâncias, dentre elas contraceptivos hormonais e antiinflamatórios, na etiologia desta sindrome.

HALBE; FONSECA (2000), afirmam que a influência da menopausa sobre a hipertensão arterial é controversa, baseando-se no fato que estudos longitudinais não mostram o aumento da pressão arterial com a menopausa, ao passo que estudos transversais demonstram elevação significativa das PAS e PAD em mulheres na pósmenopausa.

HALBE et al. (2001), em uma revisão, citam autores como BELJIC; PINES; AYALON que enfatizam o efeito benéfico da terapia hormonal (TH) sobre a hipertensão arterial.

DIEGOLI et al. (2001), enfatizam a ação estrogênica na prevenção da síndrome hipertensiva.

Diante do que foi exposto, há evidências que levam a acreditar que a TH apresenta efeitos benéficos tanto na prevenção como no tratamento da hipertensão arterial, porém deve-se lembrar que nem sempre a TH pode ser instituída como forma de tratamento, ou por recusa da paciente ou por ser a mesma portadora de alguma doença que represente contra-indicação. Estudos mais recentes, dentre eles o Heart and estrogen/progestin replacement study (HERS), e o Women's Health Initiative (WHI), deixam questões sobre a vantagem do tratamento hormonal.

Em relação à prevenção da doença cardiovascular, estes estudos se sobrepõem aos anteriores que eram observacionais. Foram realizados com grande número de pacientes e durante tempo prolongado. Os seus resultados, no entanto, devem ser considerados em relação ao regime terapêutico a ao perfil clínico das pacientes estudadas, portanto não devem ser extrapolados para mulheres submetidas à TH na peri-menopausa ou no período imediatamente após a menopausa (FERNANDES et al., 2003). 


\subsection{Gordura Corporal}

A composição corporal das pessoas inclui vários tipos de tecido, dentre eles osso, músculo, demais órgãos, líquidos corpóreos e tecido adiposo, que se distribuem nas diferentes estruturas e nos diferentes compartimentos do organismo de modo padronizado para a espécie, mas com diferenças peculiares de indivíduo para indivíduo. Ao referir-se a gordura corporal, sabe-se que sua distribuição pode estar associada a diversos problemas metabólicos, e, portanto, avaliar essa localização e os fatores que levam a ela é de interesse na prevenção das doenças (BJORNTORP, 1996). Por outro lado, o acúmulo de gordura corporal é diferente de pessoa para pessoa. Durante anos surgiram várias hipóteses procurando explicar porque algumas pessoas engordam enquanto outras permanecem magras durante a vida. ANDERSON; WADDEN (2000), comentam que a definição do peso ideal é muito difícil, porque os parâmetros têm mudado na dependência de época e culturas.

JUNQUEIRA; CARNEIRO (1999), afirmam que o tecido adiposo é um tipo especial de conjuntivo onde se observa predominância de células adiposas. Em pessoas de peso normal, corresponde a $20-25 \%$ do peso corporal na mulher e $15-20 \%$ no homem. Quanto à localização, apresenta características diferentes podendo ser dividido em dois tipos:

- Uniloculares: é o mais comum no homem, apresenta única inclusão de lipídeo ocupando quase todo o citoplasma. Sua coloração varia entre branco e amarelo-escuro dependendo da concentração de carotenóides na alimentação. É o armazenador básico de energia.

- Multiloculares: também chamado de tecido pardo ou marrom. Ao contrário do tecido branco suas células são menores, de forma poligonal e o citoplasma carregado de gotículas lipídicas responsáveis pelo armazenamento de gordura. Sua coloração pode variar de marrom a marromavermelhado por causa de sua grande vascularização e quantidade de citocromos presentes nas mitocôndrias. Apresenta algumas características próprias como não apresentar crescimento progressivo com a idade e ser 
mais encontrado na infância e nos animais que hibernam. No adulto sua quantidade é mínima e sua função é produzir aquecimento.

A gordura unilocular, está presente na camada subcutânea de todo o corpo e em locais característicos influenciado pelo sexo e idade ocorrendo com o envelhecimento um predomínio de depósito na região abdominal, em torno do omento e dos mesentérios. As membranas plasmáticas dessas células contêm receptores para várias substâncias como insulina, hormônio do crescimento, noradrenalina e glicocorticóides, facilitando a captação e liberação de ácidos graxos livres e glicerol (GARTNER; HIATT, 2003).

O tecido adiposo branco tem enorme capacidade de sofrer alterações durante a vida, o que o difere de outros tecidos. Isto pode ocorrer pelo aumento do tamanho das células já existentes quando o lipídeo é adicionado (hipertrofia) ou pelo aumento do número de células (hiperplasia). O ganho de peso pode ser resultado de hipertrofia, hiperplasia ou de combinação dos dois (BRAY, 1990). BERG (1992), afirma que quando ocorre aumento do número de células a perda de peso não interfere sobre este padrão celular.

$\mathrm{O}$ adipócito maduro consiste de uma célula com grande gotícula central de lipídeo rodeada de uma margem fina de citoplasma. Os adipócitos armazenam a gordura em quantidades de $80 \%$ a $95 \%$ de seu volume (MAHAN; ESCOTTSTUMP, 1998).

A gordura, armazenada sob a forma de triglicerídeos (TGs) é a reserva primária de energia do organismo. A gordura corpórea apropriada para a mulher adulta varia de 20 a $25 \%$ do peso corpóreo com mais ou menos $12 \%$ como gordura essencial. A gordura essencial inclui um extra de 5 a $9 \%$ de gordura corpórea especifica do sexo nas mamas, regiões pélvicas e coxas. Nos homens, a gordura corpórea é de 12 a $15 \%$ do peso corpóreo e aproximadamente 4 a $7 \%$ é de gordura essencial. Essa gordura essencial inclui, em ambos os sexos a gordura armazenada na medula óssea, coração, figado, baço, rins, intestinos, músculos e tecidos ricos em lipídeos no sistema nervoso e é necessária para o funcionamento fisiológico normal (MAHAN; ESCOTT-STUMP, 1998).

A maioria dos depósitos de gordura vem diretamente dos TGs dietéticos, pois a composição de ácido graxo de tecido adiposo imita a composição de ácido graxo da 
dieta. A composição da dieta pode ser tão importante quanto o conteúdo total de energia, sendo de grande importância no controle das gorduras (DATILLO, 1992).

Os TGs da dieta são transportados para o fígado como parte dos quilomicrons e removidos do sangue por pela enzima lípase lipoproteica (LPL), facilitando a remoção dos lipideos do sangue e a entrada através das paredes dos capilares na célula adiposa (MAHAN; ESCOTT-STUMP, 1998).

Durante o periodo reprodutivo a atividade da LPL é maior nos adipócitos glúteo-femurais que nos abdominais, promovendo armazenamento de gordura na área femural. Após a menopausa, a LPL muda seu comportamento, atuando de maneira similar nesses dois compartimentos (REBUFFÉ-SCRIVE, 1988). RAISON et al. (1988), questionam se esta especificidade da LPL ocorre apenas na pósmenopausa.

Estudo realizado por NICKLAS et al. (2000), demonstra que a redução na atividade da LPL no tecido adiposo com a perda de peso está associada com a melhora nos fatores de risco relacionados às doenças metabólicas.

A idade representa fator importante quanto ao porcentual de gordura corporal. O recém nascido apresenta $12 \%$ atingindo um pico de $25 \%$ aos seis meses. A prépuberdade, 15 a $18 \%$. A partir dos 18 anos, além da idade, o sexo tem influência, havendo tendência progressiva de aumento de gordura, maior nos homens que nas mulheres (MORAES E SANTOS, 1998).

Os padrões regionais de depósito de gordura são controlados geneticamente e diferem entre homens e mulheres. O tipo ginecóide, comum às mulheres, é caracterizado pela "forma de pêra" que é criado por depósitos mais pesados de gordura ao redor das coxas e nádegas. Essa distribuição gordurosa é benéfica representando reservas de energia para suprir as necessidades da gravidez e lactação. A andróide ou "forma de maçã" mais comum entre os homens caracteriza a gordura ao redor da cintura e abdome superior. Esse tipo de depósito de gordura é caracterizado pela rápida mobilização de ácidos graxos livres e está associado a risco significante para hipertensão, doença cardiovascular e diabete melito não insulinodependente (MAHAN, ESCOTT-STUMP, 1998). Segundo FREEDMAN et al. (1989), a distribuição de gordura regional define o risco de hiperlipidemia em crianças obesas, assim como o faz para adultos. O tecido gorduroso andróide, através 
de sua drenagem portal, pode ser uma importante fonte de ácidos graxos livres que podem exercer efeitos metabólicos complexos como: envolvimento em lipogênese hepática, aumento do fluxo neoglicogênico hepático, redução no clearance metabólico de insulina e envolvimento na resistência metabólica a insulina (BJORNTORP, 2000).

A distribuição da gordura, e não especificamente sobrepeso ou obesidade, está associada com alterações hemodinâmicas, hemostáticas e outros distúrbios metabólicos. Modificação oxidativa das lipoproteínas, especialmente da LDL representam papel chave no início e progressão da aterosclerose. Segundo MATSUZAWA et al. (1995), a distribuição de gordura visceral está presente em quase $90 \%$ dos pacientes obesos com doença cardiaca isquêmica. Eles relatam que a gordura intra-abdominal tem mostrado ter atividade tanto na lipogênese como na lipólise e seu acúmulo pode levar a altos níveis de ácidos graxos livres, um produto da lipólise, na circulação portal em direção ao figado, resultando em aumento da síntese lipídica. Pessoas com distribuição de gordura intra-abdominal mostraram, segundo ZAK et al. (2000), títulos baixos de anticorpos contra os processos oxidativos do LDL.

A regulação da distribuição do tecido adiposo é um importante problema, tendo em vista a associação restrita entre estudos epidemiológicos e metabólicos relacionados a distribuição central de gordura e ao aparecimento de doenças. Com o acúmulo de gordura visceral foram encontradas alterações endócrinas incluindo elevação do cortisol e androgênios e baixa de hormônio do crescimento, em mulheres, e baixa de testosterona em homens. Essas mudanças hormonais exercem profundos efeitos no metabolismo e distribuição do tecido adiposo. No adipócito, cortisol e insulina promovem acúmulo de lipídeo por aumento da atividade da LPL, enquanto testosterona, hormônio do crescimento e estrogênio têm efeito oposto (BJORNTORP, 1996).

Segundo MARIN; BJORNTORP (1993), esse predomínio de distribuição gordurosa visceral pode estar envolvido com distúrbios do eixo hipotálamo-adrenal podendo ser conseqüência de estresse psicológico, tão comum nos dias atuais.

A peri-menopausa e a pós-menopausa são momentos que favorecem o ganho de peso. Entre os vários fatores que propiciam esse efeito está a atuação dos 
estrogênios sobre o metabolismo da LPL nos tecidos. Além disso, há influência de local preferencial para deposição gordurosa, ou seja, há tendência a ganho de gordura abdominal, em detrimento da deposição glúteo-femural, ou seja, as mulheres passam a desenvolver um padrão de deposição semelhante ao masculino (andróide) (MANCINI, 2003).

Vários estudos foram realizados buscando esclarecer este comportamento específico da gordura em relação à menopausa. Dentre eles citamos: HASSAGER; CHRISTIANSEN (1989), estudando o efeito da terapêutica hormonal (TH) com estrogênio e estrogênio associado a progesterona no climatério concluíram que em relação à gordura corporal não houve diferença significativa entre os dois grupos em relação ao placebo. O estudo de intervenções estrogênio/progestógeno na pósmenopausa (PEPI) evidenciou aumento do peso no grupo placebo quando comparado com diferentes esquemas terapêuticos, sendo significativas as diferenças entre o grupo placebo e o tratado com estrogênio isolado (THE WRITING GROUP FOR PEPI TRIAL, 1995). Um outro estudo, avaliando mulheres em uso de estrogênio durante 15 anos, observou que as usuárias tinham índices significativamente menores de massa corpórea quando comparadas com as não usuárias, concluindo que TH usada de forma intermitente ou continuada não está associada com ganho de peso (KRITZ-SILVERSTEIN et al., 1996). SITES et al. (2001), em estudo comparativo de terapia hormonal e não hormonal em pacientes após a menopausa confirmam diminuição da gordura visceral nas usuárias.

Não há modificações no peso corporal com ou sem o uso de TH, porém ocorre predisposição a melhora na distribuição da gordura. Portanto, além da TH, outros fatores devem influenciar este ganho de peso, como dieta, exercícios físicos e uma boa higiene mental.

Além dessas alterações, a própria idade parece determinar mudanças na composição corporal e na distribuição de gordura. Os mecanismos que determinam as mudanças associadas à idade não são bem definidos, porém evidências sugerem que a perda de massa gordurosa livre é particularmente atribuída à inatividade física, freqüente em pessoas mais velhas, ou pode também ser resultado de alterações no metabolismo das gorduras. A oxidação das gorduras é menor nas pessoas mais idosas em várias situações: em repouso, durante o exercício, e em resposta a ingestão 
alimentar. Pode ocorrer pela deficiência de estrogênio e por decréscimo na capacidade intrínseca muscular de oxidação da gordura (CALLES-ESCANDON, 1997).

Outra questão que se propõe, ao se avaliar o tecido gorduroso, é o seu acúmulo em excesso, ou seja, a obesidade. Obesidade representa problema de saúde pública. Segundo BJORNTORP (2000), ela vem aumentando principalmente nos países industrializados. Não só a obesidade, mas a distribuição da gordura como é demonstrado em vários estudos epidemiológicos, como foi comentado.

Segundo JANJIC (1996), fatores hereditários contribuem significativamente para a ocorrência da obesidade em famílias, embora fatores ambientais representem papel importante em seu desenvolvimento.

BOUCHARD (1990), afirma que a obesidade apresenta um sentido mais amplo de classificação dependendo de alguns fatores como:

1. Massa corpórea ou porcentagem de gordura em excesso,

2. Gordura tronco-abdominal subcutânea em excesso (andróide),

3. Gordura visceral abdominal em excesso,

4. Gordura glúteo-femural em excesso (ginecóide).

JENSEN (1997), afirma que anormalidade no metabolismo do tecido adiposo leva a aumento na lipólise provocando liberação de grande quantidade de ácidos graxos livres e conseqüente deposição podendo contribuir para a obesidade.

Maior atenção tem sido dada ao diagnóstico da obesidade visto que sua prevalência vem aumentando em países civilizados tais como Estados Unidos, Inglaterra e Alemanha. No Brasil, aumentos foram registrados em ambos os sexos entre 1975 e 1997, sendo que nas regiões mais pobres como Nordeste, e, nos estratos da população de menor poder aquisitivo foi onde o aumento relativo da obesidade alcançou maior magnitude (MONTEIRO; CONDE, 1999).

Estudos como os de GREGOIRE et al., 1998; DELERIVE et al., 2001, têm enfatizado a presença de receptores nucleares chamados receptores ativados de proliferação de peroxissomo (PPARs) como sendo fatores de transcrição que funcionam como reguladores do metabolismo de lipoproteínas e lipídeos, homeostase da glicose, proliferação, diferenciação e apoptose celular. 
CHINETTI et al. (2001), referem que existem vários tipos de PPARs sendo o PPAR gama expresso predominantemente no intestino, tecido adiposo e células da parede vascular participando do metabolismo lipídico nestes locais.

RISTOW et al. (1998), afirmam que o aumento freqüente de fatores genéticos relacionados à obesidade podem estar envolvidos em mutações dos PPARs.

Vários estudos confirmam a importância desses receptores na prevenção das doenças cardiovasculares (JUMP; CLARKE, 1999; VAMECQ; LATRUFFE, 1999; KERSTEN; WAHLI, 2000).

Existem vários métodos para avaliação da distribuição da gordura corporal. Os métodos preferidos são:

Índice de massa corporal (IMC) ou indice Quetelet. É o que melhor correlaciona o peso à massa gordurosa. É calculado pela divisão do peso em quilogramas pela medida da altura em metros elevada ao quadrado.

$$
\mathrm{IMC}=\frac{\text { peso }(\mathrm{em} \mathrm{kg})}{\text { altura }^{2}(\mathrm{em} \mathrm{m})}
$$

DEHOOG (1998) cita Keys et al., afirmando que este índice tem a menor correlação com a altura corpórea e a maior correlação com as medidas independentes de gordura corpórea para adultos, inclusive idosos.

De acordo com este índice, podemos classificar a gordura corporal em relação ao risco de doenças:

Tabela 3 - Gordura Corporal / Risco de Doenças

\begin{tabular}{llll}
\hline \hline Classificação & ICM & Risco de Comorbidades \\
\hline \multirow{2}{*}{ Normal } & & $18.5-24.9$ & Médio \\
Sobrepeso & & $25.0-29.9$ & Aumentado \\
Obeso & Classe I & $30.0-34.9$ & Moderado \\
& Classe II & $35.0-39.9$ & Grave \\
& Classe III & $\geq 40.0$ & Muito Grave \\
\hline \hline
\end{tabular}

Mancini, 2003. 
GAMBACCIANI et al. (1999), para avaliar aumento de peso corpóreo na pré e pós-menopausa utilizam o IMC por julgarem ser o método mais confiável.

Outro método é a avaliação da proporção da circunferência da cintura e do quadril (relação cintura/quadril) para identificar os tipos corpóreos andróide e ginecóide. Quando esta medida ultrapassa 0.95 em homens e 0.85 em mulheres é indicativa de obesidade andróide e representa fator de risco para doença cardiovascular (REXRODE et al., 1998). Os mesmos autores, encontraram risco residual duas vezes maior para doença coronariana em mulheres com relação cintura/quadril acima de 0.88. HANS et al. (1995), estudando 4800 indivíduos entre homens e mulheres holandesas com idade entre 20 e 59 anos demonstraram que a medida da circunferência da cintura acima de $94 \mathrm{~cm}$ no homem ou acima de $80 \mathrm{~cm}$ na mulher se associa a prevalência dos demais fatores de risco para doença cardiovascular 1.5 a 2.0 vezes maior quando comparada à população estudada como um todo.

LANSKA et al. (1985), enfatizam que relação cintura/quadril representa o melhor método de avaliação de gordura corporal.

O Iowa Women's Health Study avaliou o risco da obesidade visceral em 30 mil mulheres entre 55 e 69 anos, acompanhadas por 11 anos, inicialmente saudáveis, demonstrando que o padrão antropométrico mais confiável na previsão foi a relação entre as medidas de cintura e quadril. Essa relação foi melhor preditor que o índice de massa corpórea (IMC), que também foi considerado um indice indicador de risco. A medida da relação cintura/quadril, em mulheres, é considerada ideal quando inferior a 0.8 (MANCINI, 2003).

MATSUDA et al. (1993), enfatizam a importância destes dois métodos na avaliação da composição corporal em um estudo realizado com 97 mulheres japonesas.

Há outros métodos passíveis de serem empregados, como sejam: o perímetro da circunferência do braço, a medida das dobras cutâneas, a medida da densidade corporal, os níveis de água ou do potássio corporal total, a condutividade elétrica, a análise da impedância bioelétrica tetrapolar, a interactância infravermelha, a ativação de nêutrons, a ressonância nuclear magnética, a tomografia computadorizada e a ultrassonografia (MONTEIRO, 2000). 
PEIRIS et al. (1989), relacionam a relação cintura/quadril e a tomografia computadorizada como os melhores métodos de avaliação da gordura abdominal e visceral. MONTEIRO (2000), concorda com eles, no referente à eficácia da tomografia computadorizada porém afirma que a técnica apresenta como limitação o alto custo e significativa radiação a que são submetidos os tecidos.

A ultrassonografia abdominal tem sido usada para avaliar a gordura visceral, porém vale salientar que este método guarda boas relações com a tomografia. FERROZZI et al. (1999), estudando crianças e adolescentes obesos confirmam esta correlação entre a tomografia e ultrassonografia. HIDA et al. (1999) confirmam sua eficácia em modelo animal.

A análise da impedância elétrica tetrapolar é um dos métodos que mais tem sido utilizado na prática clínica. A medição da bioimpedância (resistência à passagem de corrente) é realizada pela colocação de um par de eletrodos em uma das mãos e um dos pés do indivíduo. Transmite-se ao paciente corrente elétrica do tipo alternada. O corpo conduz a eletricidade através da água existente no tecido magro, sendo que a gordura não é condutora de eletricidade. Supondo-se que a quantidade de água no tecido magro seja constante, a medida deste componente permite calcular o total de massa magra. Através da medida do peso total e da massa magra, pode-se calcular a quantidade de gordura corporal. A variação do estado de hidratação pode afetar a condutividade tornando-se importante fator de erro (HOFFER et al., 1969). Deve ser usado com critério em mulheres na fase pré-menstrual e em pessoas em uso de substâncias diuréticas.

LUKASKI et al. (1985), afirmam que a bioimpedância é método seguro e não invasivo para a avaliação da gordura corporal mas reforçam o cuidado com a interferência da quantidade de líquido corporal podendo confundir os resultados.

A utilização da densitometria por dupla emissão de raios X (DEXA) na avaliação da composição corporal permite a medida tanto da massa óssea quanto do conteúdo corporal de gordura e massa magra (KIEBZAK et al., 2000). A densitometria por DEXA do corpo inteiro é o único método que avalia diretamente todos os compartimentos corporais (massa óssea, massa muscular, água e massa gordurosa), sem inferir dados a partir da medida de apenas um compartimento. $\mathrm{O}$ exame não é invasivo, é de baixa radiação, não requer nenhum preparo, sendo 
realizado durante um periodo de 10 a 15 minutos. Uma vantagem adicional do DEXA é a determinação da composição regional, permitindo o estudo particularizado de braços, pernas, tronco e abdome. Os parâmetros avaliados são comparáveis, quando obtidos nos exames de densitometria de coluna lombar e fềmur, com erro em torno de 1 a $2 \%$, oferecendo uma boa reprodutibilidade dos resultados. Apenas a massa gorda apresenta um coeficiente de variação mais elevado, em torno de 3 a $4 \%$, provavelmente relacionado a heterogeneidade dos tecidos moles em pacientes obesos (ELLIS, 2000).

MAZESS et al. (1990), dizem que, apesar da sua eficácia, mais estudos precisam ser realizados a fim de excluírem a interferência do estado de hidratação, redução de peso e alteração dos tecidos neste método. COMPSTON et al. (1992), descrevem o DEXA como apresentando algumas falhas por não conseguir isolar a quantidade de liquido corporal. LEY et al. (1992), após aplicação do DEXA para realização de estudo de pacientes com IMC variando entre 18.8 a 28, afirmam que este método é seguro para avaliação de distribuição de gordura corporal em pacientes não obesos. Muitos outros pesquisadores como HOLBROOK et al., 1991; LAMBRINOUDAKI et al., 1998; PARADISI et al., 1999; GAMBACCIANI et al., 1999, enfatizam a eficácia desse método.

WANG et al. (1994), em estudo para avaliação da relação da distribuição de gordura corporal, se relacionada com idade ou estado pós-menopausa, afirmam que não existe diferença em usar o DEXA do aparelho Hologic ou do Lunar na precisão dos resultados.

Os demais métodos não invasivos para avaliação da composição corporal (análise da ativação de nêutrons, submersão na água, água marcada, potássio corporal total, etc.) requerem a realização de mais de um destes exames para complementação de dados, pois avaliam apenas um compartimento corporal, inferindo os demais. São trabalhosos, caros e não disponíveis na prática clínica, ficando restritos aos laboratórios de pesquisa. 


\section{4 Ácido gama-linolênico}

Chamamos lipídeos ou gorduras um grupo heterogêneo de substâncias, com diferentes propriedades físicas e químicas, apresentando em comum o fato de serem solúveis em solventes orgânicos e insolúveis em água (ZAIA, 2002).

Juntamente com os carboidratos e proteínas, são macronutrientes de importância biológica, que podem ser sintetizados no organismo, com exceção dos ácidos graxos essenciais (EFAs). Exercem, nos seres vivos, funções energéticas, estruturais e homonais (MORAES E SANTOS, 1998).

Quimicamente, são cadeias hidrocarbonadas, contendo duas ou mais duplas ligações e apresentando em uma extremidade radical carboxila e na outra radical metila (KRUMMEL, 1998).

A essencialidade desses ácidos foi definida em 1930, por BURR GO; BURR $\mathrm{MM}$, ao introduzirem o conceito de EFAs considerando-os substâncias necessárias ao bom funcionamento orgânico e que, não podendo ser produzidos pelo organismo, devem ser fornecidos através da dieta. Estes pesquisadores, estudando ratos alimentados com ácidos graxos poliinsaturados (PUFAs) observaram que sua deficiência levava a problemas dermatológicos, renais, visuais, distúrbios de fertilidade, e que a reintrodução desses ácidos revertia os sintomas.

São também considerados essenciais porque são precursores das prostaglandinas (PGs), tromboxanos (TXs) e leucotrienos (LTs), chamados eicosanóides (STONE et al., 1979).

Existem dois grupos de ácidos graxos essenciais, os ômega-6 (n-6, ou $\omega-6)$ e os ômega-3 (n-3, ou $\omega-3)$, definidos pela posição da primeira dupla ligação na molécula inicial do átomo de carbono de terminação metila da cadeia (HORROBIN, 1992).

Existem dúvidas de como os ácidos graxos essenciais devem ser definidos. HORROBIN (1988), cita Sinclair em sua afirmação de que todos os ácidos graxos essenciais são ácidos graxos poliinsaturados, porém muitos ácidos graxos poliinsaturados não são ácidos graxos essenciais. Ácido alfa-linolênico (ALA) e ácido linoléico (LA) são ácidos graxos essenciais, enquanto ácido gama-linolênico 
(GLA), ácido di-homo-gama-linolênico (DGLA), ácido eicosapentaenóico (EPA), ácido docosa-hexaenóico (DHA) são ácidos graxos poliinsaturados e não são ácidos graxos essenciais.

O composto inicial das duas séries é: ácido linoléico, que é um n-6 e ácido alfa- linolênico, que é um n-3. LA e ALA são metabolizados através de uma série de dessaturações e elongamentos, produzindo seus metabólitos ativos. Acredita-se que o sistema enzimático envolvido nesse metabolismo seja idêntico, embora não haja provas. Sabe-se que n-3 e n-6 competem entre si, no padrão de metabolismo, havendo uma maior afinidade enzimática para os n-3 (HORROBIN, 1992).

Apresentamos a seguir um esquema demonstrando o metabolismo desses ácidos.

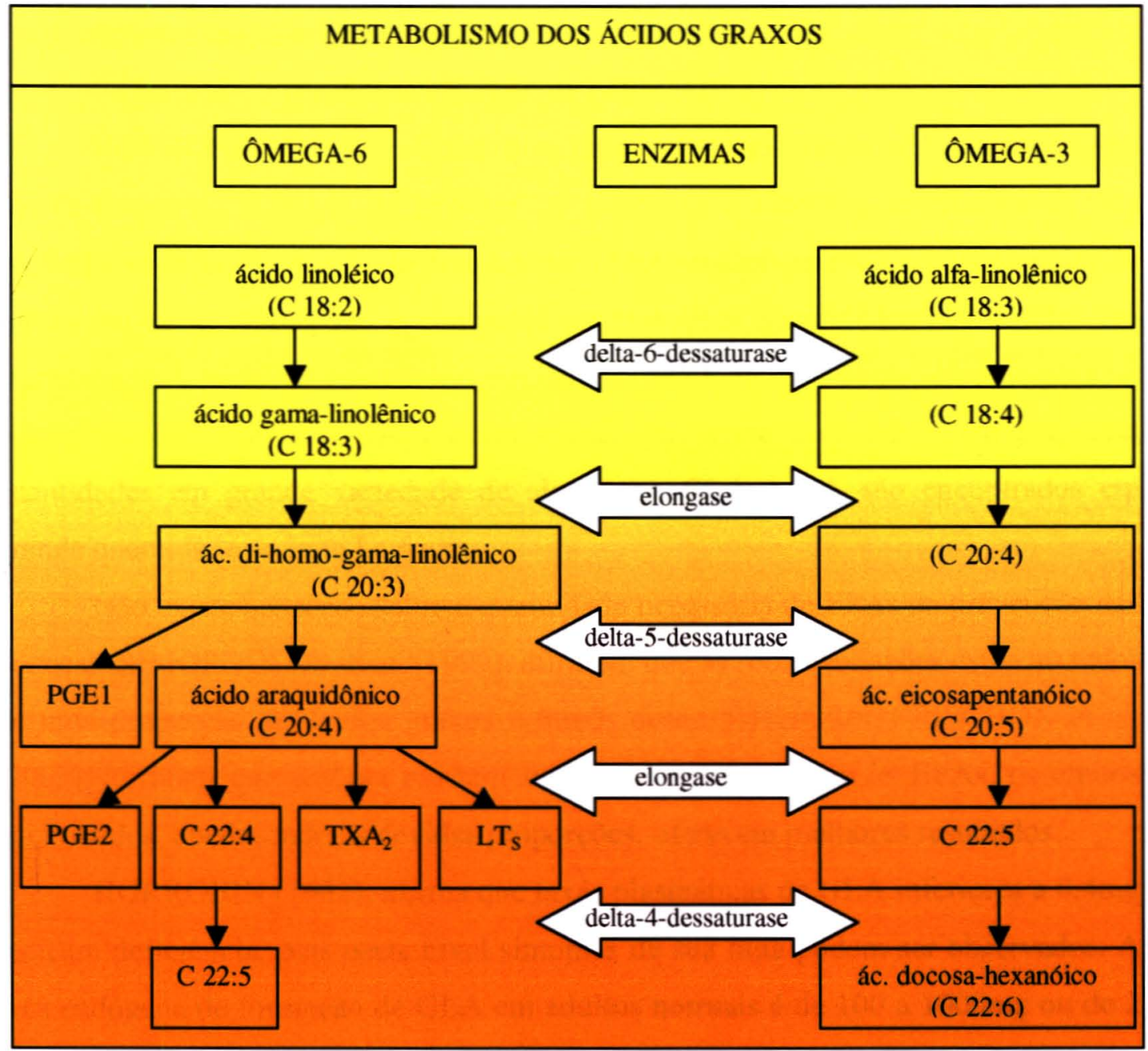

Fonte: Adaptado de Schmidt MA, 2000. 
BRENNER (1987), enfatiza a importância do sistema enzimático nestas etapas de metabolismo, citando que alterações em elongamentos e, ou, dessaturações podem ser responsáveis pelas deficiências encontradas.

Segundo HORROBIN (1992), os n-6 apresentam importantes funções dependendo do metabólito ativo envolvido. Dentre elas:

1 - Modulação da estrutura das membranas do organismo, determinando fluidez, flexibilidade e permeabilidade,

2- Formação de moléculas reguladoras, tais como prostaglandinas, tromboxanos e leucotrienos, conhecidas como eicosanóides,

3- Controle de impermeabilidade de água da pele e possibilidade de permeabilidade de outras membranas, tais como a gastro-intestinal e a barreira sangüinea do cérebro,

4- Regulação do transporte e síntese de colesterol.

HORROBIN (1992), afirma que uma substância deve ser descrita como ômega-6 quando é capaz de reverter os sintomas e afecções resultantes da sua exclusão na dieta. GLA e ácido araquidônico (AA) podem reverter as deficiências de ácidos graxos e, ambos são encontrados em pequenas quantidades distribuídos em alimentos. AA pode ser encontrado em carnes, gema de ovo, peixe, óleo de peixe e outros alimentos do mar. GLA é encontrado em aveia e cevada e em pequenas quantidades em grande variedade de alimentos. GLA e AA são encontrados em grande quantidade no leite humano.

Não existe consenso sobre a quantidade necessária de EFAs na prevenção das doenças. SIMOPOULOS et al. (1999), afirmam que as recomendações estão ao redor de uma proporção de ácidos graxos n-6:n-3, desde 5:1 até 10:1. PISCHON et al. (2003), afirmam que embora existam funções específicas para os EFAs, os efeitos combinados, obedecendo as devidas proporções, oferecem melhores resultados.

HORROBIN (1992), afirma que taxas plasmáticas de GLA inferiores a 0,4mg indicam deficiência, pois neste nível sintomas de sua falta podem ser observados. A taxa endógena de formação de GLA em adultos normais é de 100 a $1000 \mathrm{mg}$ ou de 2 a $20 \mathrm{mg} / \mathrm{kg} / \mathrm{dia}$. É também estimado que a ingestão diária de GLA e DGLA em lactentes é de 20 a $80 \mathrm{mg} /$ dia. A evidência disponível indica que somente 5 a $10 \%$ da ingestão diária de ácido linoléico pode ser convertido para GLA e metabólitos. Se a 
produção endógena de GLA é da ordem de 100 a $1000 \mathrm{mg} /$ dia e $50 \%$ disso é perdido a partir da idade de 60 anos, é razoável considerar como dose nutricional em torno de 25 a $50 \mathrm{mg} /$ dia e terapêutica 100 a $500 \mathrm{mg} /$ dia. Porém, determinadas situações requerem maior quantidade de EFAs tais como:

- Infância e processos patológicos (câncer, inflamação, processos regenerativos), onde ocorre maior taxa de divisão celular;

- Em situações de metabolismo acelerado, nos quais ocorre maior oxidação lipídica para fornecimento de energia;

- Ingestão de grande quantidade de gorduras saturadas;

- Deficiência de dessaturases e elongases;

- Pessoas do sexo masculino requerem maior quantidade de EFAs que as do feminino.

O GLA, primeiro metabólito do LA, foi inicialmente isolado da semente do óleo de prímula. Com a recente procura de complementos nutricionais com óleos contendo GLA, outras fontes surgiram, incluindo óleo de borragem, de semente de uva passa escura, e óleo de fungo. Esses óleos apresentam vantagens, dentre elas, a ausência de sintéticos e a resistência a auto-oxidação, além de possuírem em sua composição um anti-oxidante natural, geralmente a vitamina E (WILLIS; SMITH, 1989).

A etapa metabólica de formação do GLA depende da enzima delta-6dessaturase (D6D) que apresenta diminuição de sua atividade em envelhecimento, diabetes, ingestão de grande quantidade de álcool, fatores nutricionais de deficiência de piridoxina, zinco, magnésio, biotina, estresse, altos níveis de colesterol e infecções virais (HORROBIN, 1981).

Adultos que consomem adequado nível de LA e que tomam uma boa mistura dietética, com adequados nutrientes e mínima quantidade de alimentos contendo gorduras processadas, não têm necessidade de suplementação de GLA. Por outro lado, pessoas saudáveis, que estão expostas a alguma das situações acima citadas, podem ter redução da habilidade de fabricar quantidades normais de GLA endógeno e, portanto, podem considerar a possibilidade de suplementação (HORROBIN, 1992). 
HORROBIN (1981), afirma que o envelhecimento causa modificações na D6D, tanto na atividade quanto na quantidade, alterando o metabolismo do LA e podendo causar danos no sistema cardiovascular e imunológico. ZIBOH; FLETCHER (1992), descrevem a atuação do GLA em processos imunológicos, mediando os fatores pró-inflamatórios.

Comprovando a diminuição da D6D no envelhecimento, HORNYCH et al. (1999), realizaram estudo em pessoas de 75 a 91 anos, sem endocrinopatias ou doenças degenerativas, durante 3 meses, administrando óleo de prímula, $4 \mathrm{~g}$ ao dia, detectando a elevação plasmática do GLA.

A conversão de DGLA para AA, via delta-5-dessaturase (D5D), parece ser reduzida em homens, coelhos e porcos, aumentada em ratos, e ausente em gatos (WILLS 1982). Em estudo realizado em homens, sendo administrado $1 \mathrm{~g}$ de DGLA diário por 30 dias, KERNOFF et al. (1977), demonstraram aumento na quantidade de prostaglandinaEl (PGE1) em plaquetas e menor quantidade de AA, confirmando menor ação da D5D. STONE et al. (1979), afirmam que a D5D é mais ativa em ratos, confirmando maior quantidade plasmática de AA quando se administra GLA ou DGLA.

DGLA, quando metabolizado pela prostaglandina sintetase produz PGE1 que apresenta propriedades de inibir a agregação plaquetária, inibir a proliferação de músculo liso vascular e de células tumorais, e, inibir mitogênese plaquetária, que é responsável por sua proliferação (SMITH et al., 1989).

PGEl inibe a agregação plaquetária, aparentemente agindo nos mesmos receptores das prostaciclinas através do aumento da adenosina monofosfato cíclica $(\mathrm{AMPc})$ intracelular, atuando sobre a musculatura lisa das artérias provocando vasodilatação coronariana. Um efeito da PGE1 não mediado pela AMPc é reduzir a fragilidade dos eritrócitos, que é oposto ao da PGE2 (LEON et al., 1980).

Através da etapa de metabolização, DGLA pode competir com o AA evitando que os seus efeitos deletérios ocorram.

LAGARD et al. (1980), afirmam que o DGLA é mais potente em inibição de agregação plaquetária em células endoteliais vasculares que o EPA, ressaltando sua importância nos processos hipertensivos. 
WILLIS; SMITH (1981), enfatizam a importância do DGLA na biossíntese das PGs. Afirmam ainda que DGLA parece ser capaz de inibir a conversão para AA e conseqüentemente seus metabólitos.

EFAs são os principais componentes estruturais do cérebro e, através de seus efeitos nas propriedades de membrana, podem influenciar a condução nervosa, comunicação e ação dos transmissores. As prostaglandinas, derivadas dos EFAs, também são capazes de modificar a condução e função transmissora (HORROBIN, 1987).

HORROBIN (1979), relaciona PGEl com esquizofrenia. Em 1983, HOLMAN; BELL, em estudo duplo cego com $4 \mathrm{~g}$ de óleo de prímula (EPO), em pacientes esquizofrênicos, encontraram melhora do quadro.

HORROBIN (1987), refletindo sobre a deficiência de EFAs no alcoolismo, afirma que a deficiência de PGEl deve ser responsável pelos efeitos inebriantes do álcool.

SEGARNICK et al., 1985, afirmam que inibidores de prostaglandinas, como aspirina, reduzem o tempo de sono induzido pelo álcool, concluindo haver ação neurológica dos EFAs no controle do sono. SMITH (1987), reforça o envolvimento da PGEl nos processos que envolvem o humor.

O DGLA sob ação da D5D irá produzir o AA que, por sua vez, pode ser metabolizado através de duas vias: a das ciclooxigenases e a das lipooxigenases. A via das ciclooxigenases é mediada pelas enzimas ciclooxigenases ( $\mathrm{COX} 1$ e 2) produzindo prostaglandinas e tromboxanos da série 2. Embora essa série de substâncias seja relacionada a processos inflamatórios, vasoconstritores e trombogênicos, no rim apresenta função vasodilatadora e de importância no controle do equilibrio de água e sódio (OATES, 1988).

A COX1 parece ser mais bem distribuída e está mais associada à manutenção dos tecidos, sendo liberada constantemente, enquanto a COX2 está associada às respostas inflamatórias e sua expressão é induzida por elas. A outra via é mediada pela ação das lipooxigenases (LOX) produzindo leucotrienos, ácidos hidroxi e hidroperoxieicosanóicos (HETE e HPETE) e lipoxinas, envolvidas em processos imunológicos (POMPÉIA, 2002). 
Vários estudos vêm sendo realizados comprovando a ação benéfica dessas substâncias em processos degenerativos, alterações lipídicas, hipertensão, tensão prémenstrual, distúrbios psiquiátricos e distribuição de gordura corporal (PULLMAMMOOAR et al., 1990; BELCH; MUIR, 1998; NESTEL, 1987; SIMOPOULOS, 1999; ZURIER et al., 1996; JENSEN, 1997, JANJIC, 1997; GUIVERNAU et al., 1994; DREON et al., 1990; SUGANO; IKEDA, 1996; SUGANO et al., 1996; ISHIKAWA et al., 1989; RICHARD et al., 1990, ENGLER, 1993; LARSEN et al., 1999).

Descreveremos em capítulos seguintes a relação desse ácido graxo com a hipertensão e gordura corporal.

\subsection{Relação entre ácido gama-linolênico e hipertensão arterial}

Vários estudos epidemiológicos, dentre eles o de KEYS et al., 1953, YERUSHALMY; HILLEBOE, 1957, JOLLIFFE; ARCHER, 1959, relacionando o padrão de consumo de gorduras saturadas com maior incidência de doenças cardiovasculares, encorajam a investigação sobre os beneficios de mudanças alimentares na prevenção dessas morbidades (RAVNSKOV, 1998).

HELSING (1995), analisando a ocorrência de doenças cardiovasculares nos dezesseis países do Mediterrâneo, conclui que, mesmo havendo algumas diferenças referentes a padrão alimentar, apresentam em comum maior consumo de cereais e menor consumo de gordura animal, que é bastante saturada, justificando o padrão preventivo em relação às doenças.

WRITTING COMMITEE of AMERICAN HEART ASSOCIATION (2001), cita DELORGERIL et al., 1999, analisando os efeitos biológicos dos diferentes PUFAs na prevenção dos eventos cardiovasculares fatais e não fatais enfatizando a ação dos n-3 e n-6 como substâncias que atuam na sua profilaxia.

HIME et al., 2001, enfatizam as propriedades benéficas dos EFAs nas alterações metabólicas responsáveis pelo aparecimento de doenças. 
Os ácidos graxos essenciais, apesar de serem considerados pela maioria como suplemento alimentar, têm demonstrado efeitos benéficos no tratamento da hipertensão arterial, despertando interesse no campo médico. A justificativa reside no fato de que, ao haver agressão vascular, libera-se ácido araquidônico, que, por sua vez será convertido em metabólitos ativos tais como prostaglandinas, tromboxanos, prostaciclinas, leucotrienos, que dependendo do local de ação apresentam efeito diferente (KINSELLA, 1987).

A maior parte dos trabalhos obtidos na literatura foi realizada em animais.

HOFFMANN et al., 1986, em estudo comparativo, avaliando a interferência de várias dietas sobre a hipertensão arterial, em ratos, introduziram na alimentação óleo de girassol (rico em LA), linhaça (rico em ALA), prímula (rico em GLA) e palma (rico em AS). Observaram que a composição renal de fosfolípides mudou de acordo com as dietas e que os do grupo em cuja dieta preponderou GLA apresentaram melhores resultados sobre a pressão arterial. Neste grupo encontraram maior quantidade de PGE1 e PGE2 na aorta, levando os autores a questionarem o efeito isolado das prostaglandinas na hipertensão.

MILLS; WARD (1984), investigando a ação do GLA em ratos hipertensos e em ratos com hipertensão induzida por estresse realizaram um estudo comparativo utilizando dieta com GLA, concluindo que o efeito hipotensor do GLA só ocorre na vigência de estresse. Em 1992, ainda observando ratos hipertensos, MILLS et al., confirmaram o efeito hipotensor do GLA, porém em hipertensão espontânea.

Segundo MILLS (1989), o efeito hipotensor do GLA em animais demonstrou ser bastante eficaz na hipertensão induzida por estresse. $O$ estresse funciona como um fator neurogênico da hipertensão. A administração de GLA, tanto em animais como em humanos está associada com aumento de DGLA tão bem como aumento na capacidade de sintetizar prostaglandinas. É possivel que a elevação da pressão arterial, induzida pelo estresse, esteja relacionada a queda da atividade da delta-6dessaturase provocada pela epinefrina e corticosteróides.

SOMA et al., 1985, estudando ratos hipertensos suplementados com óleo de açafrão, de coco e de primula confirmaram o efeito hipotensor do óleo de prímula (maior conteúdo de GLA) em relação aos demais. 
SINGER et al., 1990, estudando ratos hipertensos, alimentados com óleo de semente de girassol (SO), óleo de prímula (EPO), óleo de peixe (FO) e associação dos mesmos determinaram diminuição quantitativa da pressão sangüínea e dos lipídios sangüíneos. A associação de EPO e FO não apresentou resultados significativos. O motivo pelo qual a combinação de EPO e FO não ter apresentado grande efeito na queda da pressão sangüinea permanece obscuro. Os PUFAs podem apresentar diferentes efeitos na pressão sangüínea e lipídios plasmáticos em ratos hipertensos. A redução da pressão sangüínea sistólica e triglicerídios plasmáticos foi mais acentuada após EPO, quando comparada com SO rico em LA e FO rico em ALA.

ENGLER et al. (1992), avaliando os efeitos da dieta com óleo de borragem sobre a pressão arterial e reatividade vascular, alimentaram ratos com óleo de gergelim ou borragem durante 7 semanas e observaram um decréscimo de $30 \mathrm{mmHg}$ na PAS em hipertensos e $10 \mathrm{mmHg}$ em normotensos com o uso de óleo de borragem, além de constatarem menor reatividade vascular.

Segundo ENGLER (1992), alterações na composição dos PUFAs podem influenciar resposta vascular, que também é de importância na regulação da pressão sangüinea modificada pelo metabolismo anormal dos ácidos graxos.

Estudo realizado por ENGLER et al., 1992, em ratas alimentadas com óleo de borragem (PUFA rico em GLA), por sete semanas, determinaram um decréscimo na pressão sistólica em ratas hipertensas de $30 \mathrm{mmHg}$ e em ratas normotensas de $10 \mathrm{mmHg}$, sugerindo pronunciado efeito do óleo de borragem sobre o estado hipertensivo .

ENGLER et al. (1998), estudando ratos hipertensos, após alimentação com óleo de borragem durante 5 semanas observaram um efeito hipotensor que os autores atribuíram à ação da PGE2 sobre o sistema renina-angiotensina-aldosterona.

Outros estudos realizados em modelos animais compararam o uso de GLA e ácido acetil salicílico (ASA) na pressão sangüínea sistólica, confirmando que o GLA tem um efeito hipotensor, em ratas hipertensas, superior ao ASA (ST.LOUIS, 1992).

SASAKI et al. (1995), procurando determinar a ação do GLA e do EPA na aterosclerose relacionada a hipertensão, estudaram ratos hipertensos alimentados ou com óleo de oliva (rico em ácido oléico), ou óleo rico em GLA ou EPA. Detectaram 
uma maior ação do EPA na redução da PA porém nenhuma das três dietas mostrou prevenir aterosclerose aórtica.

INGRAM et al. (1996), questionando a modulação das doenças renais através dos PUFAs, alimentaram ratos com alteração renal com óleo de borragem e de milho, durante vinte semanas, e encontram melhora ou estabilização do estado glomerular com as duas dietas, porém maior eficácia com o óleo de borragem, atribuindo essa ação a maior concentração de GLA em sua composição.

NARCE; POISSON (1997), observando os níveis plasmáticos de LA e AA em fígado de ratos hipertensos e normotensos detectaram maior concentração de LA em relação a AA nos hipertensos, proporcional à idade, concluindo haver uma diminuição da atividade da enzima D6D com o envelhecimento, levando a metabolização diminuída do LA.

ENGLER et al., 1998, estudando ratos hipertensos, após alimentação com óleo de borragem, confirmaram não só o efeito hipotensor sobre a PAS mas também interferência sobre o sistema renina-angiotensina-aldosterona.

GALIPEAU et al. (2001), estudando o papel do $\mathrm{TXA}_{2}$ no desenvolvimento de hipertensão em ratos confirmaram sua ação hipertensiva, sugerindo a administração de substâncias inibidoras da tromboxano sintetase.

FRENOUX et al. (2001), refletindo sobre os achados de proteção cardiovascular com a introdução de PUFAs na dieta e questionando sobre os processos oxidativos a que os PUFAs estão mais sensíveis, estudaram ratos hipertensos suplementados com GLA, EPA ou DHA. Todas as suplementações apresentaram efeito benéfico sobre a PA, aumentando o padrão antioxidante $\mathrm{e}$ resistência a peroxidação lipídica, diminuindo a velocidade de agregação plaquetária e concentração plasmática de lipídeos.

GERMAIN-BELLENGER et al. (2002), avaliando durante onze semanas o comportamento hipertensivo de ratos hipertensos em diferentes idades, após introdução de dieta contendo n-6 e n-3, observaram maior ação em ratos mais idosos onde encontraram menor quantidade plasmática de ácido araquidônico.

Além de estudos em animais, muitos autores realizaram estudos em humanos.

Em estudo realizado com 60 pacientes, com faixa etária entre 61 e 83 anos, foram selecionadas 20 hígidas, 20 com doença vascular (coronariopatia, infarto, ou 
doença vascular periférica) e 20 senis, foram administradas $10 \mathrm{~g}$ de óleo de semente de uva passa escura e, observando durante 3 meses o efeito desse óleo sobre o sistema cardiovascular e o metabolismo lipídico constatou-se decréscimo na pressão diastólica de pacientes sem doença vascular, porém, os melhores resultados foram naqueles que apresentavam alterações nas paredes vasculares, sem sintomas clínicos de esclerose. Quanto ao metabolismo lipídico, houve decréscimo nos valores de VLDL nos 3 grupos, confirmando seu efeito preventivo sobre as doenças cardiovasculares (DILLON, 1987).

MILLS et al. (1989), estudando 30 homens normotensos, submetidos a estresse, alimentados com 1,3g de óleo de borragem por 28 dias, observaram diminuição tanto na pressão sistólica como na diastólica.

Estudo com homens e mulheres hipertensos, cuja medicação anti-hipertensiva foi descontinuada durante o tempo que durou o estudo ( 2 semanas), avaliando a relação entre a pressão arterial e a biossíntese de prostaciclina e tromboxane-A, concluiu que a biossintese de prostaciclina está seletivamente diminuida nos casos de hipertensão moderada. Isso pode contribuir para o aumento da resistência periférica e aumento da incidência de trombose, que são característicos da hipertensão essencial (MINUZ et al., 1990).

DEFFERNE; LEEDS (1992), estudando o efeito do óleo de girassol (4g/dia) durante seis semanas sobre a PA de voluntários hipertensos encontraram redução na PA diastólica. Os mesmos autores, 1996, refletindo sobre a ação dos n-6 na reatividade cardiovascular, estudaram 28 homens hipertensos nos quais, após aplicação de testes aritméticos, observaram a resposta vascular. Estes voluntários receberam cápsulas de óleo de semente de uva passa escura e açafrão (6g/dia) durante oito semanas e retornaram para controle de PA a cada duas semanas. O grupo que tomou óleo de semente de uva passa escura apresentou redução de $40 \%$ na PA em comparação ao que tomou óleo de açafrão após o estresse do teste, confirmando o potencial do GLA, contido na uva passa, nos processos hipertensivos.

MÉNDEZ DE MEDINA (1998), em tese apresentada à Faculdade da Guatemala, relacionou a incidência de hipertensão arterial na Costa Rica a deficiência na alimentação do ácido linoléico. 
LARSE et al. (1999), observando a diminuição do risco cardiovascular em pessoas que consomem menor quantidade de gorduras saturadas, realizaram uma avaliação comparativa em 18 estudantes saudáveis, após introdução de dietas contendo $5 \mathrm{~g}$ de óleo de oliva, girassol ou semente de uva passa escura, encontrando redução dos níveis plasmáticos do fator VII nas três dietas, concluindo que talvez esta constatação explique a menor incidência dos acidentes vasculares em populações onde o hábito alimentar baseia-se em gorduras insaturadas.

HORNYCH et al. (1999), estudaram pessoas idosas, e declararam que doses maiores de GLA aumentam a quantidade da PGE renal, e, portanto, diminuindo o risco cardiovascular. Neste artigo os autores presumiram seja conhecida a ação vasodilatadora das prostaglandinas, já descrita em outros estudos (OATES et al., 1988).

POGZHEVA (2000), estudando pacientes com doença coronariana e hipertensão afirmou que os n-3 e n-6 exercem mudanças físicas, biológicas e químicas nas membranas celulares, promovendo melhora clínica.

HIME (2000), estudando mulheres após a menopausa hipertensas, demonstrou tendência a queda dos níveis tensionais após administração do ácido gama-linolênico.

MISSKANGAS et al. (2001), procurando relacionar dieta com ativação da proteina $\mathrm{C}$ quinase, responsável por maior agregação plaquetária, realizaram estudo de intervenção alimentar em homens voluntários com dieta rica em LA ou ácido oléico durante um mês e não observaram diferença em relação a enzima ou ativação plaquetária.

Das UN (1995), observando a menor incidência de mortalidade e morbidade por doenças cardiovasculares em países onde o consumo de EFAs é maior, associou a prevenção das doenças aos EFAs.

Das UN (2001), referiram que a suplementação com PUFAs no período de formação cerebral previne o desenvolvimento de hipertensão arterial.

IMANISH et al. (2001), afirmaram que as prostaglandinas apresentam diferenças dependendo do sítio de ação e que, no caso da hipertensão de causa renovascular, a PGE2 tem efeito benéfico. 
HORNYCH et al. (2002), observando o comportamento dos n-6 em pessoas idosas afirmaram que a idade leva a diminuição da D6D que converte LA em GLA interferindo sobre as prostaglandinas renais. Introduziram suplementação de GLA durante 3 meses, e confirmaram efeito hipotensor associado a maior bissíntese de PGE renal, com efeito vasodilatador e redução da PA.

SERRA-MAJEM (2004), enfatizou a correlação das dietas, tanto de japoneses como de mediterrâneos, nas baixas taxas de mortalidade por doenças cardiovasculares nesses países, associando não só ao hábito alimentar predominante em gorduras poliinsaturadas, mas também a presença de antioxidantes

\subsection{Relacão entre ácido gama-linolênico e gordura corporal}

Como foi descrito anteriormente, os ácidos graxos essenciais têm como uma das funções a manutenção da estrutura das membranas celulares, além de serem precursores de substâncias importantes no metabolismo como prostaglandinas, tromboxanos e leucotrienos.

Vários estudos têm sido realizados com a finalidade de comprovarem a ação benéfica da introdução desses compostos na alimentação, prevenindo ou tratando as alterações relacionadas a distribuição da gordura corporal.

JENSEN et al (1989), estudando o comportamento da gordura corporal em mulheres e homens concluíram que quanto maior a concentração de adipócitos mais devagar o processo de lipólise. Em 1998, JENSEN, afirmou que a regulação da lipólise para fornecimento de energia está diretamente relacionada à localização da gordura e a dieta ingerida.

HELENIAK; ASTON (1989), descrevendo os fatores relacionados ao ganho de peso citaram os ácidos graxos essenciais como importantes na regulação do peso. Descreveram presença de pequenas quantidades de ácido linoléico no tecido adiposo em pacientes obesos. Enfatizaram ainda que a relação desses ácidos com a redução do peso deve estar relacionada à produção da PGE que apresenta efeito termogênico e lipotrófico. 
LIN et al. (1993), comparando coelhos alimentados com dieta rica em gordura saturada ou poliinsaturada perceberam maior afinidade dos adipócitos aos ácidos graxos poliinsaturados em comparação com monoinsaturados.

PHINNEY et al. (1993), estudando ratos obesos observaram que a administração de ácido araquidônico reduziu o peso, concluindo que na obesidade há redução do ácido araquidônico na gordura, talvez provocada pela deficiência de delta-6-dessaturase, necessária para metabolizar o ácido linoléico para araquidônico.

TAKATA et al. (1994), em estudo com ratos alimentados com óleo de fungo contendo $25 \%$ de GLA e óleo de soja, que contém menor quantidade de GLA, confirmaram maior efeito do óleo de fungo na redução da gordura corporal.

MACDOUGALD (1995), descreveu que os ácidos graxos de cadeia longa são importantes agentes no controle de diferenciação do adipócito.

MCLEAN (1996), descreveu que dietas com redução de gorduras saturadas e substituição por insaturadas provenientes de óleo de borragem, prímula e semente de uva passa escura apresentaram resultado significativo na redução da gordura corporal, afirmando que isto ocorre por aumento da lipólise para produção de energia.

WOLF (1996), afirmou que a diferenciação do adipócito e a homeostase do número de células gordurosas são reguladas pelo PPAR-gama que é ativado pelas prostaglandinas.

CUNNANE; ANDERSON (1997), em estudo animal, observaram que grande quantidade de ácido linoléico ingerido sofre processo de oxidação, sendo eliminado.

REGINATO et al. (1998), afirmaram que apesar do PPAR ser considerado receptor adipogênico, as prostaglandinas, em especial a PGF2 $\alpha$, são importantes ligantes bloqueando sua atividade transcricional por indução da fosforilação via mitogen-activated protein kinase (AMP-quinase) fazendo com que exerçam função anti-adipogênica.

JENSEN (1998), afirmou que a distribuição da gordura corporal altera o metabolismo dos ácidos graxos predispondo a obesidade.

FAN; CHAPKIN (1998), afirmaram que a ingestão de GLA aumenta a quantidade de DGLA e seus metabólitos, em especial as PGs, desde que o sistema enzimático de conversão esteja íntegro. 
FERNANDEZ-REAL et al. (1999), em estudo com homens e mulheres com IMC variando de 28 a 29 observaram a presença de grande quantidade de ácidos graxos na circulação sangüinea, que pode estar relacionada a menor resistência insulínica e gordura corporal.

OBERFIELD et al (1999), em estudo de laboratório utilizando substâncias agonistas do PPAR-gama confirmaram sua ação na diferenciação do adipócito comprovando sua importância quando se deseja redução de peso.

FREAKE (1999), estudando os fatores envolvidos na obesidade afirmou que mutações no receptor PPAR podem estar associadas a casos de extrema obesidade, por impedir a ação das substâncias ligantes, entre elas, as prostaglandinas.

HIME (2000), em estudo com mulheres cardiopatas na pós-menopausa, administrando GLA durante 90 dias encontrou melhora significativa no bem estar geral com tendência a diminuição de peso corporal.

JEHL-PIETRI et al. (2000), afirmaram que existem vários tipos de receptores PPAR, porém só o PPAR-gama está envolvido na redução do adipócito.

ROCCHI; AUWERX (2000), enfatizaram a função do PPAR-gama no controle da expressão de grande número de genes envolvidos na diferenciação do adipócito, armazenamento de lipídeos e sensibilização a insulina e, afirmaram que as prostaglandinas são importantes ligantes desse receptor desempenhando destacado papel no controle da obesidade e diabetes.

MORRISON; FARMER (2000), afirmaram que o PPAR se encontra envolvido na cascata de diferenciação de adipócito.

Segundo BAR-TANA (2001), o receptor PPAR-gama é membro de uma super família de receptores nucleares. Tem característica de ligar-se aos eicosanóides desempenhando funções de promover melhor ação da insulina.

De acordo com RIBOT et al. (2001), a redução de peso, em pacientes obesos, em qualquer proporção implica diminuição do volume ou do número dos adipócitos. A regulação desse processo depende de fatores de transcrição dos adipócitos dentre eles do PPAR-gama, envolvido em vários processos de metabolismo do adipocitário implicados na perda de peso. 


\section{OBJETIVOS}

\subsection{Objetivo Geral}

- Observar o efeito do tratamento com ácido gama-linolênico em pacientes hipertensas na pós-menopausa.

\subsection{Objetivos Específicos:}

- Avaliar a ação do tratamento sobre os níveis pressóricos;

- Avaliar a ação do tratamento sobre a distribuição da gordura corporal, especificamente sobre à medida em cintura e quadril. 


\section{PROCEDIMENTO METODOLÓGICO}

\subsection{Tipo de Pesquisa}

- Estudo clínico duplo-cego prospectivo e aleatório.

\subsection{Local de Estudo}

- Ambulatório de Cardiologia da Mulher do Instituto Dante Pazzanese de Cardiologia, da Secretaria de Saúde do Estado de São Paulo, av. Dante Pazzanese, 500, Ibirapuera, São Paulo, SP, durante o periodo de 2002 a 2004.

\subsection{Populacão de estudo}

- Foi programado estudar oitenta (80) pacientes hipertensas com idade de 43 a 70 anos e tempo de menopausa variando entre dois e oito anos por um periodo de seis meses. As pacientes seriam encaminhadas do Setor de Hipertensão do Instituto Dante Pazzanese de Cardiologia e continuariam seguindo a orientação e medicação anti-hipertensiva específica recomendada para cada caso, conforme prescrição do Setor de Hipertensão. 


\subsection{Metodologia}

Foi planejado o atendimento da seguinte forma:

- Avaliar mensalmente todas as pacientes com exame clínico geral, cardiológico e ginecológico, abrangendo: peso, circunferência da cintura e quadril, pressão arterial.

- Realizar no início exames de citologia oncológica, ultrassonografia transvaginal e mamografia, como forma de assegurar a sanidade ginecológica em geral.

- Determinar o peso e altura utilizando balança digital modelo Personal, Filizola.

- Medir a circunferência da cintura e quadril usando fita métrica não elástica. A medida da cintura feita ao nível da cicatriz umbilical, e a do quadril na extensão máxima das nádegas com a paciente em posição ereta.

- Avaliar a distribuição de gordura corporal na região abdominal e femural através de densitometria por dupla emissão de raios X (DEXA) utilizando aparelho modelo DPX, Lunar Radiation Corp, Madison WI, no início e final do estudo.

- Medida da pressão arterial utilizando aparelho de coluna de mercúrio, modelo Wan Méd, e adotando métodos descritos no III Consenso Brasileiro de Hipertensão Arterial, 1998, como importantes para maior precisão no diagnóstico:

1- Certificar-se de que o paciente: não está com a bexiga cheia; não praticou exercícios físicos; não ingeriu bebidas alcoólicas, café, alimentos ou fumo até 30 minutos antes da medida. Manter pernas descruzadas e o braço na altura do coração.

2- Deixar o paciente descansar por 5 a 10 minutos.

3- Usar manguito de tamanho adequado a largura do braço.

4- Palpar o pulso radial e inflar até seu desaparecimento para estimar a pressão sistólica.

5- Posicionar a campânula do estetoscópio sobre a artéria braquial.

6- Inflar rapidamente até ultrapassar 20 a $30 \mathrm{mmHg}$ o nível estimado da pressão sistólica. Desinflar lentamente. 
7- Determinar a pressão sistólica no aparecimento dos sons e a diastólica no desaparecimento dos sons. Não arredondar os valores para digitos terminados em zero ou cinco.

8- Solicitar que o paciente não fale durante o procedimento.

- A investigação constaria da administração de cápsulas de medicamento Ativo ou Placebo. Ambas as formulações, com aspecto similar, seriam formecidas pelo Bionatus Laboratório Botânico LTDA. Cada lote de medicamento identificado por letras $\mathrm{BH}$ e $\mathrm{BJ}$ e a sua composição (placebo ou medicamento ativo) só seria conhecida pela equipe do laboratório, até que se encerrasse a pesquisa. O placebo seria óleo mineral. O medicamento ativo constaria de óleo de borragem, cuja composição inclui: ácido palmítico $(10,4 \%)$, ácido esteárico $(2,9 \%)$, ácido oléico $(15,7 \%)$, ácido linoléico $(42,4 \%)$, ácido gama-linolênico $(23,9 \%)$, ácido eicosaenóico $(2,8 \%)$, ácido araquidônico $(1,3 \%)$, sendo adicionado vitamina $E$ (lmg) (Anexos 6, 7, 8, 9, 10).

- Cada paciente orientada a tomar 1 cápsula de $1000 \mathrm{mg}$ do preparado três vezes ao dia durante 6 meses.

- Adotados como critério de exclusão pacientes que apresentassem PAS acima de $180 \mathrm{mmHg}$ e PAD acima de $120 \mathrm{mmHg}$ para afastar o risco de crise hipertensiva (KAPLAN, 1998) ou que estivessem em uso de anticoagulantes pois existe trabalhos que referem a atuação do GLA sobre plaquetas (MISIKANGAS et al, 2001).

- Inclusão de todas as pacientes após informação sobre a investigação (Anexo 3 e 4) e assinatura do consentimento pós informado (Anexo 5).

Este protocolo foi aprovado pelo Comitê de Ética Médica da Faculdade de Saúde Pública da USP e do Instituto Dante Pazzanese de Cardiologia, da Secretaria da Saúde (Anexos 1 e 2). 


\section{5 $\underline{\text { Agenda de Atendimento }}$}

- Consulta inicial, explicando-se todo o estudo e, após firmado o compromisso de participação através da assinatura do consentimento pós informado, solicitação dos exames programados.

- Na próxima consulta avaliação dos exames, realização das medidas de pressão arterial, cintura e quadril, peso, altura e fornecimento da medicação, com a devida orientação de uso: 3 cápsulas por dia de medicamento Ativo ou Placebo.

- Controles mensais por seis meses, com medida de peso, pressão arterial, cintura e quadril e, na última entrevista, outra densitometria.

- Ao término da coleta de dados, avaliação estatística.

\subsection{Avaliacão estatística}

- A avaliação estatística foi planejada pelo Departamento de Estatística do Instituto Dante Pazzanese de Cardiologia.

\subsubsection{Análise descritiva}

- Com o objetivo apenas de caracterizar a amostra estudada, apresentação em forma de tabelas ou gráficos, das freqüências relativas (porcentuais) e absolutas $(\mathrm{N})$ das classes de cada variável qualitativa. Para as variáveis quantitativas médias e medianas para resumir as informações, e desviospadrão, mínimo e máximo para indicar a variabilidade dos dados. 


\subsubsection{Análise estatística}

- Para verificar a homogeneidade dos grupos com relação as variáveis qualitativas teste Exato de Fisher (Vieira, 1998). Esse teste baseia-se nas diferenças entre valores observados e esperados, avaliando se as proporções em cada grupo podem ser consideradas semelhantes ou não. Este teste seria utilizado se os valores esperados fossem inferiores a 5 . Valores de p menores do que 0,05 indicam que existe associação estatisticamente significativa entre as variáveis.

- Para as variáveis quantitativas, idade e tempo de menopausa, teste t-Student (VIEIRA, 1998), se fosse comprovada distribuição normal.

- Para avaliar simultaneamente as diferenças entre grupos (Ativo e Placebo) e tempos (mês $0,1,2,3,4,5$ e 6), análise de variância (ANOVA) com medidas repetidas (NETER et al., 1996). Nesta análise seriam avaliados os efeitos do grupo (Ativo e Placebo), os efeitos do mês $(0,1,2,3,4,5$ e 6$)$ e os efeitos da interação entre grupo e mês. Quando a interação fosse considerada estatisticamente significante, avaliar-se-ia o efeito de grupo (conjuntamente para todos os meses) e o efeito de mês (conjuntamente para ambos os grupos). Nas situações em que o efeito de interação fosse significativo, as comparações entre grupos seriam feitas separadamente para cada mês, assim como o efeito do mês, testado separadamente para cada grupo. Para localizar as diferenças, método de comparações múltiplas com correção de Bonferroni (NETER et al., 1996).

- Definiu-se estatisticamente significantes os resultados cujos níveis descritivos (valores de p) fossem inferiores a 0,05. Para a execução dos cálculos estatísticos foi programado utilizar o software SPSS for Windows versão 10.0 - Statistical Pachage for the Social Science. 


\section{RESULTADOS}

Foram atendidas 96 pacientes hipertensas na pós-menopausa. Destas foram selecionadas aquelas que completaram o estudo conforme o programado ou seja, 81 pacientes, das quais $40(49,4 \%)$ do grupo Ativo, $41(50,6 \%)$ do grupo Placebo. A idade variou de 43 a 70 anos, com média de 53,4 e desvio padrão de 6,5 anos. A Tabela 4 apresenta as médias de idade e tempo pós-menopausa das pacientes de todo o estudo e entre o grupo Ativo e Placebo.

Tabela 4-Idade e Tempo Pós-menopausa do grupo Ativo e Placebo.

\begin{tabular}{lccccccc}
\hline & lote & $\mathrm{N}$ & Média* $^{*}$ & Mediana & $\begin{array}{c}\text { Desvio } \\
\text { Padrão }\end{array}$ & Mínimo & Máximo \\
\hline \multirow{1}{*}{ idade } & $\mathrm{BJ}$ & 40 & 57,03 & 57,00 & 6,07 & 46 & 69 \\
& $\mathrm{BH}$ & 41 & 57,83 & 55,00 & 6,87 & 43 & 70 \\
& Total & 81 & 57,43 & 56,00 & 6,46 & 43 & 70 \\
\hline \multirow{3}{*}{ tempo pós } & $\mathrm{BJ}$ & 40 & 4,80 & 5,00 & 1,73 & 2 & 8 \\
menopausa & $\mathrm{BH}$ & 41 & 4,27 & 5,00 & 1,83 & 2 & 7 \\
& Total & 81 & 4,53 & 5,00 & 1,79 & 2 & 8 \\
\hline *Anos & & & & &
\end{tabular}

Não houve diferença significativa $(p>0,05)$ entre os grupos com relação à idade e ao tempo pós-menopausa das mulheres, ou seja, os dois grupos analisados eram homogêneos com relação a essas variáveis.

Mais da metade dos pacientes eram casadas $(54,3 \%)$, seguidas por viúvas $(19,8 \%)$. A cor branca foi predominante em 55 pacientes $(67,9 \%)$. Tabagismo encontrava-se presente em apenas 6 mulheres $(7,4 \%)$. Quarenta e quatro pacientes apresentaram HAS-2 (54,3\%), 36 HAS-1 (44,4\%), e apenas uma paciente apresentou HAS-3 (1,2\%). Foram classificadas como HAS-1 as pacientes que apresentaram hipertensão arterial leve (PAS: 140-159mmHg e PAD: 90-99mmHg) como HAS-2 as 
que apresentaram hipertensão moderada (PAS: 160-179 e PAD; 100-109) e HAS-3 as com hipertensão grave (PAS: 180 e PAD: 110). (Tabela 5).

Tabela 5 - Características Sócio-demográficas do grupo Ativo e Placebo.

\begin{tabular}{|c|c|c|c|c|}
\hline $\begin{array}{l}\text { Variáveis sócio- } \\
\text { demográficas }\end{array}$ & $\begin{array}{l}\text { Placebo } \\
\text { N (\%) }\end{array}$ & $\begin{array}{l}\text { Ativo } \\
N(\%)\end{array}$ & $\begin{array}{l}\text { Total } \\
\text { N }(\%)\end{array}$ & p-valor \\
\hline \multicolumn{5}{|l|}{ Estado Civil } \\
\hline Casada & $21(51,2 \%)$ & $23(57,5 \%)$ & $44(54,3 \%)$ & \multirow{4}{*}{$0,327_{\mathrm{F}}$} \\
\hline Divorciada/Separada & $9(22,0 \%)$ & $4(10,0 \%)$ & $13(16,0 \%)$ & \\
\hline Solteira & $5(12,2 \%)$ & $3(7,5 \%)$ & $8(9,9 \%)$ & \\
\hline Viúva & $6(14,6 \%)$ & $10(25,0 \%)$ & $16(19,8 \%)$ & \\
\hline \multicolumn{5}{|l|}{ Fumante } \\
\hline Não & $37(90,2 \%)$ & $38(95,0 \%)$ & $75(92,6 \%)$ & \multirow[t]{2}{*}{$0,675_{\mathrm{F}}$} \\
\hline $\operatorname{Sim}$ & $4(9,8 \%)$ & $2(5,0 \%)$ & $6(7,4 \%)$ & \\
\hline \multicolumn{5}{|l|}{ Cor } \\
\hline Branca & $23(56,1 \%)$ & $32(80,0 \%)$ & $55(67,9 \%)$ & \multirow[t]{2}{*}{$0,032_{\mathrm{F}} *$} \\
\hline Negra & $18(43,9 \%)$ & $8(20,0 \%)$ & $26(32,1 \%)$ & \\
\hline \multicolumn{5}{|l|}{ Diagnóstico Cardíaco } \\
\hline HAS-1 & $15(36,6 \%)$ & $21(52,5 \%)$ & $36(44,4 \%)$ & \multirow{3}{*}{$0,149_{\mathrm{F}}$} \\
\hline HAS-2 & $26(63,4 \%)$ & $18(45,0 \%)$ & $44(54,3 \%)$ & \\
\hline HAS-3 & $0(0,0 \%)$ & $1(2,5 \%)$ & $1(1,2 \%)$ & \\
\hline
\end{tabular}

${ }^{*} \mathrm{p}<0,05$

F: Teste Exato de Fisher

\subsection{Pressão arterial}

Inicialmente, foi realizada uma análise da evolução da Pressão Arterial Sistólica (PAS) e da Pressão Arterial Diastólica (PAD) nos dois grupos pesquisados . 
Quanto a PAS a Tabela 6 demonstra as médias pressóricas encontradas no grupo Ativo e Placebo.

\section{$\underline{\text { Análise PAS }}$}

Tabela 6 - Evolução da Pressão Arterial Sistólica nos grupos Ativo e Placebo.

\begin{tabular}{llrrrrr}
\hline \hline PAS & Lote & $\mathrm{N}$ & \multicolumn{5}{c}{ Média** } & Desvio Padrão Mínimo & Máximo \\
\hline \multirow{3}{*}{ Mês 0 * } & & & & & & \\
& Ativo & 40 & 138,75 & 15,39 & 120 & 170 \\
& Placebo & 41 & 131,46 & 14,42 & 100 & 170 \\
& Total & 81 & 135,06 & 15,26 & 100 & 170 \\
\hline Mês 1 & Ativo & 40 & 132,50 & 14,46 & 110 & 170 \\
& Placebo & 41 & 131,95 & 11,67 & 110 & 170 \\
& Total & 81 & 132,22 & 13,04 & 110 & 170 \\
\hline Mês 2 & Ativo & 40 & 130,25 & 11,43 & 110 & 170 \\
& Placebo & 41 & 130,98 & 15,62 & 110 & 170 \\
& Total & 81 & 130,62 & 13,63 & 110 & 170 \\
\hline Mês 3 & Ativo & 40 & 129,00 & 12,15 & 110 & 160 \\
& Placebo & 41 & 130,98 & 14,97 & 110 & 170 \\
& Total & 81 & 130,00 & 13,60 & 110 & 170 \\
\hline Mês 4 & Ativo & 40 & 130,50 & 12,80 & 110 & 160 \\
& Placebo & 41 & 133,66 & 15,13 & 110 & 170 \\
& Total & 81 & 132,10 & 14,03 & 110 & 170 \\
\hline Mês 5 & Ativo & 40 & 127,50 & 9,54 & 110 & 160 \\
& Placebo & 41 & 132,44 & 12,80 & 40 & 138,75 \\
& Total & 81 & 130,00 & 11,51 & 41 & 131,46 \\
\hline Mês 6 & Ativo & 40 & 127,00 & 11,59 & 81 & 135,06 \\
& Placebo & 41 & 130,73 & 14,03 & 40 & 132,50 \\
& Total & 81 & 128,89 & 12,94 & 41 & 131,95 \\
\hline \hline p $<0,05$ & & & & & & \\
$* *$ mmHg & & & & & &
\end{tabular}

Através dos resultados da análise de variância (ANOVA) com medidas repetidas, verificou-se interação significativa entre os fatores Tempo e Grupo $(\mathrm{p}=0,019)$, dessa maneira a comparação estatística entre os grupos foi feita separadamente para cada momento analisado e a evolução ao longo do tempo também foi realizado em cada grupo.

Quanto à pressão sistólica houve diferença significativa entre os grupos apenas em relação ao tempo inicial e 5 meses $(p=0,031 ; 0,045$ respectivamente). 
Analisando cada grupo separadamente observamos que o grupo que utilizou medicamento ativo apresentou uma redução significativa ao longo do tempo ( $\mathrm{p}<0,001$ ), variando de 138,75 no mês inicial até 127 no sexto mês. Em relação ao grupo placebo não houve uma redução significativa ao longo do tempo $(\mathrm{p}=0,875)$, ficando em torno de 131.

Gráfico 1 - Nível médio da PAS das pacientes ao longo do tempo, em relação aos grupos Ativo e Placebo.

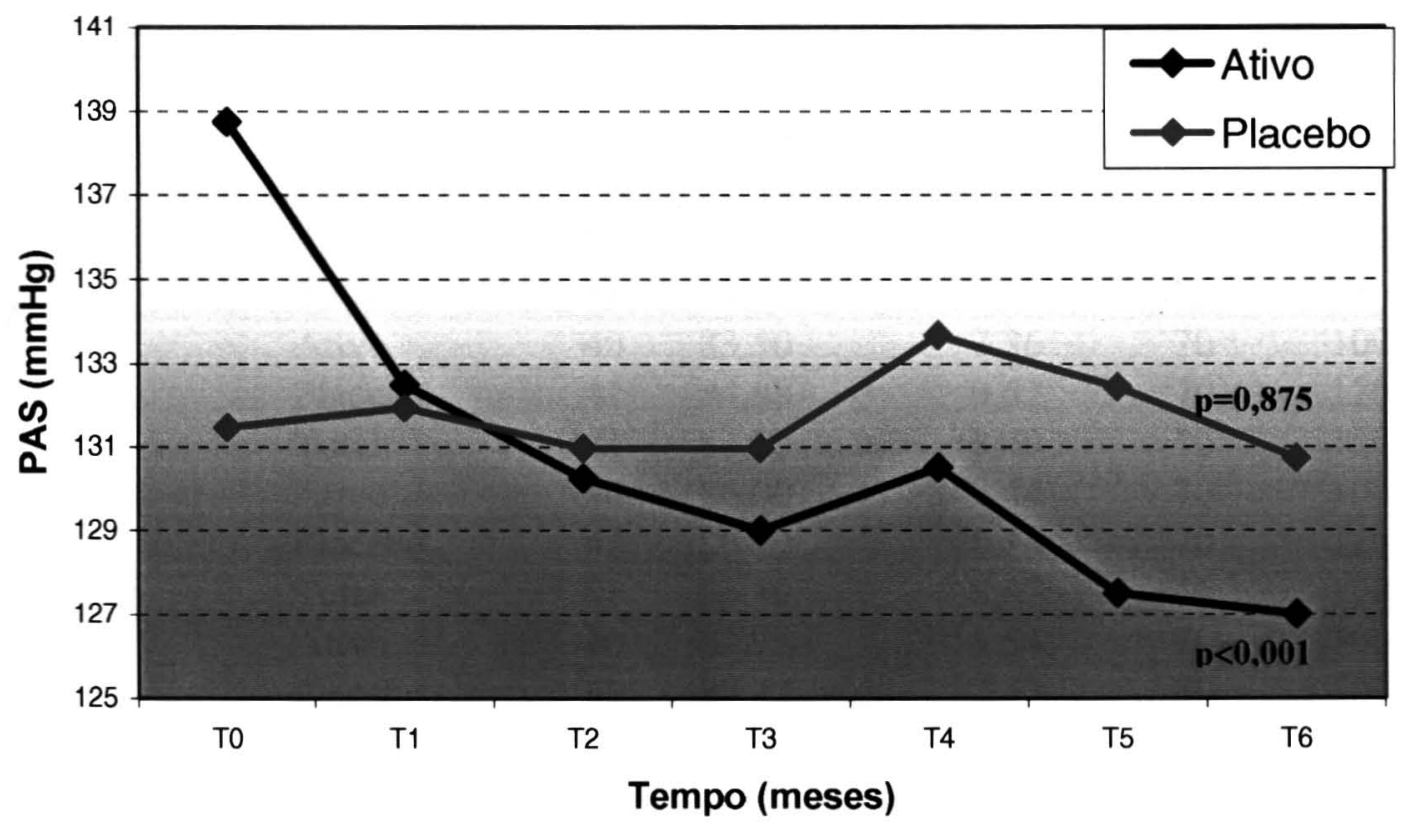




\section{$\underline{\text { Análise PAD }}$}

Tabela 7 - Evolução da Pressão Arterial Diastólica nos grupos Ativo e Placebo.

\begin{tabular}{|c|c|c|c|c|c|c|c|}
\hline PAD & Lote & $\mathrm{N}$ & & Média** & Desvio Padrão & Mínimo & Máximo \\
\hline \multirow[t]{3}{*}{ Mês 0} & Ativo & & 40 & 89,88 & 9,64 & 80 & 110 \\
\hline & Placebo & & 41 & 86,59 & 8,83 & 70 & 110 \\
\hline & Total & & 81 & 88.21 & 9,33 & 70 & 110 \\
\hline \multirow[t]{3}{*}{ Mês 1} & Ativo & & 40 & 84,50 & 7,83 & 70 & 100 \\
\hline & Placebo & & 41 & 86,10 & 7,37 & 80 & 110 \\
\hline & Total & & 81 & 85,31 & 7,6 & 70 & 110 \\
\hline \multirow[t]{3}{*}{ Mês 2} & Ativo & & 40 & 84,00 & 7,09 & 70 & 110 \\
\hline & Placebo & & 41 & 83,90 & 7,37 & 70 & 100 \\
\hline & Total & & 81 & 83,95 & 7,19 & 70 & 110 \\
\hline \multirow[t]{3}{*}{ Mês 3} & Ativo & & 40 & 83,50 & 7,36 & 70 & 100 \\
\hline & Placebo & & 41 & 84,88 & 9,52 & 70 & 120 \\
\hline & Total & & 81 & 84,20 & 8,49 & 70 & 120 \\
\hline \multirow[t]{3}{*}{ Mês 4} & Ativo & & 40 & 86,00 & 7,44 & 70 & 100 \\
\hline & Placebo & & 41 & 86,59 & 10,15 & 70 & 120 \\
\hline & Total & & 81 & 86,30 & 8,87 & 70 & 120 \\
\hline \multirow[t]{3}{*}{ Mês $5 *$} & Ativo & & 40 & 82,75 & 5,54 & 70 & 100 \\
\hline & Placebo & & 41 & 87,32 & 7,42 & 80 & 100 \\
\hline & Total & & 81 & 85,06 & 6,91 & 70 & 100 \\
\hline \multirow[t]{3}{*}{ Mês 6} & Ativo & & 40 & 83,50 & 7,36 & 70 & 100 \\
\hline & Placebo & & 41 & 85,12 & 7,46 & 70 & 100 \\
\hline & Total & & 81 & 84,32 & 7,41 & 70 & 100 \\
\hline
\end{tabular}

Em relação à Pressão Arterial Diastólica (PAD), novamente a interação entre grupo e tempo foi significativa $(\mathrm{p}=0,020)$. Analisando cada momento isoladamente, houve diferença significativa entre os grupos apenas no $5^{\circ}$ mês $(p=0,002)$. Analisando os grupos separadamente, o grupo que tomou medicamento ativo apresentou uma redução significativa ao longo do tempo $(\mathrm{p}<0,001)$, diminuindo de 
89,88 para 85,12 . O grupo placebo não mostrou diferença significativa ao longo do tempo pesquisado $(\mathrm{p}=0,255)$.

Gráfico 2 - Nível médio da PAD das pacientes ao longo do tempo, em relação aos grupos Ativo e Placebo.

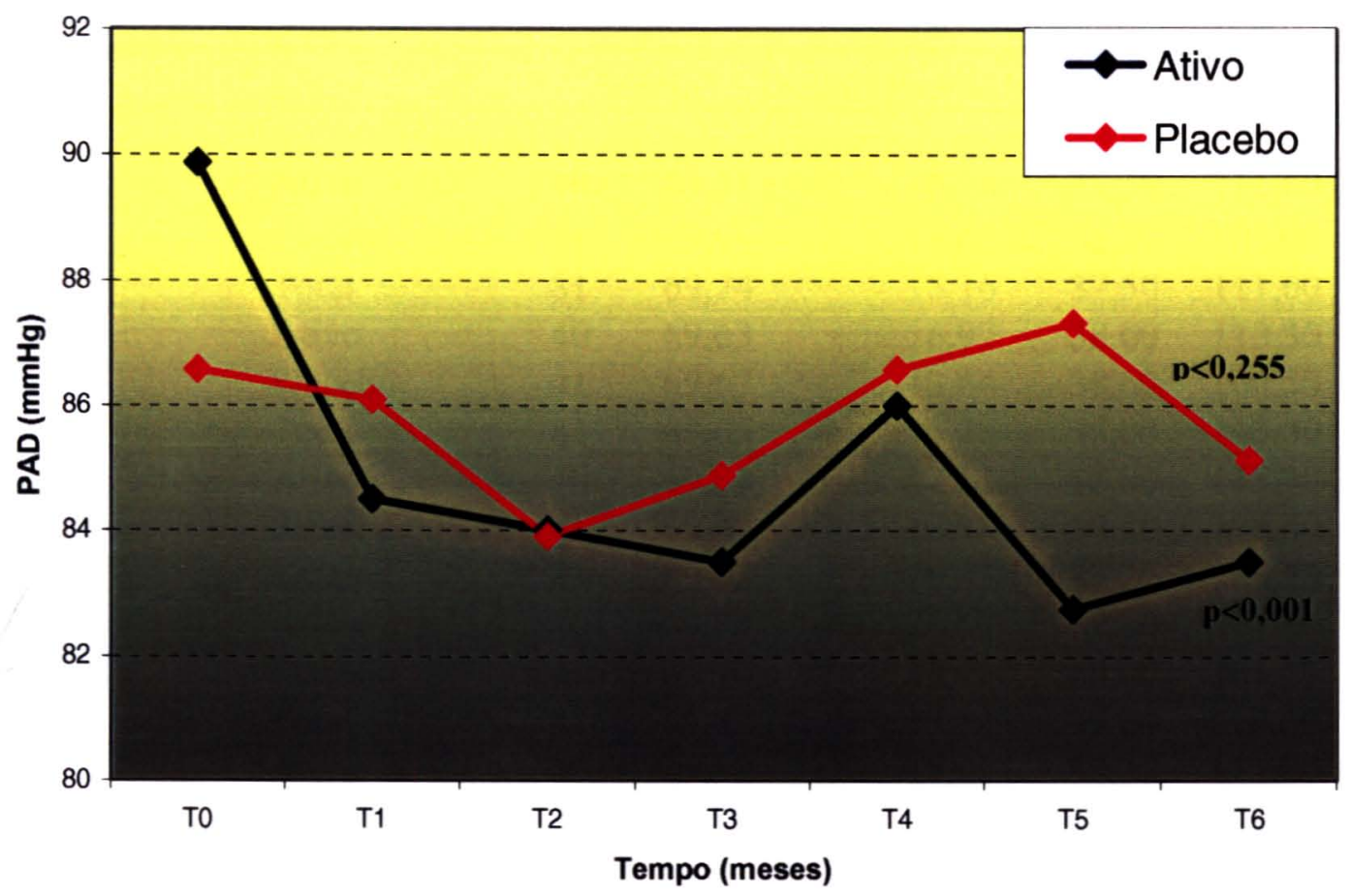

\subsection{Gordura corporal:}

Nessa etapa, foi feita uma análise da evolução das medidas referentes à gordura corporal, tais como peso, IMC, relação cintura quadril (C/Q), e distribuição da gordura na cintura e quadril, nos grupos pesquisados. O IMC, e a porcentagem de gordura na região da cintura e quadril foram analisados apenas no momento inicial e no sexto mês.

Como veremos a seguir, em relação à avaliação da gordura corporal não houve diferença significativa no peso, IMC, relação cintura/quadril e distribuição de gordura na cintura e quadril (Tabelas 8, 9, 10, 11, 12 e Gráficos 3, 4, 5, 6, 7). 


\section{PESO}

Tabela 8 - Evolução do peso corporal nos grupos Ativo e Placebo.

\begin{tabular}{|c|c|c|c|c|c|c|c|}
\hline \multirow{2}{*}{$\begin{array}{l}\text { Peso } \\
\text { Mês } 0\end{array}$} & \multirow{2}{*}{$\begin{array}{l}\text { Lote } \\
\text { Ativo }\end{array}$} & \multirow[t]{2}{*}{$N$} & \multicolumn{2}{|c|}{ Média* } & \multicolumn{2}{|c|}{ Desvio Padrão Mínimo } & \multirow{2}{*}{ Máximo } \\
\hline & & & 40 & 69,51 & 16,78 & 37,50 & \\
\hline & Placebo & & 41 & 69,96 & 13,60 & 38,70 & 105,00 \\
\hline & Total & & 81 & 69,74 & 15,16 & 37,50 & 111,60 \\
\hline \multirow[t]{3}{*}{ Mês 1} & Ativo & & 40 & 69,63 & 16,97 & 38,00 & 113,30 \\
\hline & Placebo & & 41 & 69,67 & 13,64 & 38,60 & 104,50 \\
\hline & Total & & 81 & 69,65 & 15,28 & 38,00 & 113,30 \\
\hline \multirow[t]{3}{*}{ Mês 2} & Ativo & & 40 & 69,85 & 17,12 & 38,80 & 113,30 \\
\hline & Placebo & & 41 & 69,39 & 13,79 & 37,20 & 105,40 \\
\hline & Total & & 81 & 69,62 & 15,43 & 37,20 & 113,30 \\
\hline \multirow[t]{3}{*}{ Mês 3} & Ativo & & 40 & 69,84 & 16,65 & 39,80 & 112,60 \\
\hline & Placebo & & 41 & 69,20 & 13,72 & 40,00 & 105,10 \\
\hline & Total & & 81 & 69,52 & 15,14 & 39,80 & 112,60 \\
\hline \multirow[t]{3}{*}{ Mês 4} & Ativo & & 40 & 69,99 & 16,91 & 38,30 & 112,80 \\
\hline & Placebo & & 41 & 69,08 & 13,58 & 42,60 & 103,90 \\
\hline & Total & & 81 & 69,52 & 15,23 & 38,30 & 112,80 \\
\hline \multirow[t]{3}{*}{ Mês 5} & Ativo & & 40 & 69,83 & 16,86 & 38,70 & 113,30 \\
\hline & Placebo & & 41 & 69,44 & 13,16 & 43,60 & 105,50 \\
\hline & Total & & 81 & 69,63 & 15,00 & 38,70 & 113,30 \\
\hline \multirow[t]{3}{*}{ Mês 6} & Ativo & & 40 & 69,68 & 16,93 & 38,10 & 112,00 \\
\hline & Placebo & & 41 & 69,05 & 13,42 & 43,60 & 105,60 \\
\hline & Total & & 81 & 69,36 & 15,17 & 38,10 & 112,00 \\
\hline
\end{tabular}

$\mathrm{Na}$ análise do peso não houve efeito de interação $(\mathrm{p}=0,115)$, dessa maneira as diferenças entre os grupos foram analisadas conjuntamente para todos os tempos, e a evolução ao longo do tempo também foi feita para ambos grupos. $O$ peso se manteve inalterado entre os 2 grupos $(\mathrm{p}=0,915)$, e também ao longo do tempo $(\mathrm{p}=0,627)$. 
Gráfico 4 - Nível médio de Peso ao longo do tempo, em relação aos grupos Ativo e Placebo.

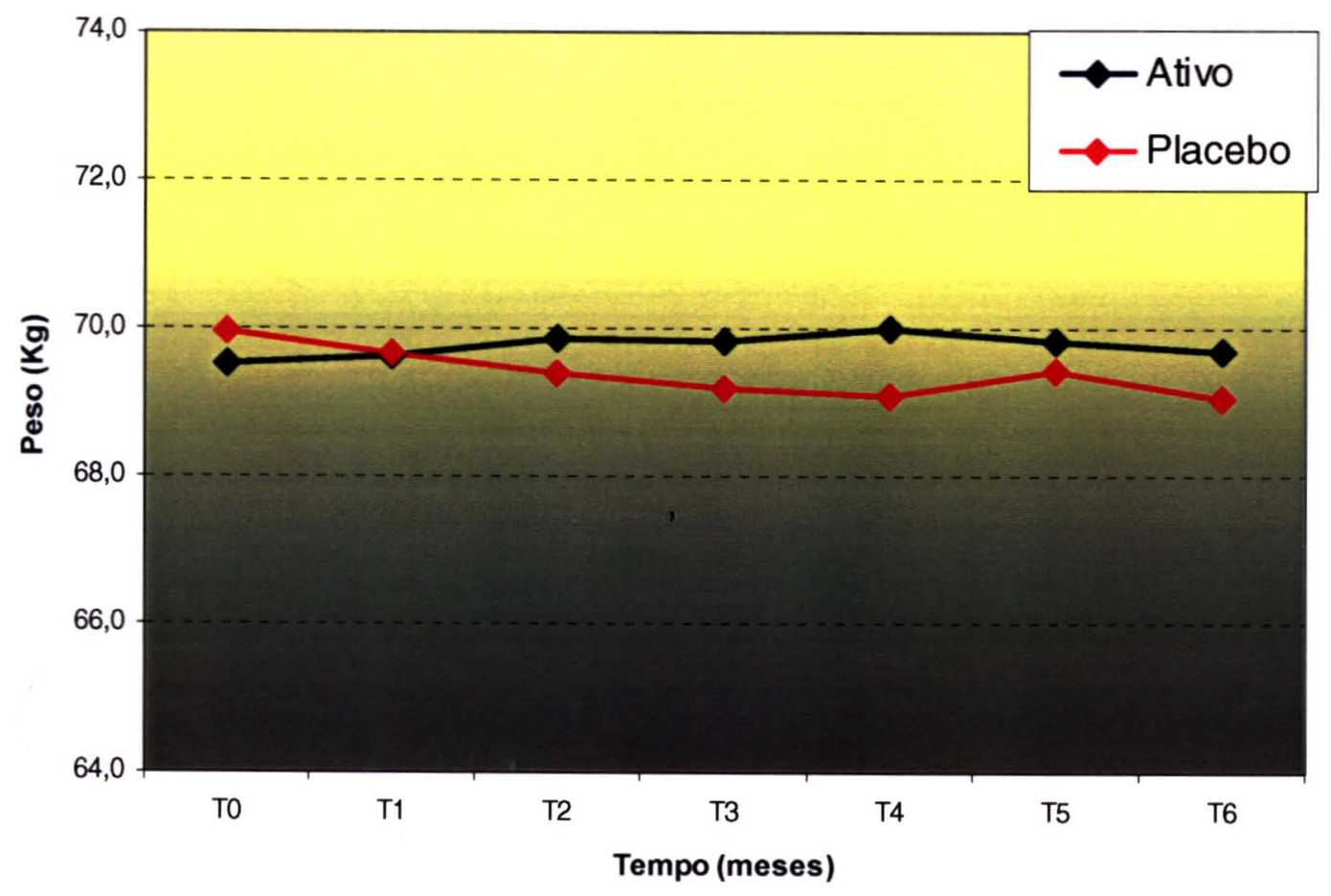

\section{IMC}

Tabela 9 - Evolução do IMC nos grupos Ativo e Placebo.

\begin{tabular}{llrrrrr}
\hline \hline IMC & Lote & $\mathrm{N}$ & & Média* & Desvio Padrão Mínimo & Máximo \\
\hline \multirow{3}{*}{ Mês 0 } & & & & & & \\
& Ativo & 40 & 28,79 & 6,42 & 17,12 & 44,37 \\
& Placebo & 41 & 29,3 & 5,68 & 19,25 & 45,45 \\
& Total & 81 & 29,05 & 6,02 & 17,12 & 45,45 \\
\hline Mês 6 & Ativo & 40 & 29 & 6,43 & 17,39 & 44,57 \\
& Placebo & 41 & 29,04 & 5,58 & 19,12 & 45,71 \\
& Total & 80 & 29,02 & 5,98 & 17,39 & 45,71 \\
& & & & & &
\end{tabular}


Quanto ao índice de massa corpórea não houve diferença significativa entre os grupos $(\mathrm{p}=0,842)$ assim com entre os tempos $(\mathrm{p}=0,858)$.

Gráfico 5 - Nível médio de IMC ao longo do tempo, em relação aos grupos Ativo e Placebo.

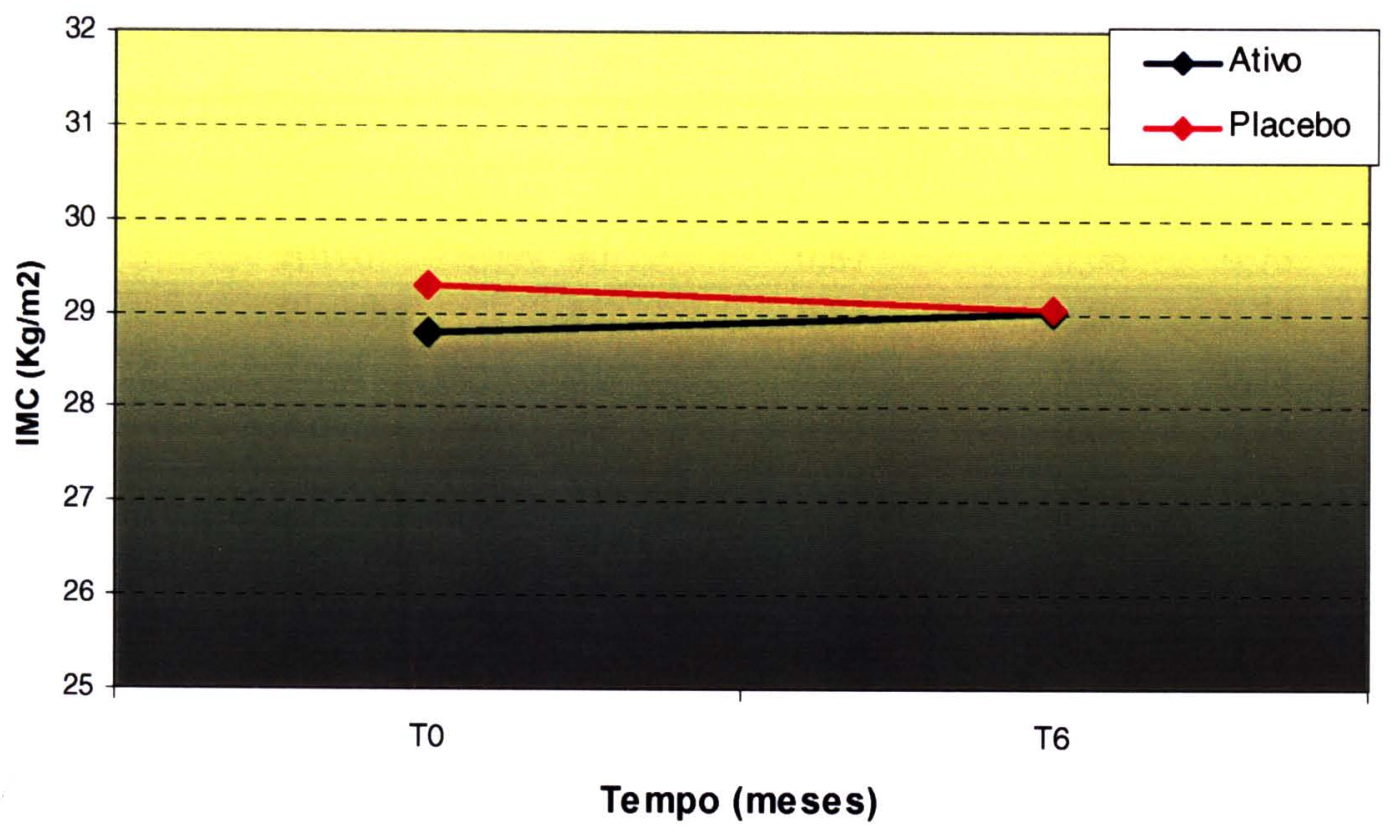




\section{CINTURA/QUADRIL}

Tabela 10 - Evolução da Relação Cintura Quadril - C/Q nos grupos Ativo e Placebo.

\begin{tabular}{|c|c|c|c|c|c|c|c|}
\hline $\mathrm{C} / \mathrm{Q}$ & Lote & $\mathrm{N}$ & Média** & & Desvio Padrão 1 & Mínimo & Máximo \\
\hline \multirow[t]{3}{*}{ Mês 0} & Ativo & & 40 & 0,87 & 0,06 & 0,73 & 1,00 \\
\hline & Placebo & & 41 & 0,85 & 0,06 & 0,74 & 1,00 \\
\hline & Total & & 81 & 0,86 & 0,06 & 0,73 & 1,00 \\
\hline \multirow[t]{3}{*}{ Mês 1} & Ativo & & 40 & 0,85 & 0,06 & 0,74 & 0,99 \\
\hline & Placebo & & 41 & 0,84 & 0,05 & 0,74 & 0,93 \\
\hline & Total & & 81 & 0,85 & 0,05 & 0,74 & 0,99 \\
\hline \multirow[t]{3}{*}{ Mês 2} & Ativo & & 40 & 0,86 & 0,05 & 0,77 & 0,93 \\
\hline & Placebo & & 41 & 0,84 & 0,05 & 0,71 & 0,94 \\
\hline & Total & & 81 & 0,85 & 0,05 & 0,71 & 0,94 \\
\hline \multirow[t]{3}{*}{ Mês 3} & Ativo & & 40 & 0,84 & 0,05 & 0,74 & 0,94 \\
\hline & Placebo & & 41 & 0,84 & 0,05 & 0,74 & 0,93 \\
\hline & Total & & 81 & 0,84 & 0,05 & 0,74 & 0,94 \\
\hline \multirow[t]{3}{*}{ Mês 4* } & Ativo & & 40 & 0,83 & 0,06 & 0,73 & 0,94 \\
\hline & Placebo & & 41 & 0,84 & 0,06 & 0,70 & 0,97 \\
\hline & Total & & 81 & 0,83 & 0,06 & 0,70 & 0,97 \\
\hline \multirow[t]{3}{*}{ Mês $5^{*}$} & Ativo & & 40 & 0,84 & 0,07 & 0,70 & 1,07 \\
\hline & Placebo & & 41 & 0,84 & 0,05 & 0,71 & 0,94 \\
\hline & Total & & 81 & 0,84 & 0,06 & 0,70 & 1,07 \\
\hline \multirow[t]{3}{*}{ Mês 6* } & Ativo & & 40 & 0,83 & 0,06 & 0,70 & 0,96 \\
\hline & Placebo & & 41 & 0,84 & 0,05 & 0,72 & 0,98 \\
\hline & Total & & 81 & 0,84 & 0,06 & 0,70 & 0,98 \\
\hline
\end{tabular}

No caso da relação cintura quadril - C/Q, a interação entre os fatores grupo e tempo foi significativa $(\mathrm{p}=0,037)$. Não houve diferença significativa entre os grupos em nenhum dos tempos analisados $(p>0,05)$. Analisando os grupos separadamente ao 
longo do tempo nota-se uma redução significativa dos valores C/Q apenas para o grupo que utilizou medicamento ativo $(\mathrm{p}<0,001)$. Essas diferenças ocorreram quando se comparou o tempo 0 com $4,5,6$ ( $\mathrm{p}=0,001 ; 0,001 ; 0,001$ respectivamente).

Gráfico 6 - Nível médio da Relação C/Q ao longo do tempo, em relação aos grupos Ativo e Placebo.

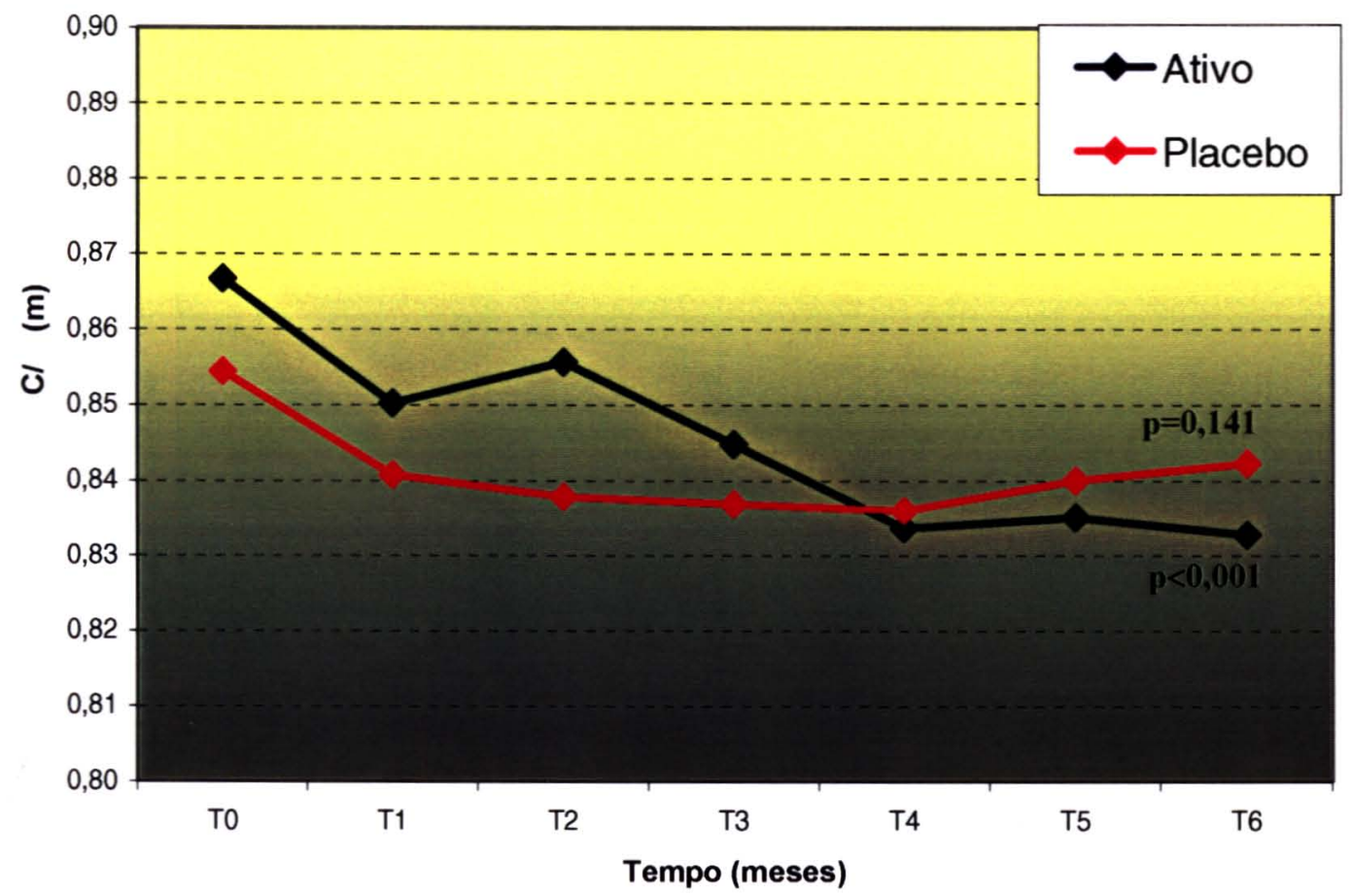

\section{CINTURA}

Tabela 11 - Evolução da Porcentagem de Gordura na região da cintura nos grupos Ativo e Placebo.

\begin{tabular}{lllllll}
\hline \hline \% Cintura & Lote & $\mathrm{N}$ & \multicolumn{2}{c}{ Média* } & \multicolumn{3}{c}{ Desvio Padrão Mínimo } & Máximo \\
\hline \multirow{3}{*}{ Mês 0 } & & & & & & \\
& Ativo & 40 & 29,40 & 8,49 & 9,00 & 47,30 \\
& Placebo & 41 & 26,31 & 7,84 & 4,20 & 43,60 \\
& Total & 81 & 27,84 & 8,27 & 4,20 & 47,30 \\
\hline Mês 6 & Ativo & 40 & 28,06 & 8,25 & 8,00 & 41,20 \\
& Placebo & 41 & 25,83 & 8,25 & 4,60 & 43,20 \\
& Total & 81 & 26,93 & 8,28 & 4,60 & 43,20 \\
\hline \hline
\end{tabular}

*Porcentagem 
Quanto à porcentagem de gordura localizada na região da cintura não houve diferença entre os grupos em todos os tempos analisados $(\mathrm{p}=0,137)$ porém houve uma redução do porcentual de cintura nos 2 grupos $(\mathrm{p}=0,036)$.

Gráfico 7 - Nível médio de porcentagem de gordura na cintura ao longo do tempo, em relação aos grupos Ativo e Placebo.

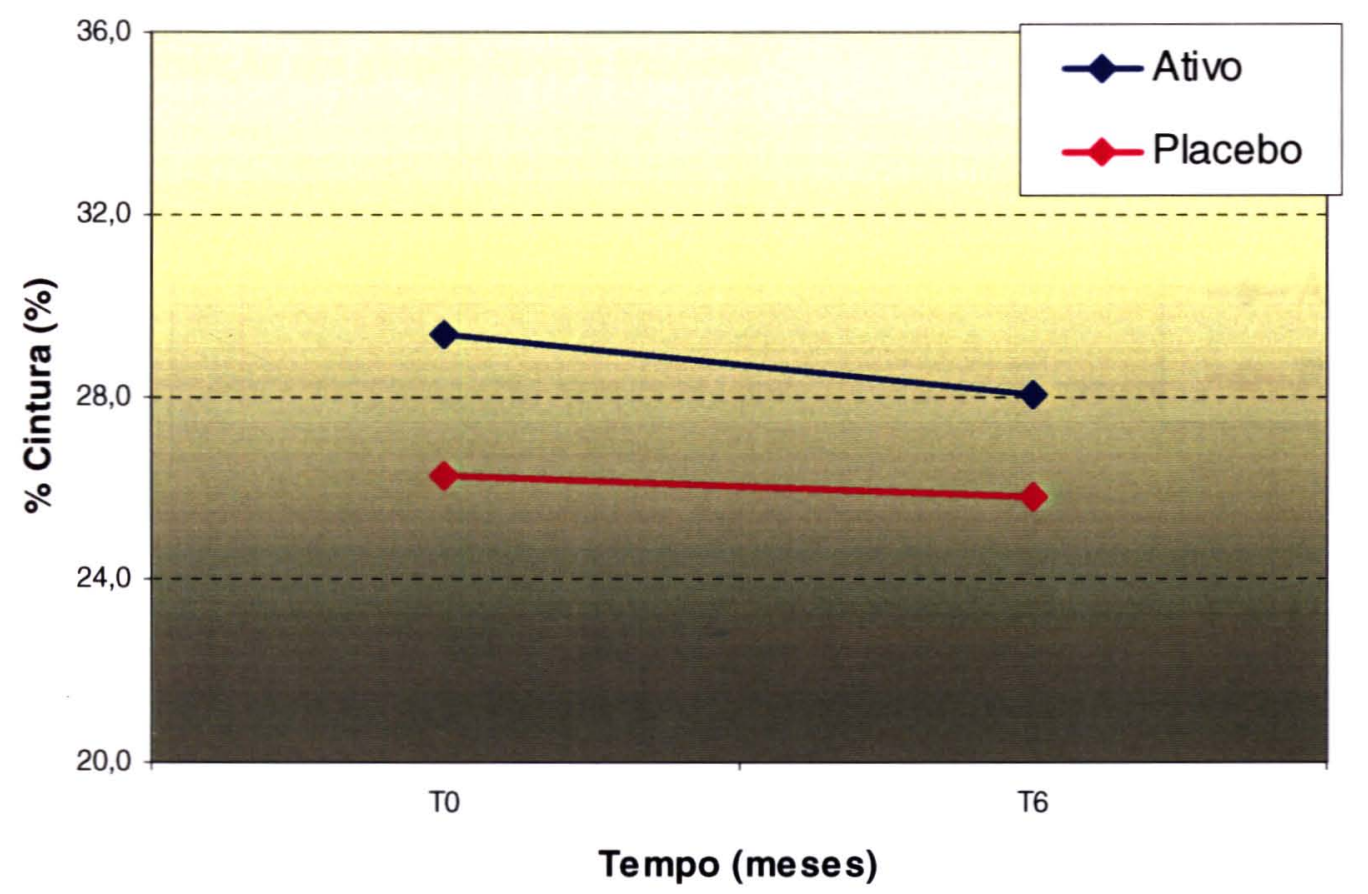

\section{QUADRIL}

Tabela 12 - Evolução do Porcentual de gordura no quadril nos grupos Ativo e Placebo.

\begin{tabular}{lllllll}
\hline \hline \% Quadril & Lote & $\mathrm{N}$ & \multicolumn{2}{c}{ Média* } & \multicolumn{3}{c}{ Desvio Padrão Mínimo } & Máximo \\
\hline \multirow{3}{*}{ Mês 0 } & & & & & & \\
& Ativo & 40 & 22,78 & 8,79 & 6,40 & 42,90 \\
& Placebo & 41 & 21,67 & 6,31 & 9,50 & 41,40 \\
& Total & 81 & 22,22 & 7,61 & 6,40 & 42,90 \\
\hline Mês 6 & Ativo & 40 & 22,70 & 8,01 & 8,00 & 43,70 \\
& Placebo & 41 & 20,73 & 7,37 & 4,00 & 41,20 \\
& Total & 81 & 21,70 & 7,71 & 4,00 & 43,70 \\
\hline \hline
\end{tabular}


Analisando a porcentagem da gordura localizada no quadril, não houve diferença entre os grupos em todos os tempos analisados $(p=0,329)$. Não houve um aumento significativo do quadril ao longo do tempo em nenhum dos grupos $(\mathrm{p}=0,452)$.

Gráfico 8 - Nível médio de porcentagem de gordura no quadril ao longo do tempo, em relação aos grupos Ativo e Placebo.

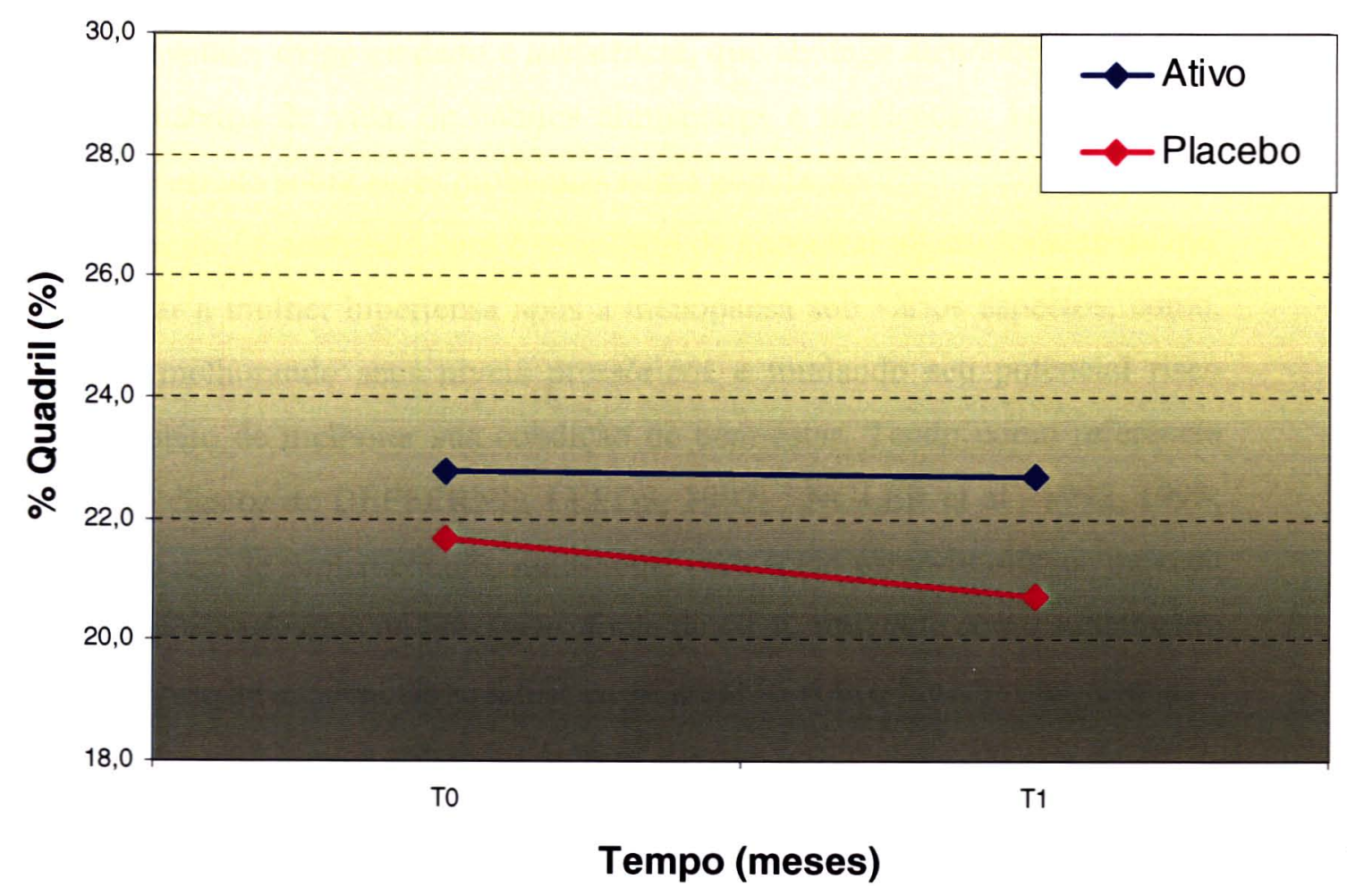




\section{DISCUSSÃO}

O periodo após a menopausa é uma fase, na vida da mulher, que envolve muitas mudanças bio-psico-sociais, que podem repercutir sobre sua saúde e sua qualidade de vida. A prevalência de hipertensão arterial também aumenta com a idade, como se pode observar na Tabela 2. Esse fato pode estar relacionado à menopausa em si, mas também a fatores do próprio envelhecimento. A hipertensão põe em risco a saúde, exige cuidado e assistência, que abrange atendimento médico, mudanças de hábitos de vida, de hábitos alimentares e medicação. Isso motiva a necessidade de estudo sobre esses problemas nessa população.

Este estudo foi realizado com o propósito de encontrar algum tratamento que pudesse auxiliar a mulher hipertensa após a menopausa sob vários aspectos, como, por exemplo, melhorando seus níveis pressóricos e mudando seu potencial risco cardiológico, além de melhorar sua condição de bem-estar. Tendo como referência estudos dentre eles os de DEFFERNE; LEEDS, 1992; ENGLER et al., 1992, 1998; HIME, 2000, o uso de suplementação nutricional com ácido gama-linolênico pareceu suprir este propósito. O óleo de borragem, fonte de GLA, utilizado como suplemento nutricional, apresenta evidências científicas de atuação sobre hipertensão arterial e gordura corporal, sem efeitos colaterais significativos.

A população estudada abrangeu mulheres após a menopausa com diagnóstico de hipertensão. Um limite para os níveis pressóricos, foi pré estabelecido em 180mm Hg para a pressão sistólica e $120 \mathrm{mmHg}$ para a diastólica, pois pacientes com hipertensão acima desses níveis correm maior risco de intercorrências clínicas graves, indesejáveis de serem encontradas durante o tempo em que estivéssemos realizando o estudo (AMODEO, 1996). Uma dúvida que surgiu durante a seleção das pacientes foi como considerar hipertensas mulheres que se apresentavam normotensas por uso de medicamento ou orientação alimentar. Concluiu-se que estas mulheres têm diagnóstico prévio de hipertensão arterial portanto são hipertensas independente dos níveis pressóricos que apresentam, no momento do estudo.

Observando os resultados, a população estudada foi homogênea, tanto em idade quanto em tempo após a menopausa (Tabela 4). Isso valida os achados. 
Houve diminuição da pressão arterial, tanto sistólica, quanto diastólica nas pacientes estudadas. Todas permaneceram com o tratamento anti-hipertensivo prescrito pelo clínico, quer medicamentoso, quer comportamental e dietético. Esta conduta não foi modificada uma vez que era prioritário o bem-estar das pacientes e não havia previsão do que aconteceria acontecer com a retirada da medicação antihipertensiva. A relação dos tratamentos realizados está à disposição, em Anexos $11 \mathrm{e}$ 12.

Nas tabelas 6 e 7 observou-se que tanto a pressão sistólica, como a diastólica mostraram redução nas pacientes que utilizaram o produto ativo, com significância estatística no quinto mês de uso. Apesar de que o decréscimo médio foi de cerca de $10 \mathrm{mmHg}$, considerando que eram pacientes sob tratamento para hipertensão, talvez a redução pudesse ter sido maior, se elas estivessem apenas sob o tratamento do óleo de borragem. ENGLER et al., 1992, em estudos em ratos, observaram maior redução pressórica nos animais hipertensos que nos normotensos. Não parece ético fazer observação, suspendendo o tratamento medicamentoso anti-hipertensivo, in anima nobile, para não colocar as pacientes em risco. MINUZ et al., 1990, decontinuaram a medicação anti-hipertensiva de seus pacientes, porém seu estudo foi de muito menor duração que o nosso, ou seja, de duas semanas apenas.

Esses dados são coerentes com os encontrados na literatura. A maior parte dos estudos em animais repete o sucesso, quanto à diminuição dos níveis pressóricos (HOFFMANN et al., 1986; MILLS; WARDS, 1984; MILLS, 1989; SOMA et al., 1985; Singer et al., 1990; Engler, 1992; Sasaki et al., 1995; Engler et al., 1998; Ingram et al., 1996; Narce; Poisson, 1997; Galipeau et al., 2001; Frenoux et al., 2001; Germain-Bellenger et al., 2002). Por outro lado, nem sempre os resultados obtidos em animais são exatamente os mesmos que podemos observar em humanos. No caso dos ácidos graxos, é sabido que seu metabolismo apresenta diferenças importantes, inerentes à diferença na secreção enzimática, bem como há diferenças de espécie para espécie (WILLS, 1982).

Estudos em humanos também mostraram redução pressórica, uns com maior evidência que outros. Os estudos apresentam dados de difícil comparação, às vezes, porque seus sujeitos eram de outras idades, ou de outro sexo, ou o tempo de observação variou. DILLON, 1987, em população de idade superior à da nossa 
amostra, relata decréscimo da pressão diastólica, especialmente em pacientes já com algum grau de lesão vascular, embora sem sinais de esclerose. O estudo não se refere ao sexo dos pacientes. O estudo de MILLS et al., 1989, foi realizado em pacientes do sexo masculino, e obteve redução tanto sistólica, como diastólica, em hipertensão induzida por estresse. Já o estudo de MINUZ et al., 1990, abrangia pessoas de ambos os sexos, com hipertensão essencial, e sua principal preocupação foi discutir o mecanismo de ação do ácido graxo. DEFFERNE; LEEDS, 1992, estudaram homens hipertensos, também por tempo mais curto do que o que estudamos. Já MÉNDEZ DE MEDINA, 1998, procurou estudar homens e mulheres, com outras características, pois se referia à população hipertensa da Costa Rica, independente de idade e sexo. O mesmo se diga em relação ao estudo de LARSEN et al., 1999, que estudaram uma população jovem. HORNYCH et al., 1999, bem como POGZHEVA et al., 2000, estudaram pacientes de faixa etária mais coerente com a das nossas pacientes.

A ação hipotensora encontrada este estudo pode ser atribuída, aos demais mecanismos de ação já descritos, como a influência das prostaglandinas e tromboxanos, decorrentes da metabolização do óleo de borragem, levando a vasodilatação e regulação reno-vascular (HOFFMANN et al., 1986; KINSELLA, 1987; MILLS, 1989; INGRAM et al., 1996; ENGLER, 1992; ENGLER et al., 1998; HORNYCH et al., 1999; GALIPEAU et al., 2001; IMANISH et al., 2001; HORNYCH et al., 2002). Para se quantificar este efeito, seria necessário outro tipo de pesquisa, e outro tipo de avaliação, como dosagens plasmáticas ou até tissulares, o que não foi realizado.

A idade pode ser um fator limitante na avaliação dos resultados obtidos. Reportando-nos a HORROBIN, 1992, quando mencionava a determinação da quantidade ideal a ser ingerida por dia, vimos que a produção endógena de GLA é da ordem de 100 a $1000 \mathrm{mg} /$ dia sendo que $50 \%$ é perdido a partir da idade de 60 anos. $\mathrm{O}$ mesmo autor referiu que determinadas situações requerem maior quantidade de EFAs tais como: momentos em que ocorre maior taxa de divisão celular e ocasiões em que haja metabolismo acelerado, hábito alimentar com grande quantidade de gorduras saturadas, deficiência de dessaturases e elongases e, o sexo masculino requerendo maior quantidade de EFAs que feminino. 
Todas essas observações são pertinentes, quando se avalia a nossa amostra. Não foi feito inquérito alimentar dessas pacientes, nem foi feita nenhuma recomendação para uniformidade dietética. Grande número de pessoas nessa faixa etária apresenta hábito intestinal estabelecido em um padrão que prejudica a absorção dos ácidos graxos. Muitas vezes sua dieta abrange o uso de gorduras saturadas (menos onerosas que as insaturadas, além de que a dieta comumente utilizada em nosso meio não procura privilegiar determinados alimentos pelas diretrizes nutricionais, mas, antes, a escolha é pelo preço, pelo sabor, pelo hábito arraigado). Outro fator que pode interferir na deficiência de absorção e metabolismo é o uso de álcool e de drogas anti-inflamatórias (HORROBIN, 1987; SEGARNICK et al., 1985). Nenhuma de nossas pacientes referiu alcoolismo, porém é impossível saber a veracidade dessas informações. Já quanto ao uso de anti-inflamatórios, a própria condição do grupo etário favorece sua indicação, pois é uma fase em que os problemas osteoarticulares são comuns. Algumas delas chegaram, mesmo, a relatar esse uso.

Com o aumento da idade ocorre alteração no metabolismo enzimático, diminuindo a quantidade e ação da D6D prejudicando a ação do ácido gamalinolênico (HORROBIN, 1981).

A idade das pacientes estudadas também ficou na faixa em que provavelmente já existiria interferência no padrão enzimático, determinando queda da D6D (HORROBIN, 1981; 1992; HORNYCH et al., 1999). Em estudo anterior não foi encontrada alteração na pressão arterial (HIME, 2000). A população estudada foi semelhante à deste trabalho, porém a dose utilizada foi bem menor $(500 \mathrm{mg} / \mathrm{dia})$ assim como o tempo de uso (90 dias). Esta foi uma das razões para escolher o esquema utilizado neste trabalho, com dose maior ( $3 \mathrm{~g} / \mathrm{dia})$ e tempo de observação maior (180 dias).

Outro fator que pode ter tido influência sobre os resultados foi o estresse. Dados de literatura encontraram maior ação do GLA na hipertensão induzida por estresse (MILLS et al., 1989; DEFFERNE; LEEDS, 1992). Em trabalho anterior (HIME, 2000) obteve-se resultado significativo na sensação de bem-estar em pacientes após a menopausa tratadas com óleo de borragem. A sensação de bem-estar é um fator condicionante de redução de estresse. Este óleo, pelo seu conteúdo em 
GLA, pode influir sobre as prostaglandinas, que, segundo SMITH, 1987, condicionam processos que envolvem o humor.

A hipertensão arterial pode ser grandemente influenciada pelas situações estressantes, pacientes participantes deste estudo vivem em uma metrópole cheia de problemas, e, portanto, com condições geradoras de conflitos. Além de serem pessoas de menor poder aquisitivo, e, no momento do estudo, o país viver dificuldades econômicas, com altos níveis de problemas sociais, que afetam a todos. Assim, quanto de seu quadro deveria ser atribuído a essas condições é imponderável, mas deve ter um papel, sem dúvida, significativo.

Em relação ao peso, após o tratamento, não houve diferença, em ambos os grupos. Esse resultado não foi de todo surpreendente, porém, em trabalho anterior (HIME, 2000), houve tendência a diminuição de peso corporal, embora não houvesse significância estatística.

A avaliação da massa corpórea (Tabela 9) das pacientes estudadas mostrou sobrepeso (média de IMC 28,79 e 29,30 respectivamente, para o grupo Ativo e Placebo), o que é bastante comum nas pacientes após a menopausa. A própria fase climatérica favorece um certo ganho de peso (MANCINI, 2003).

O IMC das pacientes foi inalterado, em ambos os grupos. A medida do IMC é um índice de cálculo fácil, apresentando boa correlação com a adiposidade corporal e massa corpórea. No entanto, não faz distinção entre gordura central e gordura periférica, além de não propiciar a possibilidade de distinguir massa magra de massa gorda, podendo subestimar a obesidade em indivíduos com grande contingente muscular (MANCINI, 2003).

A relação das medidas de cintura e quadril tem sido considerada importante marcador de risco cardiovascular e metabólico, pois reflete a distribuição adipocitária na região visceral abdominal e na região femural. $O$ metabolismo das células gordurosas é diferente antes e depois da menopausa, determinado pela ação da LPL (REBUFFÉ-SCRIVE, 1988). Essa variação pode dever-se à menopausa, em si, mas também há influência do próprio envelhecimento, pois a tendência a mudança na distribuição corporal ocorre tanto em homens como em mulheres (RAISON et al., 1988). Outro motivo para alteração da distribuição gordurosa tem sido relacionado 
ao estresse, tão comum nos dias atuais, levando a alterações do eixo hipotálamoadrenal (MARIN; BJORNTORP, 1993).

A distribuição da gordura corporal é importante na determinação de vários processos patológicos, especialmente no que se relaciona ao risco cardíaco e metabólico (BJORNTORP, 1996).

A relação das medidas de cintura e quadril mostrou diferença significativa ao longo do tempo, no grupo Ativo, no $4^{\circ}, 5^{\circ}$ e $6^{\circ}$ mês, e, como observou-se no Gráfico 5 , essa tendência a decréscimo foi progressiva. O grupo Placebo persistiu inalterado. A média não alcançou o valor 0,8 considerado ideal para o sexo feminino, segundo MANCINI, 2003, mas chegou a um valor próximo: 0,83. Note-se, no entanto, que, para outros autores, como REXRODE et al., 1998, o nivel ideal, para mulheres, é abaixo de 0,85 , o que foi atingido, e superado. Também se pode cogitar se essa tendência a decréscimo já se estabilizou, após 6 meses, ou se persistiria, caso o tratamento tivesse sido estendido por maior tempo.

Os dados obtidos estão coerentes com os da literatura, que demonstram interferência dos ácidos graxos em relação à gordura corporal, tanto em modelos animais (LIN et al., 1993; PHINNEY et al., 1993; TAKATA et al., 1994), como em seres humanos (JENSEN et al., 1989; POLIOT et al., 1990).

A avaliação da porcentagem de gordura na região da cintura e do quadril não apresentou resultados favoráveis medidos através da densitometria (Tabela 11 e 12). Era sabido que talvez a densitometria de corpo inteiro oferecesse melhores resultados, porém este exame apresentou algumas condições que impediram sua escolha. Era mais oneroso e exigia imobilidade da paciente por mais tempo, durante a realização. A densitometria óssea determinou a quantidade de gordura localizada na região da cintura e do quadril através de uma janela de observação limitada. Talvez a avaliação deste compartimento único não mensure a quantidade de gordura necessária para avaliar a distribuição andróide e ginecóide.

Este estudo não demonstrou diferença significativa entre os grupos, provavelmente porque essa nossa suposição tenha sido correta. Observando as Tabelas 8 e 9, verifica-se que houve mudança nas porcentagens. Não se obteve, entretanto, significância. Este fato, aliado ao descrito no achado quanto à relação cintura-quadril, mostra que o que deve ter ocorrido foi justamente a medida de um 
segmento corporal insuficiente para a aferição. Talvez, se tivesse sido realizada densitometria de corpo todo, medindo todo o compartimento abdominal e do quadril levaria a resultados estatisticamente significativos.

Só poderíamos chegar a conclusões uma vez realizado o estudo. Os resultados permitem concluir que bastaria ter feito a medida de cintura e quadril, da mesma forma que já havia sido demonstrado pelo Iowa Women's Health Study, que demonstrou ser a relação entre as medidas de cintura e quadril o padrão antropométrico mais confiável na previsão. Nesse estudo, essa relação foi melhor preditor que o índice de massa corpórea (IMC), que também foi considerado um indice indicador de risco (MANCINI, 2003).

A observação da modificação da relação cintura-quadril em niveis sugestivos de redução do risco de agravos à saúde, através da administração de uma medida nutricional, simples, que possa diminuir o risco cardiovascular é extremamente útil, além de factível, pois fica evidente a utilidade do tratamento proposto.

Os resultados desse trabalho trouxeram dados que permitem sugerir a inclusão do óleo de borragem como coadjuvante aos medicamentos antihipertensivos no tratamento de pacientes hipertensas após a menopausa, pois, além de proporcionar redução pressórica, poderia ter influência benéfica na diminuição do risco cardiovascular, pela redistribuição da gordura corporal. 


\section{CONCLUSÕES}

1-O tratamento com ácido gama-linolênico tem ação sobre os níveis pressóricos e sobre a distribuição da gordura corporal em mulheres hipertensas na pósmenopausa.

2-O tratamento com ácido gama-linolênico proveniente do óleo de borragem é eficaz na redução da pressão arterial, tanto sistólica, como diastólica.

3-O tratamento com ácido gama-linolênico proveniente do óleo de borragem atua modificando a distribuição da gordura corporal especificamente sobre a medida na região da cintura e do quadril. 


\section{REFERÊNCIAS}

Aepfelbacher FC, Messuli FH. Hemodynamics and pathogenesis. In: Messerli FH. Hypertension in Postmenopausal Women. New Yok: Marcel Dekker; 1996. p. 79-99.

Amaral L. Menopausa: produção de crise? Associação Psicanalítica de Curitiba em Revista 2002; 5: 114-30.

Amodeo C. Emergências hipertensivas. In: Timmerman A; Sousa JEMR; Piegas LS. Urgências Cardiovasculares. São Paulo: Sarvier; 1996. p.188-93.

Amodeo C. Hipertensão arterial: prognóstico e epidemiologia. In: Timerman A, Cesar LAM. Manual de Cardiologia do Estado de São Paulo. SOCESP, São Paulo: Atheneu; 2000. p.307-309.

Anderson DA, Wadden TA. Tratando o paciente obeso. Sugestões para a prática de atendimento primário. JAMA Brasil junho 2000; 4(5): 3172-88.

Ayres JE. Prevalence of arterial hypertension in Piracicaba city. ArqBrasCardiol 1991; 57: 33-6.

Bar-Tana J. Peroxisome proliferatior-actived receptor gamma (PPARgamma) activation and its consequences in humans. Toxicol Lett 2001; 120(1-3): 9-19.

Barreto ACP. Intervenção em populações específicas II. In: Barreto ACP, Santello JL. Manual de Hipertensão-entre a Evidência e a Prática Clínica. São Paulo: Lemos ed; 2002. p. 125-133.

Belch JJF, Muir A. n-6 and n-3 Essential fatty acids in rheumatoid arthritis and other rheumatic conditions. Proc Nutr Soc 1998: 365-9. 
Bellenger-Germain S, Poisson JP, Narce M. Antihypertensive effects of a dietary unsaturated FA mixture in spontaneously hypertensive rats. Lipids 2002; 37(6): $561-7$.

Berg F. "Unhappy" fat cell seeks balance. Obes Health 1992; 7(2):25.

Berga,S.L. - Tratamento hormonal da mulher enferma na menopausa. Clin Obstet Ginecol Am N 1994; 21(2): 237-51.

Bjorntorp P. The regulation of adipose tissue distribution in humans. Int $\mathbf{J}$ Obes Relat Metab Disord 1996; 20(4): 291-302.

Bjorntorp P. Metabolic difference between visceral fat and subcutaneous abdominal fat. Diabetes Metab 2000; 26 (3): 10-2.

Bouchard C. Genetic influences on body composition and regional fat distribution. Contemp Nutr 1990; 15(10): 1 .

Bouer J. Hormônio deixa a mulher até 8 anos mais jovem. In: Folha de São Paulo, Caderno Cotidiano 1999; jul 25: 1-25.

Bray GA. Obesity. In: Brown ML. Present Knowledge in Nutrition. $6^{\text {th }}$ ed. Washington, DC, International Life Sciences Institute, Nutrition Foundation, 1990.

Brenner RR. Biosynthesis and interconversion of the essential fatty acids. In: Wills AL; Smith DL. New protective Roles for Selected Nutrients. New York: Spiller GA, Scala J, editors. Dihomo-gamma-linolenic and gamma-linolenic acids in health and disease 1989 p. 39-108. 
Burr GO, Burr MM. On the nature and role of the fatty acids essential in nutrition. J Biol Chem 1930; 86: 587-621.

Bursztyn PG, King MH. Fat induced hypertension in rabbits: the effects of dietary linoleic and linolenic acid. J Hypertens 1986; 4(6): 699-702.

Calles-Escandon J, Poehlman ET. Aging, fat oxidation and exercise. Aging (Milano) 1997; 9(1-2): 57-63.

Chinetti G, Fruchart JC, Staels B. Peroxisome proliferator-activacted receptors (PPARs): nuclear receptors with functions in the vascular wall. Z Kardiol 2001; 90(3): 125-32.

Compston JE, Bhambhani M, Laskey MA, Murphy S, Khaw KT. Body composition and bone mass in post-menopaual women. Clin Endocrinol 1992; 37: 426-31.

Cunnane SC; Anderson MJ. The majority of dietary linoleate in growing rats in beta-oxidized or stored in visceral fat. J Nutr 1997; 127(1): 146-52.

Datillo A. Dietary fat and its relationship to body weight? Nutr Today 1992; 27 (1): 13 .

Das UN. Essential fatty acid metabolism in patients with essential hypertension, diabetes mellitus and coronary heart disease. Prost Leuk Essent Fatty Acids 1995; 52(6): 387-91.

Das UN. Can perinatal supplementation of long-chain polyunsaturated fatty acids prevent hypertension in adult life? Hypertension 2001; 38(3): E6-8.

Debert-Ribeiro MB, Ribeiro AB, Stabile Neto C. Hypertension and economic activities in São Paulo, Brazil. Hypertension 1981; Suppl II 3 (6): 233-37. 
Defferne JL, Leeds AR. The antihypertensive affect of dietary supplementation with 6-desaturated essential fatty acid concentrate as compared with sunflower seed oil. J Hum Hypertens 1992; 6: 113-9.

Defferne JL, Leeds AR. Resting blood pressure and cardiovascular reactivity to mental arithmetic in mild hypertensive males supplemented with blackcurrant seed oil. J Hum Hypertens 1996; 10: 531-37.

DeHoog S. In: Mahan LK, Escott-Stump S. Krause. Alimentos, Nutrição e Dietoterapia. Trad. de Favano A. São Paulo: Ed. Rocca Ltda, 1998; Avaliação do estado nutricional. p. 370-95.

Delerive P, Fruchart JC, Staels B. Peroxisome proliferator-activated receptors in inflammation control. J Endocrinol 2001; 169(3): 453-9.

Di Fraia Fo A; Corona J. Alimentação e saúde da mulher. In: Olszewer E; Pereira D.H.M, Di Fraia Fo A. Ginecologia e Obstetricia em Medicina Ortomolecular. São Paulo: Roca; 2001.Capítulo 14. p. 143-149.

Diegoli MSC, Diegoli CA, Fonseca AM, Bagnoli VR. Terapia de reposição hormonal em mulheres hipertensas. In: Fonseca AM, Bagnoli VR, Halbe HW, Pinotti JÁ Terapia de Reposição Hormonal em Situações Especiais. Rio de janeiro: Revinter; 2001. p. 23-31.

Dillon JC. Essential fatty acid metabolism in the ederly: effects of dietary manipulation. Lipids Mod Nutr 1987; 93-106.

Dreon DM, Vranizan KM, Krauss RM, Austin MA,Wood PD. The effects of polyunsaturated fat vs monounsaturated fat on plasma lipoproteins. JAMA 1990; 263: $2462-6$. 
Ellis KJ. Human body composition: in vivo methods. Physiol Rev 2000; 80: 650671.

Engler MM, Engler MB, Erickson SK, Paul SM. Dietary gamma-linolenic acid lowers blood pressure and alters aortic reativity and cholesterol metabolism in hypertension. J Hypertens 1992; 10: 1197-203.

Engler MM, Engler MB, Paul SM. Effects of borage oil rich in gamma-linolenic acid on blood pressure and vascular reactivity. Nutr Res 1992; 12: 519-28.

Engler MM, Schambelan M, Engler MB, Ball DL, Goldfriend TL- Effects of dietary gamma-linolenic acid on blood pressure and adrenal angiotensin receptors in hypertensive rats. Proc Soc Exp Biol Med 1998; 218(3): 234-7.

Ewin J. O lado Sadio das Gorduras. Ácidos Graxos Essenciais para uma Vida e uma Aparência Saudáveis. Trad. de Rodrigues AB. Rio de Janeiro: Editora Campos; 1997; A História dos ácidos graxos. p. 7-16.

Fagart R, Staessen Jan A, Beniaszewski L, Brosens J. The epidemiology of menopause and its association with cardiovascular disease. In Messerli FH. Hypertension in Postmenopausal Women. New York; 1996. p. 67-78.

Fan YY, Chapkin RS. Importance of dietary gamma-linolenic acid in human health and nutrition. J Nutr 1998; 128(9): 1411-4.

Fernandes CE, Melo NR, Lima GR, Baracat EC. Doeças cardiovasculares e terapêutica de reposição hormonal-estado atual de conhecimentos. In: Fernandes CE. Menopausa, Diagnóstico e Tratamento. São Paulo: Editora Segmento; 2003. p. 59-77. 
Fernandez-Real JM; Sanchis D; Ricart W; Casamitjana R et al. Plasma oestronefatty acid éster levels are correlated with body fat mass in humans. Clin Endocrinol 1999; 50(2):253-60.

Ferrozzi F, Zuccoli G, Tognini G, Castriota-Scanderbeg A, Bacchini E, Bernasconi S, et al. Radiol Med (Torino) 1999; 98(6): 490-4.

Fonseca AM, Halbe HW. Fisiologia do climatério. In: Tratado de Ginecologia, $2^{a}$ ed. São Paulo: Roca; 1994.

Freake HC. A genetic mutation in PPAR gamma is associated with enhanced fat cell differentiation: implications for human obesity. Nutr Rev 1999; 57(5): 1546.

Freedman DS et al. Relation of body fat patterning to lipid and lipoprotein concentrations in children and adolescents: The Bogalusa Heart Study. Am J Clin Nutr 1989, 50: 930.

Frenoux JM, Prost ED, Belleville JL, Prost JL. A polyunsaturated fatty acid diet lowers blood pressure and improves antioxidant status in spontaneously hypertensive rats. J Nutr 2001; 131(1):39-45.

Furtado, AM. Um corpo que pede sentido: um estudo psicanalítico sobre mulheres na menopausa. Rev. Latinoam Psicopat Fund 2001; IV (3): 27-37.

Galipeau D, Arikawa E, Sekirov I, McNeil JH. Chronic thromboxane synthase inhibition prevents fructose-induced hypertension. Hypertension 2001; 38(4): $872-6$.

Gambacciani M, Ciaponi M, Cappagli B, Benussi C, De Simone L, Genazzani AR. Climateric modifications in body weight and fat tissue distribution. Climateric 1999; 2: 37-44. 
Gartner LP, Hiatt JL.Tratado de Histologia em cores. $2^{a}$ ed. São Paulo: Ed. Guanabara Koogan; 2003. p. 89-104.

Great Smokies Laboratory. Essential and Metabolic Fatty Acids Analysis. Ashville (NC); 1998. p.1-2.

Gregoire FM, Smas CM, Sul HS. Understanding adipocyte differentiation. Physiol Rev 1998; 78(3): 783-809.

Guivernau M, Meza N, Barja P, Roman O. Clinical and experimental study on the long-term effect of dietary gamma-linolenic acid on plasma lipids, platelet aggregation, thromboxane formation, and prostacyclin production. Prost Leuk Essent Fatty Acids 1994; 51: 311-6.

Hans TS van Leer, Seidel JC, Lean ME. Waist circunference in the identification of cardiovascular risk factors: prevalence study in a random sample. ВМJ 1995; 311: 1401-5.

Halbe HW, Fonseca AM. Síndrome do climatério. In: Halbe HW. Tratado de

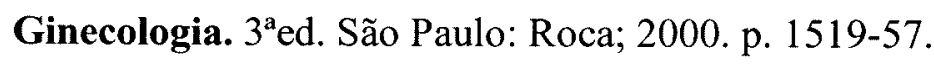

Halbe HW, Hayashida SAY, Ramos LO, Bagnoli VR et al. Coração, vasos e esteróides sexuais. Sinopse Ginecol Obstet 2001; 1: 12-19.

Harrbo J, Marslew V, Gotfredsen A, Christiansen C. Posmenopausal hormone replacement therapy prevents central distribution of body fatty after menopause. Metabolism 1991; 40(12): 1323.

Hassager C; Christiansen C. Estrogen/Gestagen therapy changes soft tissue body composition in postmenopausal women. Metabolism 1989; 38(7): 662-5. 
Heleniak EP, Aston B. Prostaglandins, brown fat and weight loss. Med Hypotheses 1989; 28: 13-33.

Helsing E. Traditional diets and disease patterns of the Mediterranean, circa 1960. Am J Nutr 1995; 61 : 1329S-37S.

Hida Y, Matsui N, Kawada T, Fushiki T. Ultrasonograghy evaluation of abdominal fat in live rats. J Nutr Sci Vitaminol 1999; 45(5): 609-19.

Hime LFCC. Tratamento de pacientes Pós-menopausadas Cardiopatas com Ácido Gama-linolênico São Paulo; 2000.[Dissertação de mestrado - Faculdade de Saúde Pública da USP].

Hime LFCC; Lopes CMC; Hime GA. Importância dos ácidos graxos essenciais na prevenção das doenças. Sinopse Ginecol Obstet 2001; 3: 68-70.

Holbrook TL, Barret-Connor E, Klauber M, Sartoris D. A population-based comparison of quantitative dual-energy X-ray absorptiometry with dual-photon absorptiometry of the spine and hip. Calcif Tissue Int 1991; 49(5): 305-7.

Hoffer E, Meador C, Simpson D. Correlation of whole-body impedance with total body water volume. Journal Applied Physiology 1969; 27: 531-34.

Hoffmann P, Block HU, Beitz J, Taube C, Forster W, Wortha P, et al. Comparative study of blood pressure effects of four different vegetable fats on young, spontaneously hypertensive rats. Lipids 1996; 21(12):733-7.

Holmann RT, Smythe L, Johnson S. Effect of sex and age on fatty acid composition of human serum lipids. Am J Clin Nutr 1979; 32: 2391-9.

Holman CP; Bell AFJ. A trial of evening primrose oil in the treatment of schizophrenia. J Orthomol Pschiatry 1983; 12: 302-4. 
Hornych A, Girault F, Oravec S, Forette B, Horrobin DF. Effect of gammalinolenic acid on plasma and membrane lipids and renal prostaglandins in old subjects. Br J Clin Pharmacol 1999; 48(6): 869-70.

Hornych A, Oravec S, Girault F, Forette B, Horrobin DF. The effect of gammalinolenic acid on plasma and membrane lipids and renal prostaglandin synthesis in older subjects. BratisI Lek Listy 2002; 103(3): 101-7.

Horrobin DF. Schizophrenia as a prostaglandin deficiency disease. Lancet 1979: 936-37.

Horrobin DF. A new concept of lifestyle- related cardiovascular disease: the importance of interactios between cholesterol, essential fatty acids, prostaglandin E1 and thromboxane A2. Med Hypotheses 1980; 6: 785-800.

Horrobin DF. Loss of delta-6-desaturase activity as a key factor in aging. Med Hypotheses 1981; 9 (7): 1211-20.

Horrobin DF, Manku MS. How do polyunsaturated fatty acids lower plasma cholesterol levels? Lipids 1983; 18: 558-62.

Horrobin DF. Essential fatty acids, prostaglandins, and alcoholism: an overview. Alcohol Clin Exp Res 1987; 11: 2-9.

Horrobin DF. Prostaglandin E1: physiological significance and clinical use. Wien Klin Wochenschr 1988; 100: 471-7.

Horrobin DF, Begin ME, Huang YS, Cunnane SC, Manku MS, Nassar BA. Clinical significance of essential fatty acids. Nutrition 1988; 4: 337-41. 
Horrobin DF. Nutritional and medical importance of gamma-linolenic acid. Prog Lipid Res 1992; 31: 163-94.

Hurd,W.L.- Menopause. In Novak's Gynecology. 12th ed. Williams \& Wilkins: Baltimore; 1996.

Imanishi M, Tsuji T, Nakamura S, Takamiya M. Prostaglandin $\mathrm{I}(2) / \mathrm{E}(2)$ rations in unilateral renovascular hypertension of different severities. Hypertension 2001; 38(1): 23-29.

Ingram AJ, Parbtani A, Clark WF, Spanner E, Huff MW, Philbrick, et al. Dietary alteration of dihomogamma-linolenic/arachidonic acid ratio in a rat 5/6-renalablation model. J Am Soc Nephrol 1996; 7(7): 1024-31.

Ishikawa T, Fujiyama Y, Igarashi O, Morino M, Tada N, Kagami A et al. Effects of gammalinolenic acid on plasma lipoproteins and apolipoproteins. Atherosclerosis 1989; 75(2/3): 95-104.

Janjic D. Android-type obesity and gynecoid-type obesity. Schweiz Rundsch Méd Prax 1997; 86(5): 149.

Jehl-Pietri C, Bastie C, Gillot I, Luquet S, Grimaldi PA. Peroxisome-proliferatoractivated receptor delta mediates the effectsof long-chain fatty acids on postconfluent cell proliferation. Biochem 200; 350: 93-8.

Jensen MD, Haymond MW, Rizza RA, Cryer PE et al. Influence of body fat distribution on free fatty acid metabolism in obesity. J Clin Invest 1989; 83(4):1168-73.

Jensen MD. Health consequences of fat distribution. Horm Res 1997; 48(5): 8892.

Jensen MD. Diet effects on fatty acid metabolism in lean and obese humans. 
Jump DB; Clarke SD. Regulation of gene expression by dietary fat.

Am J Clin Nutr 67(3): 531S-534S, 1998.

Annu Rev Nutr 1999; 19:63-90.

Junqueira LC, Carneiro J. Histologia Básica. $9^{\mathrm{a}}$ ed. Rio de Janeiro: Ed. Koogan S.A; 1999.

Kaplan NM. Clinical Hypertension. $17^{\text {th }}$ ed. Baltimore, MD: Williams \& Wilkins; 1992. Hypertensive Crisis. p. 265-80.

Kernoff PBA, Willis AL, Stone KJ, Davies JA, McNicol GP. The anti-trombotic potencial of dihomo-gamma-linolenic acid in man. Br Med J 1977; 2: 1441-44.

Kersten S, Wahli W. Peroxisome proliferator activated receptor agonists. Exs 2000; 89: 141-51.

Kiebzak GM, Leamyb LJ, Pierson LM, Nord RH et al. Measurement precision of body composition variables using the Lunar DPX-L densitometer. J Clin Densitometry 2000; 3: 35-41.

Kinsella JE. Effects of polyunsaturated fatty acids on factors related to cardiovascular disease. Am Cardiol J 1987; 60: 23G-32G.

Kritz-Silverstein D, Barret-Connor E. L. Long-term postmenopausal hormone use obesity, and fat distribution in older women. JAMA 1996; 275: 46.

Kohlmann Jr O, Guimarães AC, Carvalho MHC, Charles Jr HC, Machado CA, et al. III Consenso Brasileiro de Hipertensão Arterial. Hipertensão ArterialDiagnóstico e Classificação. Arquivos Brasileiros de Cardiologia 1998; 1: 1-5. 
Krummel D. Lipídeos. In: Malban LK: Escott-Stump S. Krause. Alimentos, Nutrição e Dietoterapia. Trad. Favano A. São Paulo: Ed. Rocca Ltda, 1998; p. 49-62.

Lacruz RL, Navarro AM, Calatayud JMG. Hipertensión y fatores de coagulación en el Climaterio y Menopausia. Climat Menopausia 1993; (3): 166-72.

Lagarde $\mathrm{M}$, Burtin $\mathrm{M}$, Dechavanne $\mathrm{M}$, Sicard $\mathrm{B}$, Coiffier B. Dihomogammalinolenic acid $(20: 3 \omega 6)$ is more anti-aggregatory than eicosapentaenoic acid $(20: 503)$ in a platelet-endothelial cell mixture. Prostaglandins Med 1980; 4: 177-83.

Lambrinoudaki I, Georgiou E, Douskas G, Tsekes G, Kyriakidis M, Prukakis C. Metabolism 1998; 47(11): 1379-82.

Lanska DJ, Lanska MJ, Hartz AJ, Rimm AA. Factors influencing anatoamic location of fat tissue in 52953 women. Int J Obes 1985; 9: 29-38.

Larsen LF, Jespersen J, Marckmann P. Are olive oil diets antithrombotic? Diets enriched with olive, rapessed, or sunflower oil affect postprandial factor VII differently. Am J Clin Nutr 1999; 70: 976-82.

Lenfant C; Roccella EJ. A call to action for more agressive treatment of hypertension. J Hipertens 1999; 17 (suppl 1): S3-S17.

Ley CJ, Lees B, Stevenson JC. Sex-and menopause-associated changes in bodyfat distribution. Am J Clin Nutr 1992; 55: 950-4.

Leon H, Willis AL, Landaw S, Fisher JM, Fleming J. Effect of prostaglandin $\mathrm{E}_{2}$ $\left(\mathrm{PGE}_{2}\right)$ on guinea-pig and human red cells (RBC). Fed Proc 1980; 39: 391. 
Levy D, Larson MG, Vasan RS et al. The progression from hypertension to congestive heart failure. JAMA 1996; 275: 1557-62.

Lin DS, Connor WE, Spenler CW. Are dietary saturated, monounsaturated, and polyunsaturated fatty acids deposited to the same extent in adipose tissue of rabbits? Am J Clin Nutr 1993; 58(2): 174-9.

Lopes CMC; Halbe HW. Músculo e gordura no climatério. In: Pinotti JA, Halbe HW, Hegg R. Menopausa. São Paulo: Roca; 1995. p.73-79.

Lukaski HC, Johnson PE, Bolonchuk WW, Lykken GI. Assessment of fat-free mass using bioeletrical impedance measurements of the human body. Am J Cin Nutr 1985; 41: 810-17.

MacDougald OA, Lane MD. Adipocyte differentiation. When precursors are also regulators. Curr Biol 1995; 5(6): 618-21.

McLean L. Dietary system high in oil intake for treatment of obesity and for the lowering of saturated fats. US Patent 1996; 5: 484-623.

Mahan LK, Escott-Stump S. Krause. Alimentos, Nutrição e Dietoterapia. Trad. de Favano A. São Paulo: Ed. Rocca Ltda, 1998; Controle do peso e distúrbios alimentares. p. 465-503.

Mancini, MC. Obesidade pós-menopausica - fisiopatologia, diagnóstico e tratamento. In: Fernandes CE. Menopausa Diagnóstico e Tratamento. São Paulo: Editora segmento; 2003. p. 103-10.

Marin P, Bjorntorp P. Endocrine-metabolic pattern and adipose tissue distribution. Horm Res 1993; 39 (S3): 81-3. 
Matsuda T, Imai K, Komiya S. Relationship of anthropometric indices of body fat to cardiovascular risk in Japanese women. Ann Physiol Anthropol 1993; 12(3): $135-44$.

Mazess RB, Barden HS, Bisek JP, Hanson J. Dual-energy x-ray absorptiometry for total-body and regional bone-mineral and soft-tissue composition. Am J Clin Nutr 1990; 54: 1106-12.

Méndez de Medina, MM. Nutrición preventiva: hipertensión; diagnóstico preliminar de la situación de la hipertensión en Costa Rica y factores nutricionales asociados. Guatemala; 1988. [Dissertação de mestrado - Faculdade de Ciências Médicas da Guatemala].

Mills DE; Ward R. Attenuation of psychosocial atress-induced hypertension by gamma-linolenic acid (GLA) administration in rats. Proc Soc Exp Biol Med 1984; 176(1): 32-7.

Mills DE, Summers MR, Ward RP. Gamma linolenic acid attenuates cardiovascular responses to stress in boderline hipertensive rats. Lipids 1985; 20 : $573-7$.

Mills DE, Prkachin KM, Harvey KA, Ward RP. Dietary fatty acid supplementation alters stress reactivity and performance in man. J Hum Hypertens 1989; 3: 111-6.

Mills DE, Ward RP, McCutcheon D, Dixon H, Ly H, Scholey J. Attenuation of cyclosporine-induced hypertension by dietary fatty acids in the borderline hypertensive rat. Transplantation 1992; 53(3): 649-54.

Minuz P, Barrow SE, Cockcroft JR, Ritter JM- Prostacyclin and thromboxane biosynthesis in mild essential hypeertention. Hypertension 1990; 15: 469-74. 
Misikangas M, Freese R, Turpeinen AM, Mutanen M. High linoleic acid, low vegetable, and high oleic acid, high vegetable diets affect platelet activation similarly in healthy women and men. $\mathbf{J}$ Nutr 2001; 131(6): 1700-5.

Monteiro CA, Conde NL. Arq Bras Endocrinol Metab 43 (3): 186-194, 1999.

Monteiro JC. Obesidade: diagnóstico, métodos e fundamentos. In: Halpern A; Matos A; Suplicy HL; Mancii MC et al. Obesidade. São Paulo: Ed. Lemos; 2000.p. 31-51.

Moraes IN. Longevidade Viver Mais e Melhor. São Paulo: Roca; 2004. p. 160.

Moraes e Santos T. Lipídeos. In: Dutra-de-Oliveira JE; Marchini JS. Ciências Nutricionais. São Paulo: Ed. Sarvier; 1998. p. 87-97.

Morrison RF, Farmer SR. Hormonal signaling and transcriptional control of adipocyte differentiation. J Nutr 2000; 130(12): 3116-21.

Nachtigall LE. Cardiovascular disease and hypertension in womem. Obstet Gynecol Clin North Am 1987; 14: 89-105.

Narce M, Poisson JP. Polyunsaturated fatty acid biogenesis is impaired in spontaneously hypertensive rat, in relation to the pathogenesis of hypertension. $\mathbf{J}$ Hypertens, 1997; 15(6): 697-98.

Nestel PJ. Polyunsaturated fatty acids (n-3, n-6). Am J Clin Nutr 1987; 45: $1161-7$.

Neter J, Kutner M H, Nachtsheim CJ, Wasserman W. Applied Linear Statistical Models. $4^{\text {a }}$ ed. U.S.A.: Times Mirror Higher Education Group; 1996. p. 1408. 
Nicklas B, Rogus EM, Berman DM, Dennis KE, et al. Responses of adipose tissue lipoprotein lipase to weight loss affect lipid levels and wieght regain in women. Am J Physiol Endocrinol Metab 2000; 279(5): 1012-9.

Nobre F, Costa Lima NK. Hipertensão arterial: conceito, classificação e critérios diagnósticos. In: Timerman A, Cesar LAM. Manual de Cardiologia do Estado de São Paulo. SOCESP, São Paulo: Atheneu, 2000. p. 303-306.

Oakley CM. Revisão-capítulo 1. In: Messerli FH. Hypertension in postmenopausal women. New Yok: Marcel Dekker; 1996. p. 1-11.

Oates JA, Fitzgerald GA, Branch RA, Jackson EK, Knapp HR, Roberts LJ IIClinical implications of prostaglandin and thrmboxane A2 formation. $\mathbf{N}$ Engl $\mathbf{J}$ Med 1988; 319(12): 761-7.

Oberfield JL, Collins JL, Holmes CP, Goreham DM, Cooper JP, Cobb JE, et al. A peroxisome proliferator-activated receptor gamma ligand inhibits adipocyte differentiation. Proc Natl Acad Sci USA 1999; 96(11): 6102-6.

Palak RT. Management of hypertension: can we prevent heart failure? Cong $\mathbf{H}$ Fail 1998; 4: 24-31.

Paradisi G, Smith L, Burtner C, Leaming R, Garvey WT, Hook G, et al. Dual energy X-ray absorptiometry assessment of fat mass distribution and its association with the insulin resistance syndrome. Diabetes Care 1999; 22(8): $1310-7$.

Peiris AN, Sothmann MS, Hennes MI, Lee MB, Wilson CR, Gustafson AB, et al. Relative contribution of obesity and body fat distribution to alterations in . glucose insulin homeostasis: predictive values of selected indices in premenopausal women. Am J Clin Nutr 1989; 49: 758-64. 
Phinney SD, Tang AB, Thurmond DC, Nakamura MT et al. Anormal polyunsaturated lipid metabolism in the obese Zucker rat, with partial metabolic correction by gamma-linolenic acid administration. Metabolism 1993; 42(9): 1127-40.

Pischon T, Hankinson SE, Hotamisligil GS, Rifai N, Willett WC, Rimm EB. Habitual dietary intake of n-3 and n-6 fatty acids in relation to inflammatory markers among US men and women. Circulation 2003; 108(2): 155-60.

Pogzheva AV, Kondakova NM, Baikov VG. Study of fatty acid composition of cell membranes during the use of soya oil in diet therapy of pacients with cardiovascular disease. Vopr Pitan 2000; 69(5):39-42.

Pompéia C. Ácido araquidônico. In: Curi R, Pompéia C, Miyasaka CK, Procópio J. Entendendo a gordura e os ácidos graxos. São Paulo: Ed. Manole: 2002. p. 344-65.

Porto CC, Araújo DG, Kluthcouski JMC, Correia ARG, Sousa EP et al. Hipertensão arterial sistêmica. Hábitos de vida e fatores correlatos. JBM 1999; 76(3): 35-44.

Pouliot MC, Despres JP, Nadeau A, Tremblay A et al. Associations between regional body fat distribution, fasting plasma free fatty acid levels and glucose tolerance in premenopausal women. Int J Obes 1990; 14(4): 293-302.

Pullman-Mooar S, Laposata M, Lem D, Holman RT, Leventhal LJ, DeMarco D, et al. Alteration of the cellular fatty acid profile and the production of eicosanoids in human monocytes by gamma-linolenic acid. Arthritis Rheum 1990; 33(10): 1526-33. 
Raison J, Basdevant A, Sitt Y, Guy-Grand B. Regional differences in adipose tissue lipoprotein lipase activity in relation to body fat distribution and menopausal status in obese women. Int J Obesity 1988; 12: 465-72.

Rayner TE; Hower PR. Purified omega-3 fatty acids retard the development of proteinuria in salt-loaded hypertensive rats. J Hypertens 1995; 13(7): 771-80.

Ravnskov $\mathrm{U}$. The questionable role of saturated and polyunsaturated fatty acids in cardiovascular disease. J Clin Epidemiol 1998, 51: 6443-60.

Rebuffé-Scrive M. Steroid hormones and distribution of adipose tissue. Acta Med Scand 1988; 723S: 143-6.

Reddy KS; Katan MB. Diet, nutrition and the prevention of hypertention and cardiovascular diseases. Public health Nutrition 2004; 7(1-A): 167-86.

Reginato MJ, Krakow SL, Bailey ST, Lazar MA. Prostaglandins promote and block adipogenesis through opposing effects on peroxisome proliferator-activated receptor gamma. J Biol Chem 1998; 273(4): 1855-8.

Reis da Costa A. Tratamento da hipertensão arterial sistêmica: prevenção de acidente vascular cerebral e insuficiência coronariana. In: Barreto ACP, Santello JL. Manual de hipertensão. São Paulo: Lemos; 2002. p. 149-68.

Rexrode KM, Carey VJ, Hennekens $\mathrm{CH}$, Walters EE et al. Abdominal adiposity and coronary heart disease in women. JAMA 1998; 280: 1843-8.

Richard JL, Martin C, Maillf M, Mendy F, Delplanque D, Jacotot B. Effects of dietary intake of gamma-linolenic acid on blood lipids and phospholipid fatty acids in healthy human subjects. J Clin Biochem Nutr 1990; 8: 75-84. 
Ribot J, Rantala M, Kesaniemi YA, Palou A et al. Weight loss reduces expression of SREBPIC/ADD1 and PPAR gamma2 in adipose tissue of obese women. Pflugers Arch 2001; 441(4): 498-505.

Ristow M, Muller-Wieland D, Pfeiffer A, Krone W, Kahn CR. Obesity associated with a mutation in a genetic regulator of adipocyte differentiation. $\mathbf{N}$ Engl J Med 1998; 339 (14): 953-9.

Rocchi S; Auwers J. Peroxisome proliferator-activated receptor gamma, the ultimate liaison between fat and transcription. Br J Nutr 2000; 84(S2): 223-7.

Rocha JC. Hipertensão arterial. Diagnóstico e tratamento 1998; 3(2): 6-9.

Sakamoto LC.; Halbe HW. Epidemiologia do climatério. In: Menopausa. São Paulo:Roca; 1995. p.1-9.

Sasaki S, Nakamura K, Uchida A, Itoh H et al. Effects of gamma-linolenic and eicosapentaenoic acids on blood pressure in SHR. Clin Exp Pharmacol Physiol 1995; 22(S1): 306-7.

Schmidt MA. Gorduras Inteligentes. Trad. de Pereira DH. São Paulo: Roca; 2000; Mantendo o cérebro no fluxo: os mensageiros. p. 26-36.

Segarnick DJ, Cordasco DM, Rotrosen J. Prostanoid modulation (mediation?) of certain behavioural effects of ethanol. Pharmacol Biochem Behav 1985; 23: 7175.

Serra-Majem L. Japomediterranean diet? Nature 2004; 58(9): 1324-25.

Shewmon DA. Lipídeos, aterosclerose e a mulher na pós-menopausa. Clínicas Obstétricas e Ginecológicas da América do Norte 1994; 21(2): 349-67. 
Simopoulos AP, Leaf A, Salem N. Essentiality and recommended dietary intakes for omega-6 and omega-3 fatty acids. Ann Nutr Metab 1999; 43: 127-30.

Simopoulos AP. Essential fatty acids in health and chronic disease. Am J Clin Nutr 1999; 70(S3): 560S-69S.

Singer P, Moritz V, Wirth M, Berger, Forster D. Blood pressure and serum lipid from SHR after diets supllemented with evening primrose, sunflowerseed or fish oil. Prost Leuk Essent Fatty Acids 1990; 40: 17-20.

Singer P, Moritz V, Wirth M, Berger, Forster D. Blood pressure and serum lipid from SHR after diets supplemented with evening primrose, sunflower seed or fish oil. Prost Leuk Essent Fatty Acids 1990; 40: 17-20.

Sites CK, Brochu M, Tchernof A, Poehlman. Relationship between hormone replacement therapy use with body fat distribution and insulin sensitivity in obese postmenopausal women. Metabolism 2001; 50(7).

Smith DL. Cyclooxygenase and lipoxygenase products: a compendium. In: Willis AL: Handbook of the eicosanoids: prostaglandins and related lipids vol 1 . Boca Raton: CRC press; 1987. p. 47-83.

Smith DL, Willis AL, Nguyen N, Conner D, Zahedi S, Fulks J. Eskimo plasma constituents dihomo- $\gamma$-linolenic acid, eicosapentaenoic acid and docosahexaenoic acid inhibit the release of atherogenic mitogens. Lipids 1989; 24: 70-5.

Soma M, Manku MS, Horrobin DF. The effects of hydrogenated coconut oil, safflower oil, and evening primrose oil on development of hypertension and sodium handling in spontaneously hypertensive rats. Can J Physiol Pharmacol 1985; 63(4): 325-30. 
St.Louis C, Lee RMKW, Rosenfeld J, Farbas-Badjak A. Antihypertensive effect of gama-linolenic acid in spontaneously hypertensive rats. Hypertension 1992; 19: 111-5.

Stone KJ, Willis AL, Hart M, Kirtland SJ, Kernoff PBA, Mcnicol GP. The metabolism of dihomo- $\gamma$-linolenic acid in man. Lipids 1979; 11: 175-80.

Sugano M, Ide T, Ishida T, Yoshida K. Hypocholesterolemic effect of gammalinolenic acid as evening primrose oil in rats. Ann Nutr Metabol 1996; 30: 28999.

Sugano M, Ikeda I. Comparative evaluation of the hypocholesterolemic effect of octadecatrienoic acids. In: Huang YS, Mills DE. Gamma-linolenic acid: metabolism and its roles in nutrition and medicine. Champaign: AOCS Press; 1996.p. 175-188.

Takada R, Saitoh M, Mori T. Dietary gamma-linolenic acid enriched oil reduces body fat content and induces liver enzyme activities relating to fatty acid betaoxidation in rats. $\mathbf{J}$ Nutr 1994; 124: 469.

The writing group for the PEPI trial. Effects of estrogen or estrogen/progestin regimens on the heart disease risk factors in postmenopausal women trial. JAMA 1995; 273 (3): 199-208.

Urbanetz AA, Urbanetz LAGLT, Baú C, Michelon L, Soledad P. TRH na prevenção de doença cardíaca coronariana. Femina 1998; 26(3): 181-86.

Vieira, S. Introdução à Bioestatística. Rio de Janeiro: Campus, 3ª ed. 1998.

Vamecq J; Latruffe N. Medical significance of peroxisome proliferator-activated receptors. Lancet 1999; 354 (9173): 141-8. 
Wang Q, Hassager C, Ravn P, Wang S, Christiansen C. Total and regional bodycomposition changes in early postmenopausal women: age-related or menopauserelated? Am J Clin Nutr 1994; 60: 843-8.

Whelton PK, Russell Rp. Systemic hypertension. In: McGehee Harvey et al. Principles and practice of medicine $22^{\text {nd }}$ ed. California: Appleton e Lange; 1984. p. $127-44$.

Wills AL. Unaswered questions in EFA and PG research. Prog Lipid Res 1982; 20: 834-50.

Wills AL, Smith DL. New protective roles for selected nutrients. New York: Spiller GA, Scala J, editors. Dihomo-gamma-linolenic and gamma-linolenic acids in health and disease 1989. p. 39-108.

Writing Committee. Summary of the scientific conference on dietary fatty acids and cardiovascular health: conference summary from the nutrition committee of the American Heart Association. Circulation 2001; 103(7): 1034-39.

Wolf G. Adipocyte differentiation is regulated by a prostaglandin liganded to the nuclear peroxisome proliferator-activated receptor. Nutr Rev 1996; 54(9): 290-2.

Zaia DAM. Os lipídios e a origem da vida. In: Curi R, Pompéia C, Miyasaka CK, Procópio J. Entendendo a gordura e os ácidos graxos. São Paulo: Ed. Manole; 2002. p. 3-4.

Zak A; Zeman M; Tvrzicka E; Stipek S; et al. Effect of fat distribution on lipoprotein composition and parameters of lipoperoxidation. Sb Lek 2000; 101(1): 71-6. 
Ziboh VA; Fletcher MP. Dose-response effects of dietary gamma-linolenic acidenriched oils on human polymorphonuclear-neutrophil biosynthesis of leukotriene B. Am J Clin Nutr 1992; 55(1): 39-45.

Zurier RB, Rossetti RG, Jacobson EW, DeMarco DM, Liu NY, Temming JE, et al. Gamma-Linolenic acid treatment of Rheumatoid arthristis. Arthritis Rheum 1996; 39(11): 1808-17. 


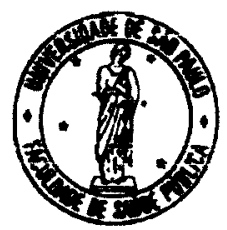

A-1

\section{Universidade de São Paulo}

\section{Faculdade de Saúde Pública}

COMITÉ DE ÉTICA-COEP

Av. Dr. Amaldo, 715-CF.P 01246-904-Săo Paulo - Brasil

Telefones: (55-11) 3066-7779 - fone/fax (55-11) 3064 -7314 - e-mail: mdgracas@usp.br

\section{Of.COEP/46/02}

São Paulo, 20 de fevereiro de 2002

Pelo presente, informo que o Comitê de Ética em Pesquisa da Faculdade de Saúde Pública da Universidade de São Paulo-COEP, em sua 01 a ./02, Sessão Ordinária, realizada em 19.02.02, analisou e aprovou, de acordo com os requisitos da Resolução CNS/196/96, o Protocolo de Pesquisa n. ${ }^{\circ} 638$, intitulado: "EFEITO DO ÁCIDO GAMA-LINOLÊNICO SOBRE A HIPERTENSÃO ARTERIAL E GORDURA CORPORAL, apresentado pela pesquisadora Lúcia de Fátima Cahino da Costa Hime.

Atenciosamente,

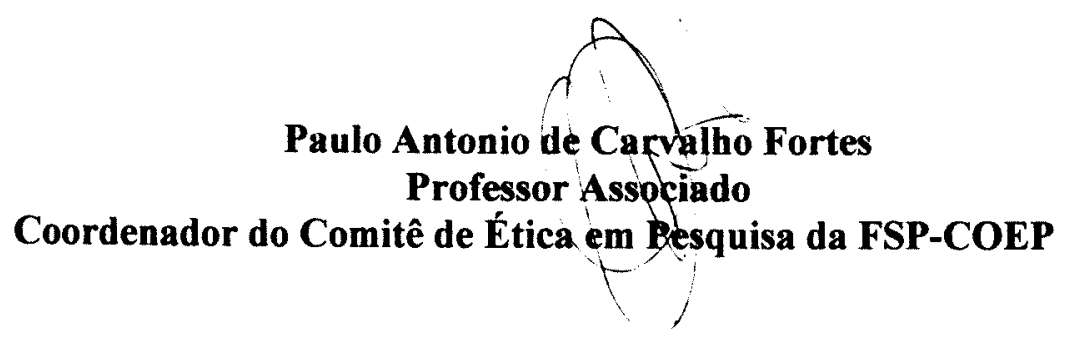


SECRETARIA DE ESTADO DA SAÚDE COORDENADORIA DE SAÚDE DA REGIÃO METROPOLITANA DA GRANDE SÃO PAULO INSTITUTO DANTE PAZZANESE DE CARIDIOLOGIA

AV.DK.DANTE P.AZZANESE.SOO-PRÉDIO I-MAC'KSOID-IBIR.APIERA-(04012-180-S.P FONE:( 11 ) 5085-4040/ FAX: ( 11$) 5579-7474$

FORMULÁRIO de APROVAÇ̃o dO COMITÊ dE ÉTICA EM PESQUISA - CEP -

N. ${ }^{\circ}$ DO PROTOCOLO NO CEP: $3087 / 2002$

(ESTE N` DEVERÁ CITAR NAS CORRESPONDÊNCIAS REFERENTES A ESTE PROJETO)

INVESTIGADORA PRINCIPAL: Drª Lúcia de Fátima C. Costa Hime

TÍTUlO DO PROTOCOLO: “ Efeito do Ácido Gama -Linolênico Sobre a Hipertensão Arterial e Gordura Corporal ”.

O Comitê de Ética em Pesquisa avaliou o Protocolo de Estudo e o Termo de Consentimento Livre e Esclarecido, declarando que as informações enviadas atendem aos aspectos fundamentais das resoluções CNS 196/96 e 292/99, sobre as Diretrizes e Normas Regulamentadoras de Pesquisa Envolvendo Seres Humanos.

Diante do exposto, O Comitê de Ética em Pesquisa, manifesta-se pela aprovação do projeto de pesquisa proposto.

Solicitamos que enviem relatórios periódicos no decorrer da pesquisa, informando através de relatório final dos resultados obtidos.

Situação: Projeto Aprovado

São Paulo, 23 de Abril de 2002

\section{MEMBROS DO COMITÊ DE ÉTICA EM PESQUISA}

DR. PEDRO SILVIO FARSKY

ENFa. FERNANDA ANAJAS CALDAS FARIAS

ENFa. CÉLIA HIROMI SHIOTSU

Dra. CLÁUDIA GRAVINA TADDEI

Dra. CLARISSE OGAWA ÍNDIO DO BRASIL

DR. JOÄO MANOEL ROSSI NETO

ENG. EDDIE LUÍS ALONSO JR.

SR. PETERNEY NEVES DA SILVA
PRESIDENTE

SECRETÁRIA

MEMBRO EFETIVO

MEMBRO EFETIVO

MEMBRO EFETIVO

MEMBRO EFETIVO

MEMBRO EFETIVO

MEMBRO EFETIVO

Dr. Pedro Silvio Farsky

PRESIDENTE DO COMITÊ DE ÉTICA EM PESQUISA 


\section{EFEITO DO ÁCIDO GAMA-LINOLENICO SOBRE A HIPERTENSÃO ARTERIAL E GORDURA CORPORAL}

Informações destinadas à paciente

Você está sendo solicitada a participar de uma pesquisa sobre o tratamento das conseqüências da menopausa.

Introdução: A última menstruação da mulher, também chamada menopausa, ocorre, no Brasil, por volta dos 48 anos de idade. A parada das menstruações é devida à menor produção dos hormônios femininos, pelos ovários. A ausência desses hormônios pode trazer sintomas desagradáveis para algumas mulheres, por exemplo, ondas de calor e suores, principalmente durante a noite, perturbando o sono. Também podem ocorrer outras modificações do corpo, que causam sintomas e perturbações, às vezes sérias, que interferem no bom funcionamento do organismo. Um exemplo é a deposição do colesterol e cálcio nas artérias, aumentando o risco de infarto do coração ou de derrame cerebral. Outras mulheres, ainda, podem ter alterações da forma do corpo, com mudanças na distribuição do tecido gorduroso. Pode também haver agravamento de outros problemas de saúde (que já existiam), como alteração da pressão arterial, ou diabete.

O tratamento dessas conseqüências da menopausa, além de uma dieta e de exercícios físicos adequados, pode ser feito com hormônios. Algumas mulheres não podem tomar hormônios. Existem substâncias produzidas por plantas que podem ser utilizadas para fins de tratamento.

Objetivo da pesquisa: Pretendemos estudar a eficácia do tratamento com medicamentos contendo substâncias de origem vegetal na diminuição dos sintomas da menopausa, bem como na pressão arterial e na gordura do corpo. Para esse estudo, serão feitas várias consultas, todas documentadas com exame clínico e laboratoriais com a finalidade de determinar a melhor maneira de tratar você, sem interferir no seu tratamento cardiológico.

Informações sobre o estudo: Serão convidadas a participar do estudo 80 mulheres que já tiveram sua última menstruação há mais de 1 ano e menos de 5 anos. 
Em todas será feita uma consulta inicial, com exame clínico, cardiológico e ginecológico além de solicitação de exames de sangue, ultra-som do útero e ovários, exame de Papanicolaou, mamografia, densitometria óssea e medida de pressão arterial.

Todas as consultas, exames e medicamentos serão fornecidos gratuitamente. Todas as pacientes tomarão cápsulas gelatinosas, porém algumas cápsulas conterão medicamento ativo e outras não. O conteúdo do medicamento distribuído não será do conhecimento nem do médico nem da paciente, para diminuir a expectativa de efeitos. Será garantido segredo das informações fornecidas pelas pacientes para a pesquisa, só sendo divulgado os resultados sem mencionar os nomes das pessoas.

Duração do estudo: Será de 6 meses. Após a conclusão do estudo, os resultados serão tornados públicos, quer sejam favoráveis ou não ao tratamento da menopausa e você continuará a ser atendida no ambulatório e tratada com os mesmos medicamentos, se estiverem disponiveis, ou então com outros medicamentos.

Observação importante: Sua participação é absolutamente voluntária. Você poderá interromper sua participação no estudo, se desejar. Ou, se os médicos julgarem necessário, o tratamento poderá ser interrompido e substituído por outro. A sua desistência do estudo, se ocorrer, não afetará de forma alguma o seu direito de tratamento no Instituto Dante Pazzanese de Cardiologia. 
EFEITO DO ÁCIDO GAMA-LINOLENICO SOBRE A HIPERTENSÃO ARTERIAL E A GORDURA CORPORAL

Termo de consentimento pós-informado

Eu, matriculada no Instituto Dante Pazzanese de Cardiologia com número

nascida

em

................e

residente

$\grave{a}$

Rua

CEP

Fone

após devidamente esclarecida sobre o tratamento proposto, concordo em participar da investigação clínica para tratamento da menopausa com medicamento não hormonal, comprometendo-me a tomar os medicamentos fornecidos, a realizar os exames que forem solicitados para o estudo e a comparecer às consultas agendadas.

Caso decida não continuar o tratamento, isso não afetará meu direito de continuar a ser atendida no Ambulatório de Cardiopatia e Gravidez do Instituto Dante Pazzanese de Cardiologia.

São Paulo, de de

Lúcia de Fátima Cahino da Costa Hime

Responsável pela pesquisa

Fone para contato: 5085-4221 
SECRETARIA DE ESTADO DA SAÚDE

COORDENACCÁO DOS INSTITUTOS DE PESQUISA

INSTITUTO ADOLFO LUTZ-DIVISAOO DE BROMATOLOGIA E QUIMICA

Av. Dr. Arnaldo, 355 - São Paulo - CEP: 01246-902

Tel: (011) 3068-2800 - Fax: (011) 853-3505

\section{Boletim de Análise 7205 /2000}

Modelidade de Análise: ORIENTAÇÃO

Programa: OUTROS

Nome do Produto: OLEO DE BORRAGEM

Data de Fabricaçio: NĀO CONSTA

Data de Validade: NÄO CONSTA

Número do Lote: NÃO CONSTA

Registro: N/C

Interessado: BIONATUS LABORATÓRIO BOTȦNICO LTDA

Logradouro: Av. Murchid Homsi,915 - SJosé do Rio Preto/SP

Pais: BRASIL

Local de Coleta: LABORATÓRIO

Requerente: BIONATUS LABORATÓRIO BOTÂNICO LTDA

Percoa de Contato: JULIANA DE OLIVERA BORGES

Documento: S/N.O

Data de Entrada: $12 / 07 / 2000$

Descrigẽo da Amostra: AMOSTRA A GRANEL ACONDICIONADA EM FRASCO DE PLÁSTICO, DENOMINADA AMOSTRA A.

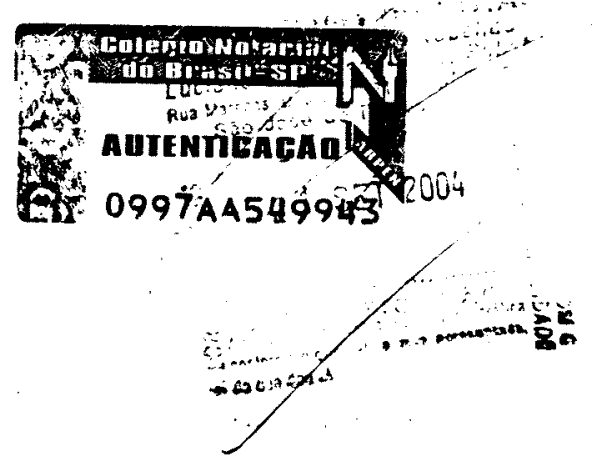




\section{Boletim de Análise 7205 /2000}

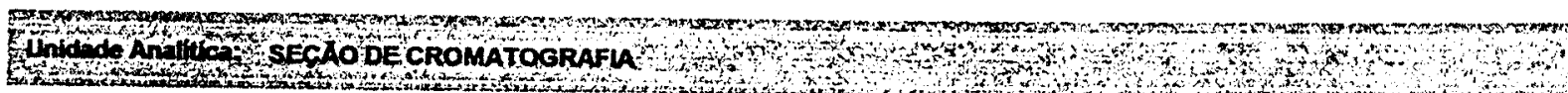

Nome do Ensaio: Composição de ácidos graxos em óleos de origem vegetal

Resultado: Composição de ácidos graxos (\% p/p de metil ésteres):

10,9
Ácido palmítico (C16:0)
Ácido esteárico (C18:0)
Ácido oléico (C18:1)
Ácido linoléico (C 18:2)
Ácido gama-linolênico (C18:3)
Ácido eicosaenóico $(\mathrm{C} 20: 1)$
Ácido araquidônico $(\mathrm{C} 20: 4)$

Conclusĩ̈o do Enidito:

SATISFATÓRIO

Nota: Este resultado tem valor restrito e amostra analisada, sendo vedado seu uso para fins de propaganda.

Concluä̈: SATISFATORIA

Em, 14082000

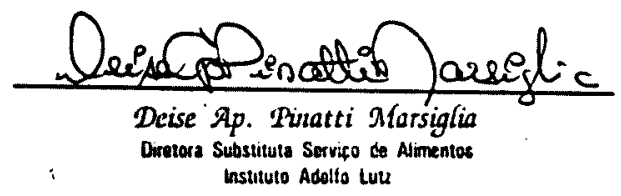

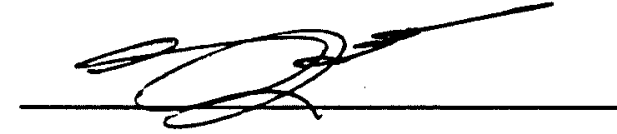

ODAIR TENEBON

Diretor - Divisio de

Bromatologia e Quimica

RQ 2,079.306

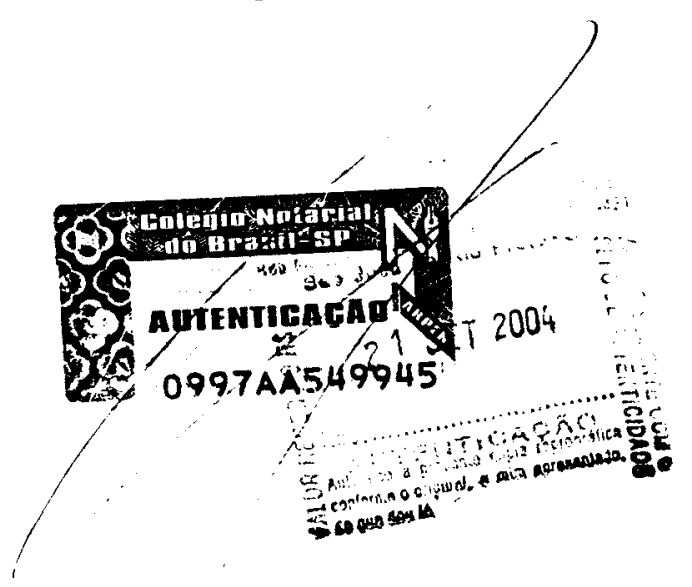


SECRETARIA DE ESTADO DA SAÜDE

COORDENACÁO DOS INSTITUTOS DE PESOUISA

INSTITUTO ADOLFO LUTZ-DIVISAO DE BROMATOLOGIA E QUIMICA

Av. Dr. Arnaldo, 355 - São Paulo - CEP: 01246-902

Tel: (011) 3008-2800 - Fax: (011) 8533505

Data: $1408 / 2000$

Mora: $17: 48$

\section{Boletim de Análise $7206 / 2000$}

Modalidade de Análise: ORUENTAÇÃO

Programa: OUTROS

Nome do Produto: ÓLEO DE BORRAGEM

Data de Fabricagão: NÃO CONSTA

Data de Validade: NAOO CONSTA

Número do Lote: NÃO CONSTA

Regiatro: N/C

Interessado: BIONATUS LABORATORIO BOTÃNICO LTDA

Logradouro: Av. Murchid Homsl,915 - SJosé do Rio Preto/SP

Pais: BRASIL

Local de Coleta: LABORATÓRIO

Requerenta: BIONATUS LABORATORIO BOTÂNICO LTDA

Pescos de Contato: JULLANA DE OLIVERA BORGES

Documento: S/N.O

Data de Entrada: 12/07/2000

Descrigäo da Amontra:

AMOSTRA CAPSULAS 1000mg. ACONDICIONADA EM SACO DE PLÁSTICO, DENOMINADA AMOSTRA B.

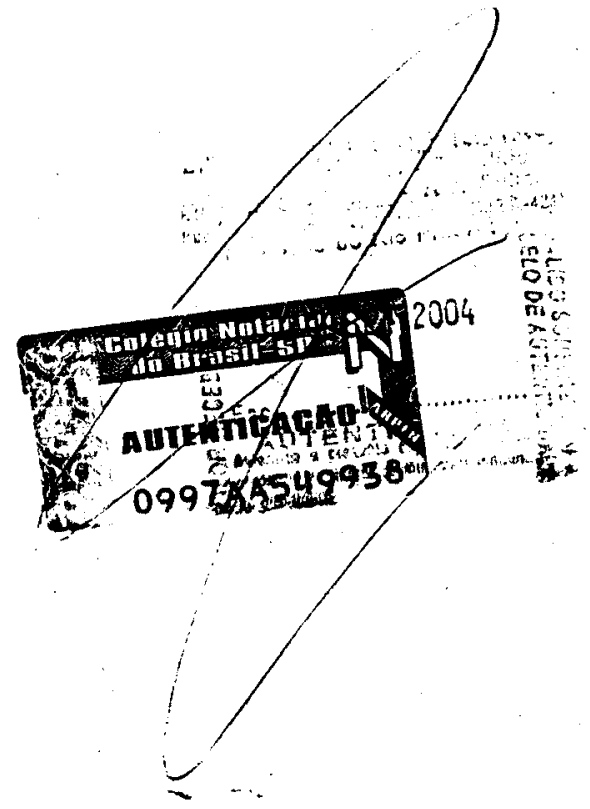


SECRETARIA DE ESTADO DA SAÜDE

COORDENAC̄ÁO DOS INSTITUTOS DE PESQUISA

INSTITUTO ADOLFO LUTZ-DIVISAO DE BROMATOLOGIA E QUIMICA

Av. Dr. Amaldo, 35 - São Paulo - CEP: 01246002

Tel: (011) 3068-2800 - Fax (011) 8533605

Data: $1408 / 2000$

Hora: 17:48

\section{Boletim de Análise $7206 / 2000$}

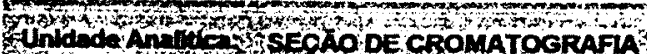

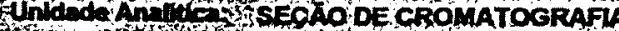

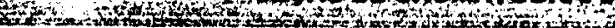

Nome do Enanio: Composição de ácidos graxos em óleos de origem vegetal

Resultado: Composição de ácidos graxos (\% p/p de metil ésteres):

\begin{tabular}{|c|}
\hline $\begin{array}{l}\text { jdo palmítico (C16:0) } \\
\text { jdo esteánico }(\mathrm{C} 18: 0) \\
\text { jdo oléico }(\mathrm{C} 18: 1) \\
\text { joo linolérco }(\mathrm{C} 18: 2) \\
\text { jdo gama-linolènico }(\mathrm{C} 18: 3) \\
\text { jdo eicosaendico }(\mathrm{C} 20: 1)\end{array}$ \\
\hline
\end{tabular}

Acido araquidónico $(\mathrm{C} 20: 4) \ldots 1,3$

Conclusäo do Ensaio: SATISFATORIO

Nota: Este resutado tem valor restrito a amostra analisada, sendo vedado seu uso para fins de propaganda.

Conclusẽo: SATISFATÓRTA

Em, 1408/2000

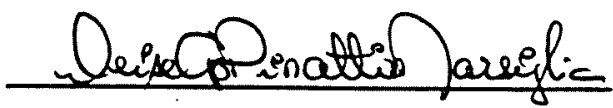

Deise Ap. Pinatti Marsiglia Onetaro Substituta Sorvifo de Alimentos Instituto Adotio Lut

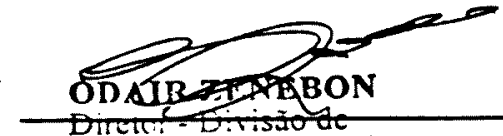

Bromatologia e Química

RO 2.679.306

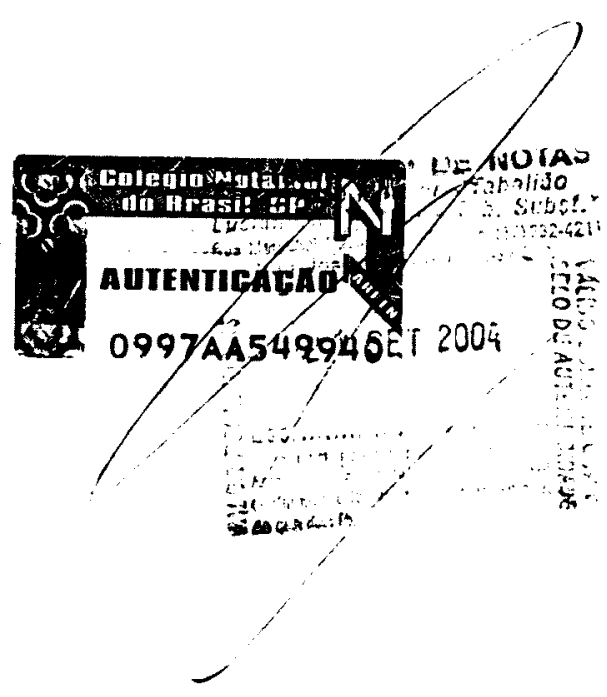




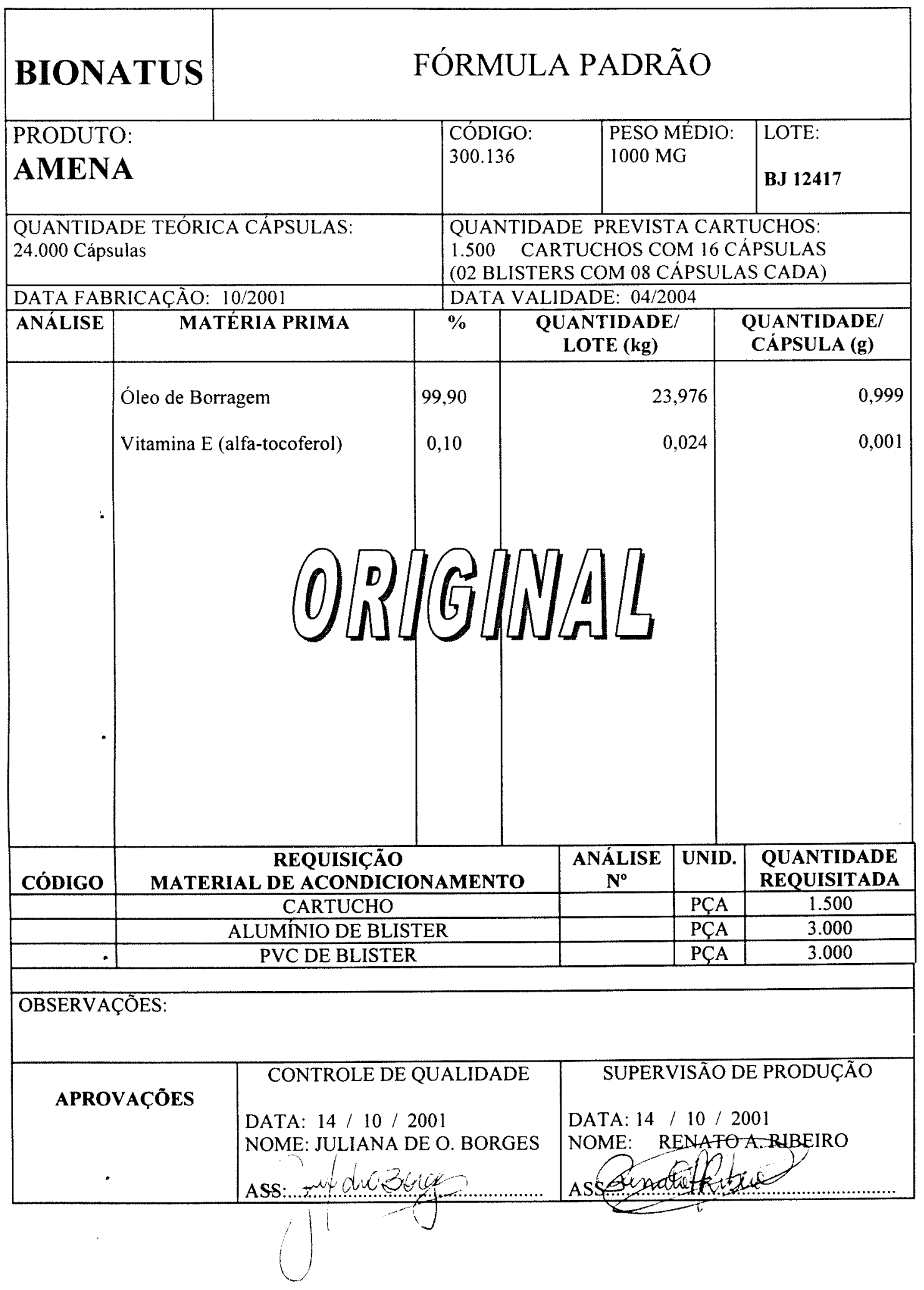


Tabela de pacientes do grupo Ativo e medicação anti-hipertensiva

\begin{tabular}{|c|c|c|}
\hline ALF & 484849E & Clortalidona, Conversil \\
\hline AS & 557979 & Maleato de Enalapril \\
\hline BIS & 517952 & Captopril, Cloridrato de Propanolol, Hidroclorotiazida \\
\hline BM & 355894 & Maleato de Enalapril \\
\hline DMP & 538691 & Maleato de Enalapril, Clortalidona Atenolol \\
\hline DR & 556291 & Dieta Hipossódica \\
\hline DTS & 331568 & Digoxina, Sulfato de Quinidina \\
\hline DJS & $401359 H$ & Captopril \\
\hline EVS & $\mathbf{3 8 7 7 3 0}$ & Hidroclorotiazida \\
\hline FGG & $463369 \mathrm{C}$ & Maleato de Enalapril, Atenolol, Clortalidona \\
\hline GT & 359626 & Hidroclorotiazida \\
\hline GMD & $458120 B$ & Hidroclorotiazida, Cloridrato de Propanolol \\
\hline HN & 556930 & Hidroclorotiazida \\
\hline HMC & $508181 \mathrm{~F}$ & Maleato de Enalapril, Cloridrato de Propanolol \\
\hline IMC & 559514 & Dieta Hipossódica \\
\hline IT & $4888993 E$ & Cloridrato de Propanolol, Hidroclorotiazida \\
\hline JMR & 537034 & Captopril \\
\hline $\mathbf{J J S}$ & 485949 & Maleato de Enalapril, Hidroclorotiazida \\
\hline $\mathbf{J} \mathbf{J}$ & 556172 & Hidroclorotiazida \\
\hline $\mathbf{J F}$ & 477060 & Maleato de Enalapril, Hidroclorotiazida \\
\hline LO & 305730E & Cloridrato de Propanolol \\
\hline MADR & 542236 & Captopril \\
\hline MCR & 543718 & Hidroclorotiazida \\
\hline MJGF & $\mathbf{5 5 5 1 3 0}$ & Hidroclorotiazida \\
\hline MJLX & $503813 K$ & Cloridrato de Propanolol, Clortalidona \\
\hline MNS & 480103 & Atenolol, Hidroclorotiazida \\
\hline MPS & 474649 & Atenolol, Amlodipina \\
\hline MSR & 494958D & Atenolol \\
\hline MVS & 554073 & Matrilix SR \\
\hline MJR & 558809 & Hidroclorotiazida \\
\hline ovs & $472474 \mathrm{~K}$ & Clortalidona \\
\hline MOS & $440320 G$ & Maleato de Enalapril \\
\hline NOS & 395050 & Maleato de Enalapril, Amlodipina \\
\hline NML & $429816 \mathrm{~F}$ & Cloridrato de Propanolol, Maleato de Enalapril, Hidroclorotiaziada \\
\hline AO & 556929 & Clotarlidona \\
\hline RCT & 513423 & Conversil, Clortalidona \\
\hline RSS & 525419 & Hidroclorotiazida \\
\hline RCO & $425712 \mathrm{~A}$ & Hidroclorotiazida, L-Tiroxina sódica \\
\hline RMC & 485632 & Maleato de Enalapril \\
\hline VMS & $502863 \mathrm{~A}$ & Cloridrato de Propanolol \\
\hline
\end{tabular}


Tabela de pacientes do grupo Placebo e medicação anti-hipertensiva

\begin{tabular}{|c|c|c|}
\hline $\mathbf{A L}$ & $492082 \mathrm{C}$ & Maleato de Enalapril, Hidroclorotiazida \\
\hline AS & 9543470 & Clortalidona \\
\hline ACD & 479993 & Atenolol, Maleato de Enalapril, Metformina \\
\hline ADR & 436874 & Maleato de Enalapril, Clortalidona, AAS \\
\hline CMAC & $357404 D$ & Clortalidona \\
\hline $\mathrm{CPO}$ & 545076 & Hidroclorotiazida \\
\hline CPS & $419389 H$ & Cloridrato de Propanolol, Clortalidona \\
\hline CLM & 529989 & Hidroclorotiazida \\
\hline DDB & $412200 \mathrm{C}$ & Atenolol, Amiodarona \\
\hline EBC & 302022 & Alfa Metildopa, Clortalidona \\
\hline $\mathbf{E C F}$ & $491344 \mathrm{~F}$ & Captopril, Amitriptilina \\
\hline $\mathbf{E L}$ & 557959 & Maleato de Enalapril \\
\hline SEM & 463273J & Losartana Potássica, Nifedipina, AAS \\
\hline FRZ & 452417 & Maleato de Enalapril, Amlodipina, Hidroclorotiazida \\
\hline FRS & $\mathbf{5 3 3 5 3 5}$ & Hidroclorotiazida \\
\hline GMS & 372446 & Alfa Metildopa, Hidrocorotiazida, Nifedipina \\
\hline НМH & 556913 & Hidroclorotiazida \\
\hline IMS & 349943B & Hidroclorotiazida, Cloridrato de Propanolol \\
\hline ISS & $512870 \mathrm{~F}$ & Ramipril, Atenolol \\
\hline JSS & $452545 \mathrm{E}$ & Maleato de Enalapril \\
\hline LGM & $508478 A$ & Atenolol, Amlodipina, Clortalidona \\
\hline LRA & 524480 & Atenolol \\
\hline LCP & 556176 & Captopril, Hidroclorotiazida \\
\hline MAP & 459216 & Nifedipina, Atenolol \\
\hline MAJ & $446041 D$ & Maleato de Enalapril, AAS \\
\hline MAL & 538268 & Hidroclorotiazida \\
\hline MBG & 540972 & Captopril, Clortalidona \\
\hline MDF & 324658 & Atenolol, Maleato de Enalapril, AAS \\
\hline MJC & 445109 & Atenolol \\
\hline MJS & 559046 & Digoxina, Amlodipina, Losartana Potássica \\
\hline MLE & 460598 & Hidroclorotiazida, Atenolol \\
\hline MOS & $481666 \mathrm{C}$ & Captopril, Metformina \\
\hline MPS & 473642 & Maleato de Enalapril, Hidroclorotiazida \\
\hline MAL & 524074 & AAS, Propanilnitrato \\
\hline NS & 547751 & Captopril, Hidroclorotiazida \\
\hline RMS & $510916 B$ & Atenolol, Captopril, Hidroclorotiazida \\
\hline $\mathbf{S M}$ & $461221 D$ & Captopril, Clortalidona \\
\hline SRO & $449717 \mathrm{H}$ & Hidroclorotiazida, Amitriptilina \\
\hline VFC & 306228 & Amilodipina, Clortalidona \\
\hline VCO & 556520 & Clortalidona \\
\hline VSM & $402977 \mathrm{H}$ & Metformina, Clortalidona, Atenolol \\
\hline
\end{tabular}

